San Jose State University

SJSU ScholarWorks

Master's Theses

Master's Theses and Graduate Research

Fall 2017

\title{
Preparation and Characterization of a (Viologen) Containing Main Chain PEG-Carbon Nanotubes Phase for Hybrid Supercapacitor Application
}

Kanishka Rana

San Jose State University

Follow this and additional works at: https://scholarworks.sjsu.edu/etd_theses

\section{Recommended Citation}

Rana, Kanishka, "Preparation and Characterization of a (Viologen) Containing Main Chain PEG-Carbon Nanotubes Phase for Hybrid Supercapacitor Application" (2017). Master's Theses. 4883.

DOI: https://doi.org/10.31979/etd.xvq6-3d59

https://scholarworks.sjsu.edu/etd_theses/4883

This Thesis is brought to you for free and open access by the Master's Theses and Graduate Research at SJSU ScholarWorks. It has been accepted for inclusion in Master's Theses by an authorized administrator of SJSU ScholarWorks. For more information, please contact scholarworks@sjsu.edu. 
PREPARATION AND CHARACTERIZATION OF A (VIOLOGEN) CONTAINING MAIN CHAIN PEG-CARBON NANOTUBES PHASE FOR HYBRID SUPERCAPACITOR APPLICATION

\author{
A Thesis \\ Presented to \\ The Faculty of the Department of Chemistry \\ San José State University \\ In Partial Fulfillment \\ of the Requirements for the Degree \\ Master of Science
}

by

Kanishka Rana

December 2017 
(c) 2017

Kanishka Rana

\section{ALL RIGHTS RESERVED}


The Designated Thesis Committee Approves the Thesis Titled PREPARATION AND CHARACTERIZATION OF A (VIOLOGEN) CONTAINING MAIN CHAIN PEG-CARBON NANOTUBES PHASE FOR HYBRID SUPERCAPACITOR APPLICATION

by

Kanishka Rana

APPROVED FOR THE DEPARTMENT OF CHEMISTRY

SAN JOSÉ STATE UNIVERSITY

December 2017
Roger Terrill, Ph.D.
Department of Chemistry
Joseph Pesek, Ph.D.
Department of Chemistry
Chester Simocko, Ph.D.
Department of Chemistry 


\title{
ABSTRACT
}

\section{PREPARATION AND CHARACTERIZATION OF A (VIOLOGEN) CONTAINING MAIN CHAIN PEG-CARBON NANOTUBES PHASE FOR HYBRID SUPERCAPACITOR APPLICATION}

\author{
by Kanishka Rana
}

Supercapacitors (SCs) and batteries are recognized as the two most important electrical energy storage devices. SCs have some distinct advantages such as high-power density and long cycle life when compared to batteries. However, they have yet to match the energy densities of batteries. In an effort to improve the energy density of SCs, a hybrid supercapacitor was developed using a pair of single-walled carbon nanotube electrodes and two polyethylene glycol $\left(\mathrm{PEG}_{400}\right)$ gel-polymer electrolytes (GPEs) containing redox additives of viologen (V) and ferrocene dicarboxylic acid (Fc), respectively. The introduction of $\mathrm{V}$ and $\mathrm{Fc}$, was expected to improve the energy performance of the SC due to reversible Faradaic reactions between them in the corresponding GPEs. The V-PEG polymer electrolyte was used in the oxidation half-cell and the Fc-PEG polymer electrolyte was used in the reduction-half cell of the SC, which were separated by polycarbonate membranes in a sandwich configuration. The electrochemical performances of the SC were evaluated by cyclic voltammetry and chronoamperometry. The results confirmed V-PEG polymer and Fc-PEG polymer as suitable electrolyte materials for their application in a hybrid supercapacitor. 


\section{ACKNOWLEDGMENTS}

I would like to thank my research advisor Dr. Roger Terrill for his continued support and guidance in carrying out this research project. I appreciate all his contributions of time, and ideas to make my graduate school experience productive and stimulating. I would also like to thank my committee members, Dr. Simocko, and Dr. Pesek for their valuable time in evaluating my research work and provide insightful comments.

I would like to acknowledge Shalaka Rahangdale, my fellow lab mate for helping me throughout this project. I would also like to thank my parents for all their love and encouragement. Most importantly, I must thank my loving and supportive husband, Manish Rana, for his patience and unyielding support throughout the process of researching and writing this thesis. This accomplishment would not have been possible without him. 


\section{TABLE OF CONTENTS}

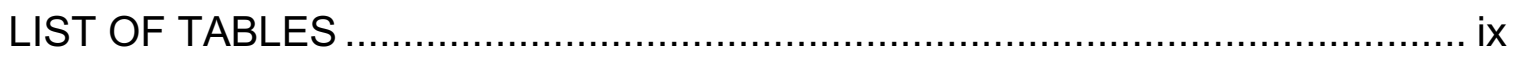

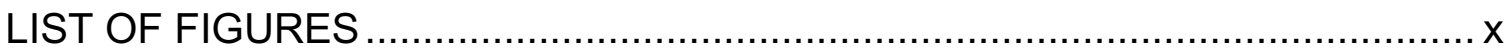

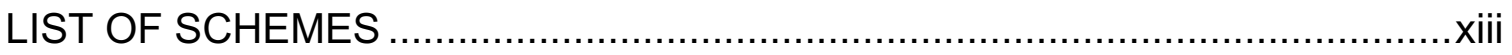

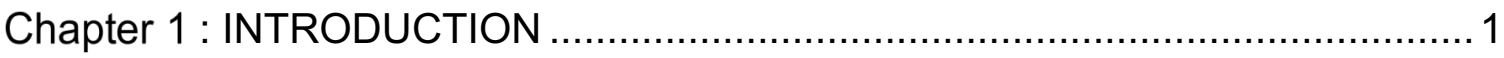

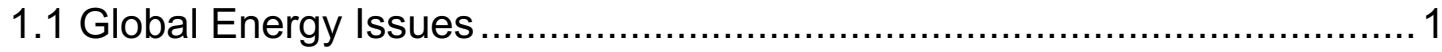

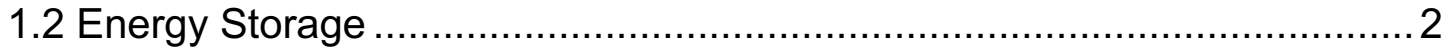

1.3 Electrical Energy Storage Systems ................................................

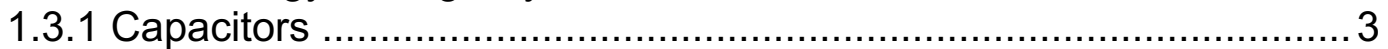

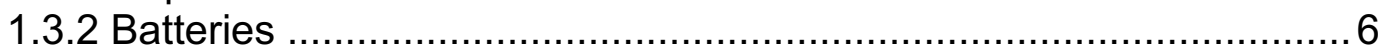

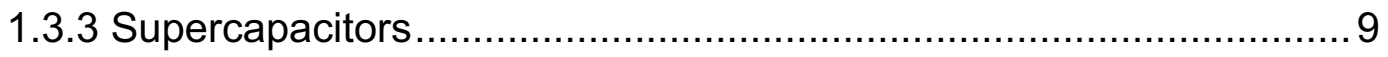

1.4 Performance Comparison of Energy Storage Systems …..................... 12

1.5 Research Motivation and Objective ………....................................... 15

Chapter 2 : MATERIALS FOR THE OXIDATION HALF-CELL OF THE

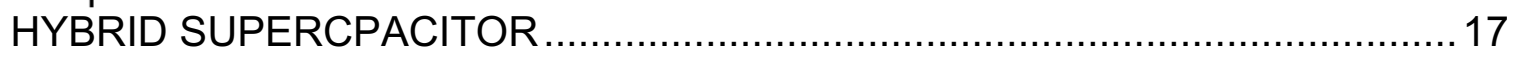

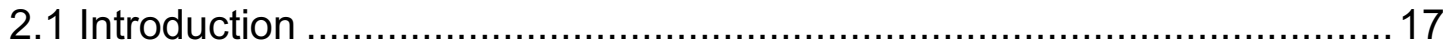

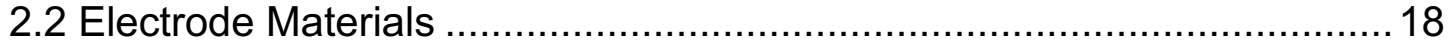

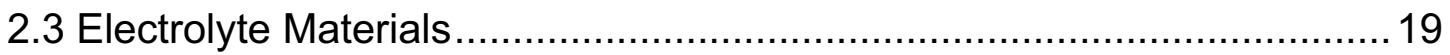

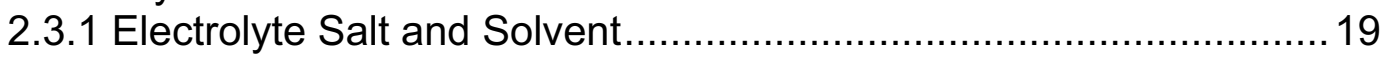

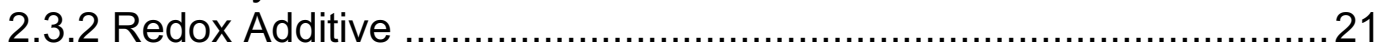

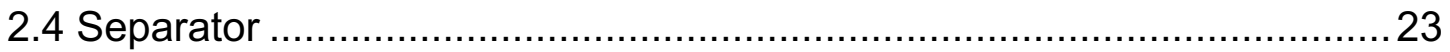

Chapter 3 : FUNCTIONALIZATION OF SINGLE-WALLED CARBON

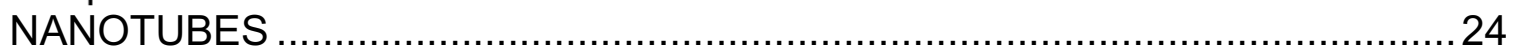

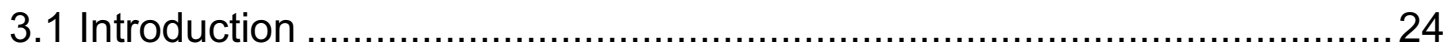

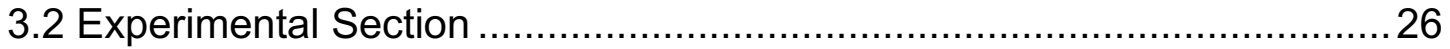

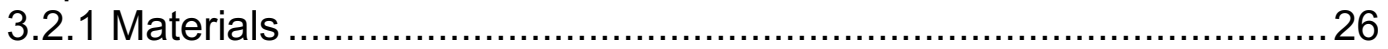

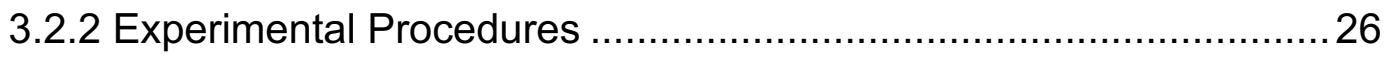

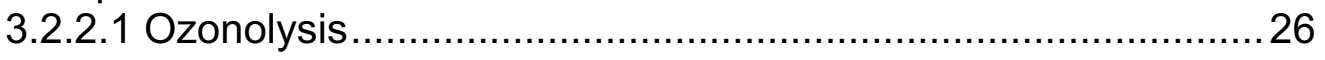

3.2.2.2 Maleic Anhydride Treatment ............................................ 27

3.2.2.3 Concentrated $\mathrm{H}_{2} \mathrm{SO}_{4} / \mathrm{HNO}_{3}$ Mixture (3:1) Treatment ..............27

3.2.2.4 Nitric Acid Oxidation .......................................................28

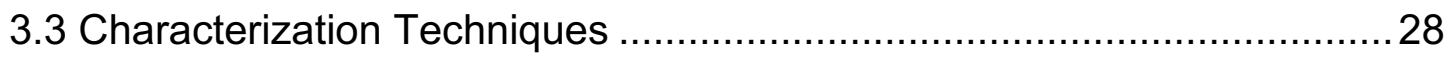

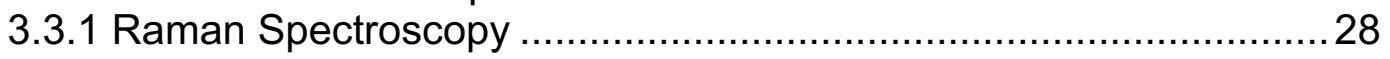

3.3.2 Attenuated Total Reflection Fourier-Transform Infrared

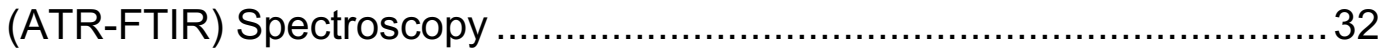

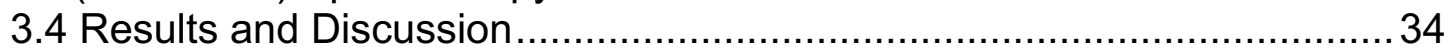

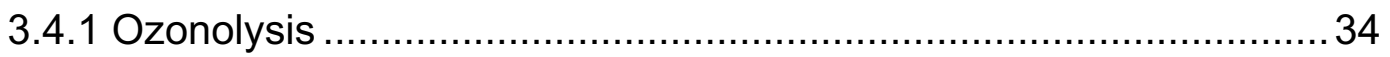

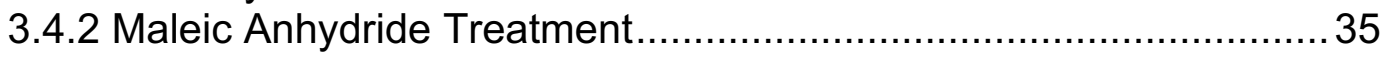


3.4.3 Concentrated $\mathrm{H}_{2} \mathrm{SO}_{4} / \mathrm{HNO}_{3}$ Mixture (3:1) Treatment..................... 35

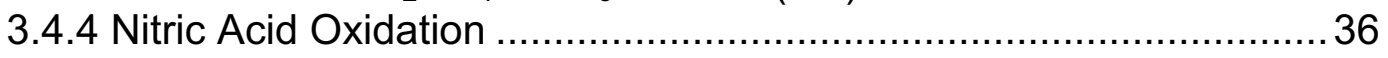

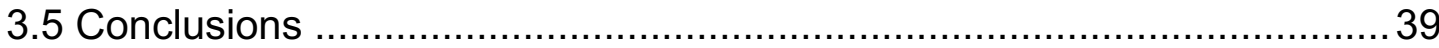

Chapter 4 : SYNTHESIS OF VIOLOGEN-POLYETHYLENE GLYCOL

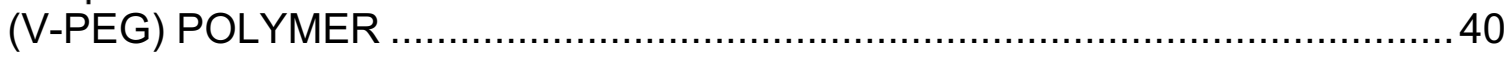

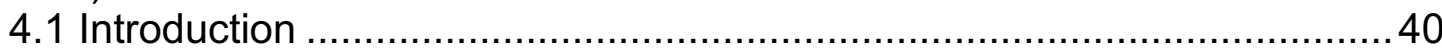

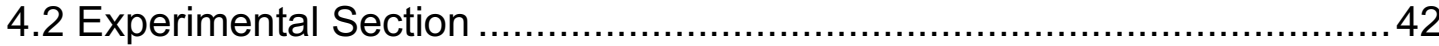

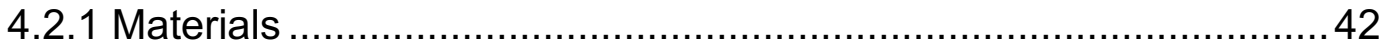

4.2.2 Experimental Procedures ......................................................... 42

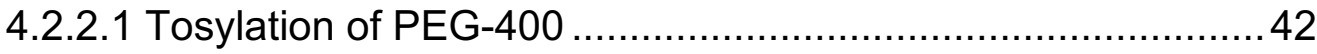

4.2.2.1.1 Tosylation of PEG using Triethylamine ........................ 43

4.2.2.1.2 Tosylation of PEG using Pyridine .............................. 43

4.2.2.2 Synthesis of Viologen-Polyethylene Glycol Polymer............... 44

4.3 Characterization Techniques ..........................................................4 44

4.3.1 Nuclear Magnetic Resonance Spectroscopy (NMR) .................... 45

4.3.2 Electrochemical Analysis ..................................................... 46

4.3.2.1 Liquid Phase Characterization ........................................ 50

4.3.2.2 Semi-Solid Phase Characterization ..................................... 52

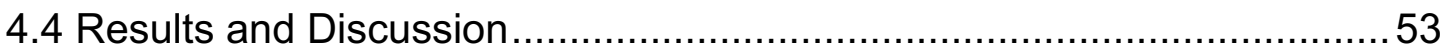

4.4.1 Nuclear Magnetic Resonance Spectroscopy (NMR) Results ..........53

4.4.1.1 Ditosylated PEG ....................................................... 53

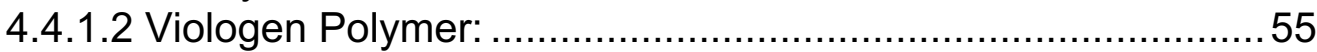

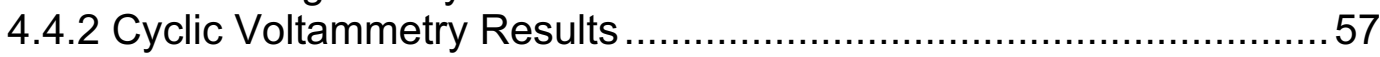

4.4.2.1 Liquid Phase Characterization ...........................................57

4.4.2.1.1 Analysis of 4,4'-bipyridine using Micro- and

Ultramicroelectrode............................................................. 57

4.4.2.1.2 Analysis of Viologen Polymer using Micro- and

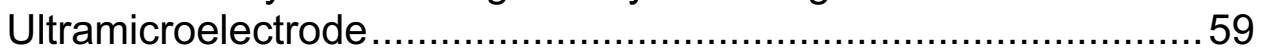

4.4.2.2 Semi-Solid Phase Characterization ....................................6 60

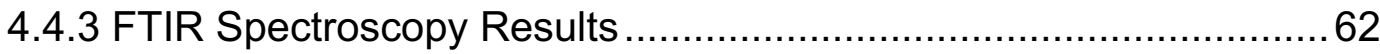

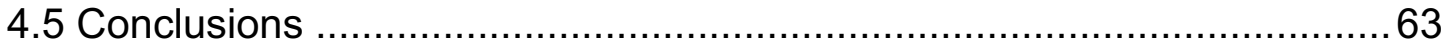

Chapter 5 : FUNCTIONALIZATION OF OXIDIZED SINGLE-WALLED

CARBON NANOTUBES WITH V-PEG POLYMER .......................................65

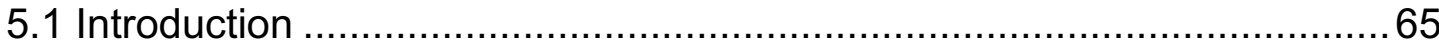

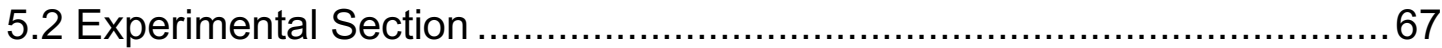

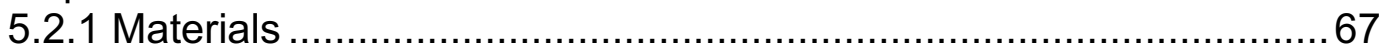

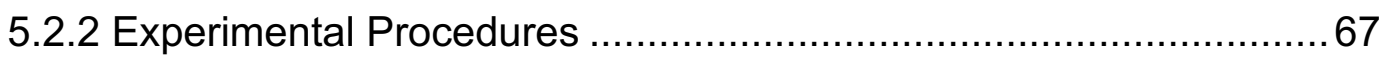

5.2.2.1 Grafting SWCNTs with V-PEG Polymer .............................67

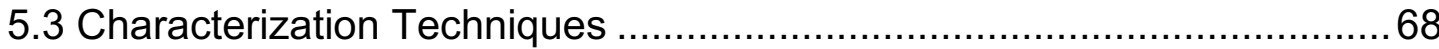

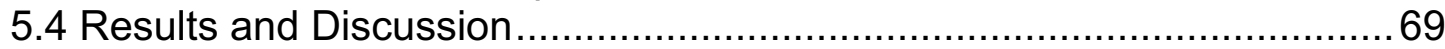

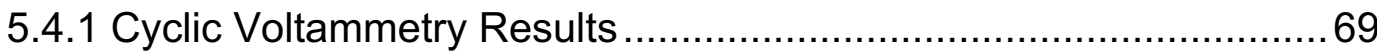

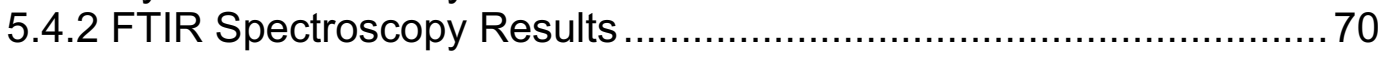




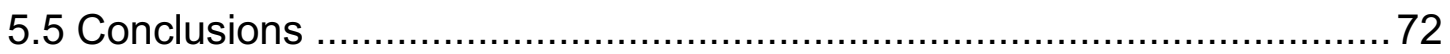

Chapter 6 : CELL FABRICATION AND CHARACTERIZATION .......................73

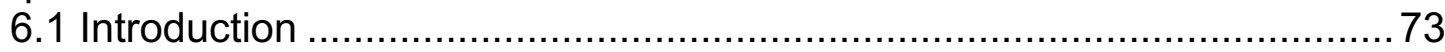

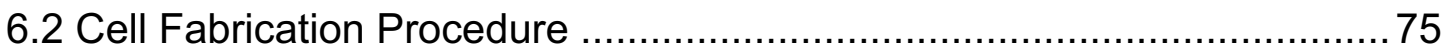

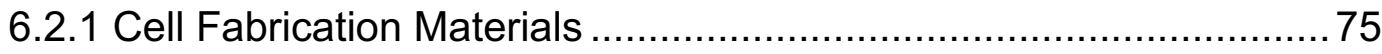

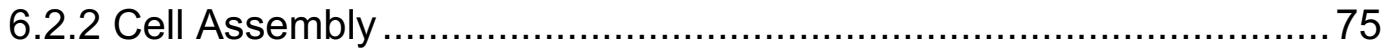

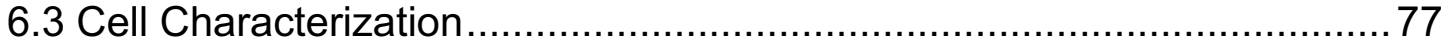

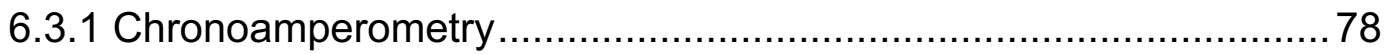

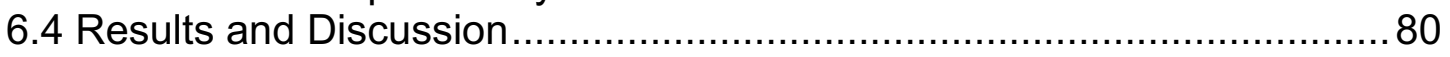

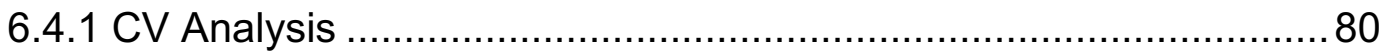

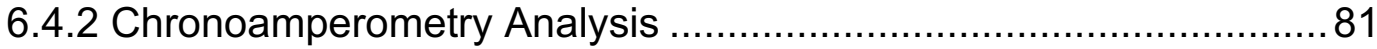

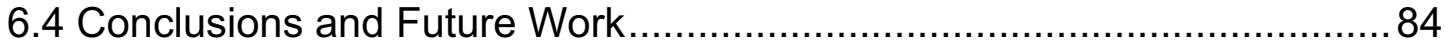

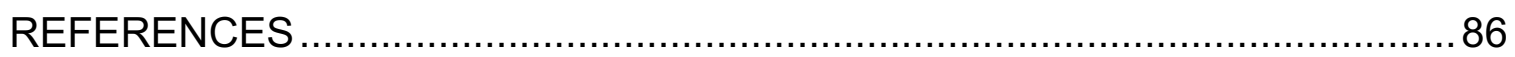




\section{LIST OF TABLES}

Table 1.1 Performance Comparison Table. …................................................ 14

Table 6.1 Chronoamperometry Graphs of the Prototype Cell. .........................82

Table 6.2 Charging-Discharging Currents of the Prototype Cell. ......................84 


\section{LIST OF FIGURES}

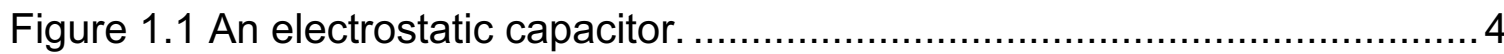

Figure 1.2 Representation of the commonly used lithium-ion battery based on $\mathrm{LiCoO}_{2}$ cathodes and graphite anodes.

Figure 1.3 An electric double layer supercapacitor showing charge accumulation at the electrode/electrolyte interface.

Figure 1.4 Ragone plot of energy density vs power density for various energy storage systems.

Figure 2.1 Proposed hybrid supercapacitor in a sandwich-type configuration.

Figure 2.2 Structure of single-walled carbon nanotubes............................... 18

Figure 2.3 Possible structures of V-PEG polymer........................................22

Figure 3.1 A schematic view of the energy transitions involved in (a) Rayleigh scattering, (b) Raman scattering (stokes scattering) and (c) Raman scattering (anti-stokes).

Figure 3.2 Schematic representation of infrared beam path length through the ATR crystal.

Figure 3.3 Solubility test of CNTs, (1) p-SWCNTs in water and (2) acid treated SWCNTs in water.

Figure 3.4 Raman spectra of (a) p-SWCNTs and (b) acid treated SWCNTs. ....37

Figure 3.5 FTIR spectra of (a) p-SWCNTs and (b) acid treated SWCNTs..........38

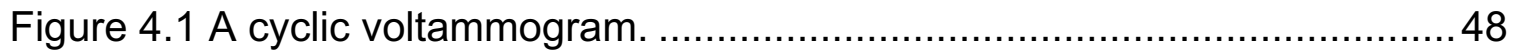

Figure 4.2 Three-electrode electrochemical cell setup for analysis of 4,4'-bipyridine.

Figure 4.3 Three-electrode electrochemical cell setup for analysis of viologen polymer. 52

Figure 4.4 Semi-solid phase characterization setup for viologen polymer. 53 
Figure $4.5{ }^{1} \mathrm{H}$ NMR spectrum of ditosylated PEG in DMSO and structural identification.

Figure $4.6{ }^{13} \mathrm{C}$ NMR spectrum of ditosylated PEG in DMSO and structural identification.

Figure $4.7{ }^{1} \mathrm{H}$ NMR spectrum of viologen polymer in DMSO and structural identification.

Figure $4.8{ }^{13} \mathrm{C}$ NMR spectrum of viologen polymer in DMSO and structural identification.

Figure 4.9 Cyclic voltammogram of 4,4'-bipyridine using Pt microelectrode.......58

Figure 4.10 Cyclic voltammogram of 4,4'-bipyridine using Pt ultramicroelectrode.

Figure 4.11 Cyclic voltammogram of viologen polymer using $\mathrm{Pt}$ microelectrode.

Figure 4.12 Cyclic voltammogram of viologen polymer using $\mathrm{Pt}$ ultramicroelectrode.

Figure 4.13 Cyclic voltammogram of viologen polymer using Ag plate as $\mathrm{AE}$ and $\mathrm{RE}$, and $\mathrm{Pt}$ as the working electrode.

Figure 4.14 FTIR spectra of (a) PEG-400, (b) viologen polymer and (c) 4,4'-bipyridine.

Figure $5.1 \mathrm{CV}$ setup for analysis of the SWCNTs/V-PEG polymer composite.

Figure 5.2 Cyclic voltammogram of SWCNTs/V-PEG polymer composite using Pt ultramicroelectrode.

Figure 5.3 FTIR spectra of (a) o-SWCNTs, (b) SWCNTs/V-PEG polymer composite and (c) V-PEG polymer.

Figure 6.1 The schematic representation of the supercapacitor cell with SWCNTs/Fc-PEG polymer and SWCNTs/V-PEG polymer composites.

Figure 6.2 Aluminium current collector with a platinum cavity. 76 
Figure 6.3 Schematic of prototype cell fabrication procedure.

Figure 6.4 Electrochemical setup for analysis of the prototype cell. ..................78

Figure 6.5 (a)Potential waveform and (b) the signal for double pulse chronoamperometry.

Figure 6.6 Cyclic voltammograms of the prototype cell at scan rate (a) $0.1 \mathrm{~V} \mathrm{~s}^{-1}$, (b) $0.01 \mathrm{~V} \mathrm{~s}^{-1}$ and (c) $0.05 \mathrm{~V} \mathrm{~s}^{-1}$. 81 


\section{LIST OF SCHEMES}

Scheme 2.1 Schematic illustration of lithium-ion conduction in PEG. ...............21

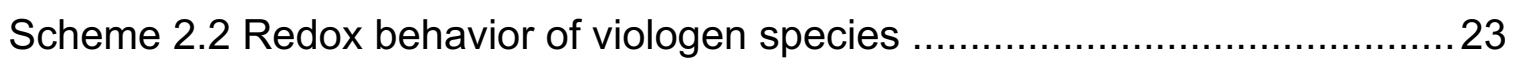

Scheme 3.1 Diels-Alder reaction mechanism. ...........................................25

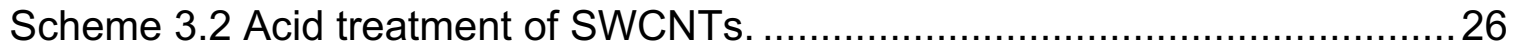

Scheme 4.1 Tosylation of (a) PEG-400 using (b) p-toluenesulfonyl chloride......41

Scheme 4.2 Synthesis of viologen-polyethylene glycol polymer using

(a) ditosylated PEG and (b) 4,4-bipyridine. ................................................... 42

Scheme 5.1 Acyl chlorination of oxidized-SWCNTs.......................................6

Scheme 5.2 Mechanism of acyl chloride formation using oxalyl chloride. ..........66

Scheme 5.3 Grafting of viologen polymer to acyl-chlorinated SWCNTs. ...........67 


\section{Chapter 1 : INTRODUCTION}

\subsection{Global Energy Issues}

At present, the consumption of fossil fuels has dramatically increased due to the rapid development of the global economy and the increasing world population. It has not only depleted the existing fossil fuel reserves, but also adversely impacted the environment, resulting in increased health risks and global climate change. To address these concerns, clean, sustainable and efficient renewable energy sources as well as new technologies associated with energy conversion and storage have become the primary focus in the industrial and scientific communities. ${ }^{1}$

Renewable energy is energy that is generated from natural processes, which are naturally replenished faster than consumed. This includes hydropower, tidal, solar, geothermal, biomass, and wind energies. The fluid flows associated with wind, hydroelectric, and tidal energies are utilized to drive a generator. The energy from the sun is used to super-heat water to convert it into steam, that drives an electricity-generating turbine. ${ }^{2}$ Geothermal energy helps to create electricity by using heat sources from within the earth. Biomass is converted into biofuels which are used in the same way as fossil fuels. However, each form of renewable energy conversion suffers from its own set of complications and some are easier to exploit than others. Renewable energy sources like solar and wind are not constant as they depend on the weather or climate to work effectively. In 
order to effectively implement these intermittent energy sources, it is pivotal to develop efficient electrical energy storage systems. ${ }^{2,3}$

\subsection{Energy Storage}

The process of converting electrical energy from a power grid into a storable form is referred as electrical energy storage (EES). ${ }^{4}$ EES, is one of the key technologies that enables electricity to be produced from intermittent energy sources. In addition, it also plays a pivotal role in reducing the electricity costs by storing electricity generated at off-peak times when the generation cost is low and helps to maintain the power quality and reliability. ${ }^{2}$

In recent decades, a wide variety of EES systems have been developed for the effective implementation of renewable energy sources. These systems can be classified in a variety of ways, such as response time and useful storage durations. In general, these methods differ in the form of energy stored in the system. ${ }^{4}$ They can be grouped into mechanical, thermal, electrical, electrochemical, chemical, and thermochemical energy storage systems. They all differ in characteristics like efficiency, energy density or power density. The most common mechanical storage systems are kinetic energy storage systems like flywheels and potential energy storage systems like compressed air energy storage (CAES) and pumped hydro storage (PHS). ${ }^{5}$ Thermal energy storage systems include low temperature energy storage (cryogenic energy storage, aquiferous cold energy storage) and high temperature energy storage (steam or hot water accumulators, hot rocks, latent heat systems such as phase change 
materials). ${ }^{5}$ Electrical energy storage systems include electrostatic capacitors, supercapacitors, and superconducting magnetic energy storage systems. ${ }^{4}$ Electrochemical energy storage systems include lead-acid or lithium-ion batteries. Chemical energy storage systems include fuel cells, and thermochemical energy storage systems include solar fuel cells. ${ }^{4}$

Among these technologies, electrochemical energy storage systems are recognized as the most effective and practical technologies for reversibly storing electrical energy. ${ }^{3}$ Currently, the major commercialized energy storage systems available in the market are capacitors, batteries, and supercapacitors. They are the focus of current research because of their key role regarding mobile energy. The structure, mechanism and performance comparison of these devices are discussed in the following sections of this chapter.

\subsection{Electrical Energy Storage Systems}

\subsubsection{Capacitors}

Conventional capacitors, also known as electrostatic capacitors, are passive electrical devices that are capable of directly storing electrical energy, without converting it into another form of energy. ${ }^{6}$ This technology was started by the invention of the Leyden jar by Pieter van Musschenbroek in 1746 at the University of Leyden in Holland. It was the first device capable of storing electrical charge in the form of electrostatic field. ${ }^{7}$

A typical electrostatic capacitor is composed of two parallel conducting plates called electrodes separated by an insulating dielectric material, as shown in 
Figure 1.1. When an external voltage is applied across the conducting parallel plates, a charge of $-Q$ on the negative electrode and a charge of $+Q$ on the positive electrode are accumulated. These charges are kept apart by the insulating dielectric between these electrodes, this produces an electric field. This resulting electric field allows the capacitor to store energy.

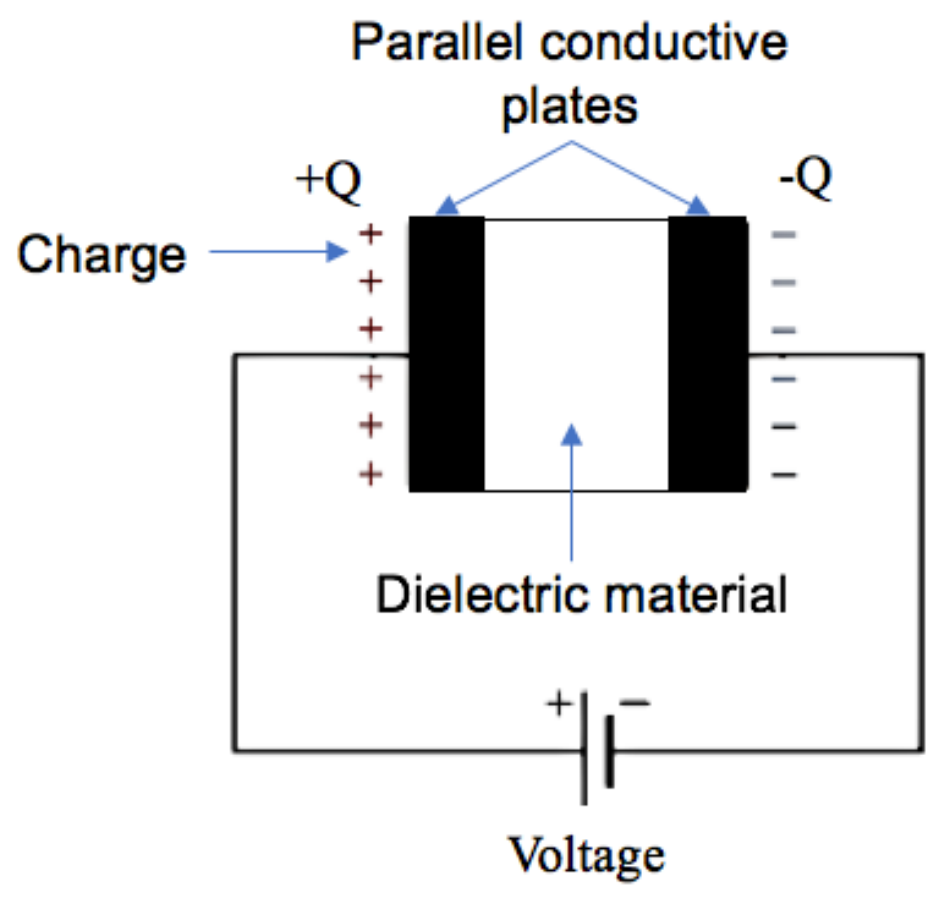

Figure 1.1 An electrostatic capacitor.

An ideal electrostatic capacitor is characterized by a constant parameter called the capacitance $C$. Capacitance reflects the capability of a capacitor to store the electric charge and is defined as the ratio of the accumulated charge $Q$ to the strength of the applied voltage $V$ :

$$
C=Q / V
$$


The capacitance of a conventional parallel-plate capacitor with a dielectric medium between the electrodes can be calculated using the following equation:

$$
C=\varepsilon_{0} \varepsilon_{r} \frac{A}{d}
$$

Where $A$ is the surface area of each electrode, $d$ is the distance between them, $\varepsilon_{o}$ is the dielectric constant (or "permittivity") of free space, and $\varepsilon_{r}$ is the dielectric constant of the insulating material between the electrodes.

As per above equation, the capacitance of a capacitor can be increased by shortening the distance between electrodes, increasing the surface area of electrodes, and lastly by using an insulating dielectric material with high permittivity. ${ }^{8}$ For low voltage, single polarity applications, ideal candidates for the electrode material are carbon based materials with porous structure and high conductivity, like carbon nanotubes, activated carbon or graphene. ${ }^{6}$

The two main attributes of a capacitor or any energy storage device is its energy density (specific energy) and power density (specific power). These values are calculated as energy or power per unit mass or per unit volume. Energy density is expressed in Watt-hours per kilogram $\left(\mathrm{Wh} \mathrm{kg}^{-1}\right)$ and the power density in Watt per kilogram $\left(\mathrm{W} \mathrm{kg}^{-1}\right) \cdot{ }^{6,8}$ The energy $\mathrm{E}$ stored in a capacitor is given by the equation:

$$
E=\frac{1}{2} C V^{2}
$$

Equation 1.3

The maximum power is determined by the following equation:

$$
P_{\text {max }}=\frac{V^{2}}{4 \times E S R}
$$

Equation 1.4 
Here ESR is the equivalent series resistance. This resistance arises due to internal components of the capacitor (e.g., electrodes, current collectors and

dielectric material). ${ }^{8}$ Generally, electrostatic capacitors have high power density, they can be charged and discharged quickly. But they have a very low energy density and are unable to store a large amount of charge. These characteristics make electrostatic capacitors suitable for those applications in which power bursts are required.

\subsubsection{Batteries}

Batteries are the most widely used electrochemical energy storage devices in industry and daily life. They are capable of storing and releasing charge via electron flow through oxidation-reduction reactions. This technology was started by the invention of the voltaic pile by Alessandro Volta in 1800. It was the first electrical battery that could continuously supply electric current to a circuit and consisted of pairs of zinc and copper discs piled on top of each other. ${ }^{9}$

A typical battery is composed of one or more electrochemical cells connected in series or parallel, which generate electric current with a desired voltage from an electrochemical reaction. Each electrochemical cell contains two electrodes electronically isolated from each other and an electrolyte that facilitates ionic transport between them. One electrode is responsible for the reduction reactions and other for oxidation reactions. During operation (charging or discharging), one electrode is oxidized and releases electrons to move through an external circuit. This electrode is commonly called the anode, or the negative electrode. The 
other electrode attracts the electrons from the external circuit and gets reduced. This electrode is commonly called the cathode or the positive electrode and the electrons moving from the anode to the cathode through the external circuit produce electric current. ${ }^{10}$

On the basis of charging capabilities of batteries, they are grouped into two categories: primary (or disposable) batteries, and secondary (or rechargeable) batteries. The primary batteries permit only a single charge-discharge cycle as the reactions occurring in them are not reversible in nature (e.g., zinc-carbon batteries). ${ }^{9}$ On the other hand, the rechargeable batteries can be charged and discharged multiple times due to the reversible nature of the electrochemical reactions occurring in them (e.g., lithium-ion batteries). In a rechargeable battery, the electrodes reverse roles during charging and discharging. ${ }^{9}$

Lithium-ion batteries are currently the leading energy storage systems due to their fast response time, high energy density, light weight, small dimensions, and no memory effect. Since there commercialization by Sony in 1990, they have become the most common power source for various applications in industrial and consumer electronics. ${ }^{10}$ In these batteries, the cathode is generally made of lithium intercalated metal oxides like cobalt oxide, as they are capable of releasing and inserting lithium ions in their lattice. The anode is generally made of graphite or other carbon materials that have large interlayer distances to allow easy insertion of lithium ions and minimal strain. ${ }^{11}$ 
During the charging process, the lithium ions are intercalated into the graphite anode from the cathode host material. The lithium ions move through the electrolyte while the electrons move through the external circuit towards the anode. During the discharge process, when the voltage source is removed and battery is connected to an external load, the role of electrodes is reversed in the sense that the electrode that allowed the insertion of the lithium ions, will now give away the lithium ions and these ions are accepted by the other electrode, as shown in Figure 1.2. ${ }^{11,12}$

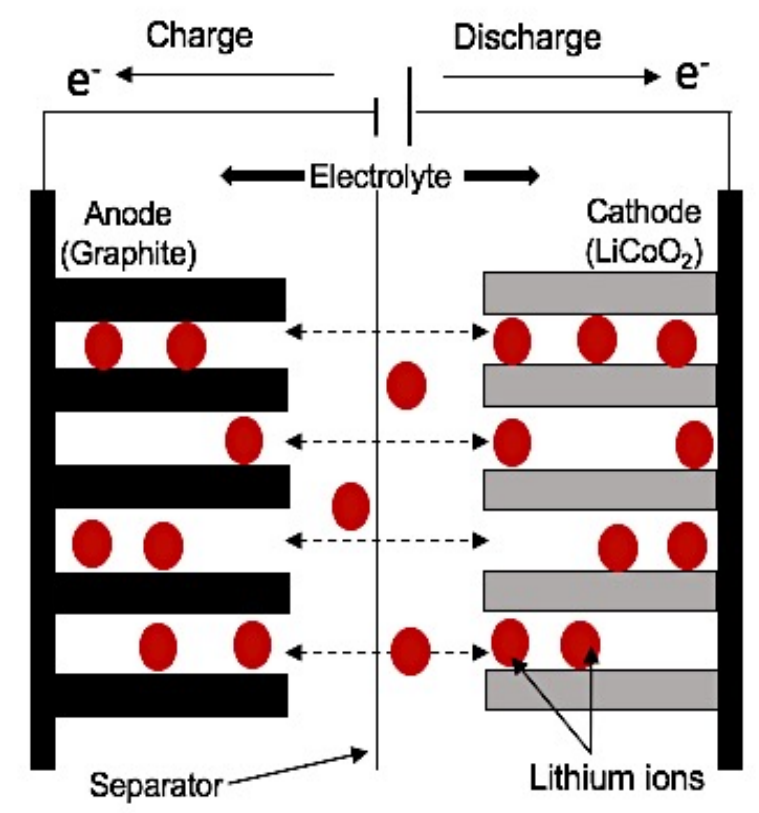

Figure 1.2 Representation of the commonly used lithium-ion battery based on $\mathrm{LiCoO}_{2}$ cathodes and graphite anodes.

Lithium-ion batteries exhibit high energy density due to the participation of most of the electrode. But still there are certain limitations associated with them. They have limited power density. The charge-discharge rate is limited by the 
intercalation/deintercalation of lithium ions, which involves the expansion of the host lattice to accommodate multiple layers of the lithium ions. In addition, due to this process the materials inside the battery degrade overtime and they lose their ability to retain charge. ${ }^{11}$

\subsubsection{Supercapacitors}

Traditional supercapacitors, also called electric double layer supercapacitors, are charge-storing devices that are governed by the same basic principles as electrostatic capacitors (discussed in Section 1.3.1). They incorporate electrodes with a much higher surface area for more charge storage and much thinner dielectric materials to decrease the separation between the electrodes. This results in an increased capacitance and energy density. But unlike capacitors, the charge does not consist exclusively of electrons or holes in metal electrodes, this charge is stored at the interface between the surface of the metal electrodes and the electrolytic solution. This technology was discovered by coincidence in the early 1950'S, when researchers were experimenting with porous carbon electrodes, in the design of capacitors. They discovered that porous activated carbon with a high specific surface area can be used for energy storage, and the first patent was granted to Becker at General Electric Corp. in 1957. In 1971, these devices were successfully commercialized and marketed as

"supercapacitors" by the Japanese company, NEC corporation. ${ }^{1,13}$

A typical supercapacitor contains two porous conducting electrodes, an electrolyte, and a porous ion conducting membrane separator that mechanically 
separates the two electrodes as shown in Figure 1.3. During the process of charging, the electrons move from the negative electrode towards the positive electrode through an external circuit. To maintain electrical neutrality, the cations diffuse across the separator towards the negative electrode while anions diffuse towards the positive electrode within the electrolyte. This results in the accumulation of charge at the electrode/electrolyte interface by electrostatic means. Opposite charges reside on two different layers; one set resides on the electrode and the other of opposite polarity in the electrolyte as shown in Figure 1.3. These accumulated charges hence form an electric double-layer which is separated by a monolayer of solvent molecules, also referred to as the inner Helmholtz plane (IHP) and can be idealized as a molecular dielectric. Hence, this interface can be treated as a capacitor with an electric double-layer capacitance and both the electrodes can be treated as two capacitors in series. ${ }^{14,15}$ 


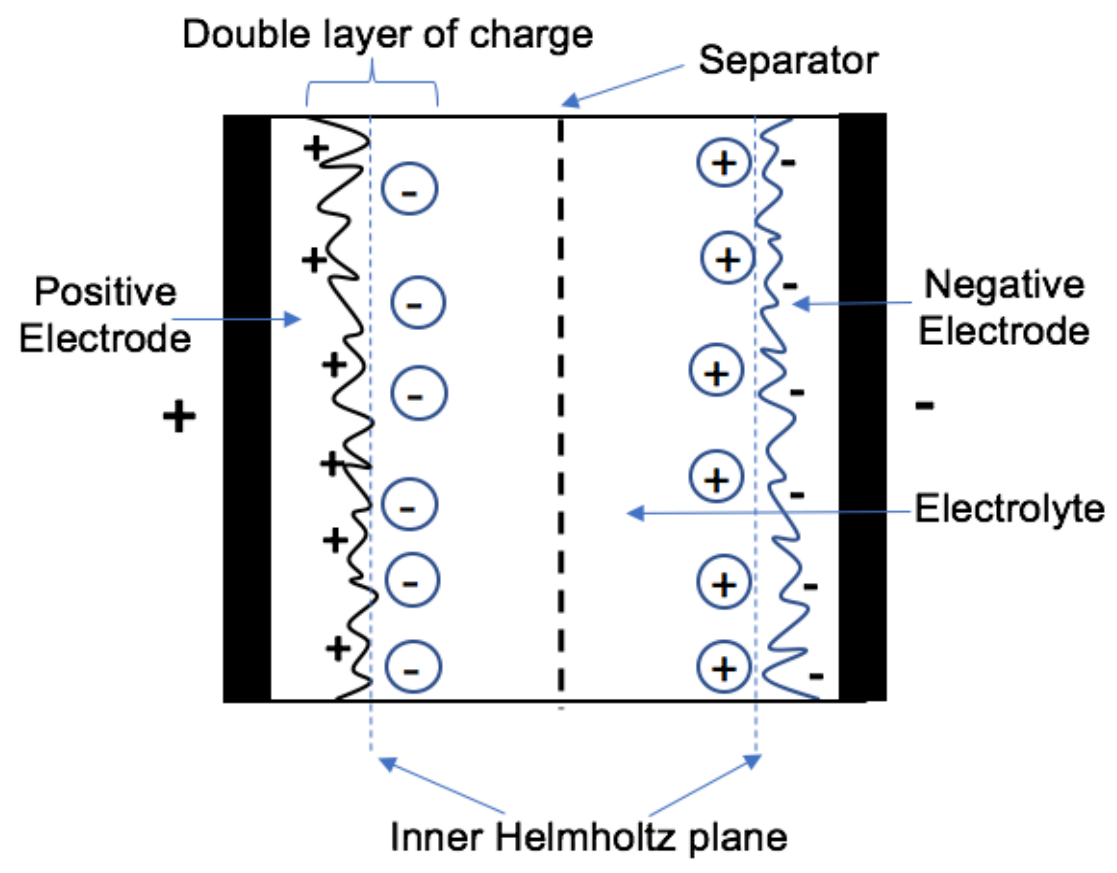

Figure 1.3 An electric double layer supercapacitor showing charge accumulation at the electrode/electrolyte interface.

The total capacitance of a supercapacitor (SC) can be described by the equation:

$$
1 / C_{T}=1 / C_{1}+1 / C_{2} \quad \text { Equation } 1.5
$$

Here $C_{T}$ is the total capacitance and $C_{1}, C_{2}$ are individual capacitance of each electrode.

During the discharging process, when the applied voltage is replaced with a load, ions diffuse back into the electrolyte and the role of electrodes is reversed. In the whole process of charging and discharging, the concentration of electrolyte remains constant as no net ion exchange takes place between the electrolyte and the electrode, and no charge transfer occurs at the interface. ${ }^{1}$ The processes of charging and discharging can be expressed as equations: 
At the positive electrode, during charging:

$$
E_{X}+A^{-} \rightarrow E_{X}^{+} / / A^{-}+e^{-} \quad \text { Equation } 1.6
$$

At the positive electrode, during discharging:

$$
E_{X}^{+} / / A^{-}+e^{-} \rightarrow E_{X}+A^{-} \quad \text { Equation } 1.7
$$

At the negative electrode, during charging:

$$
E_{y}+C^{+}+e^{-} \rightarrow E_{y}^{-} / / C^{+} \quad \text { Equation } 1.8
$$

At the negative electrode, during discharging:

$$
E_{y}^{-} / / C^{+} \rightarrow E_{y}+C^{+}+e^{-} \quad \text { Equation } 1.9
$$

Here $E_{x}$ and $E_{y}$ denotes the electrodes, $A^{-}$and $C^{+}$the anions and the cations and // the electrode/electrolyte interface.

Supercapacitors exhibit high-power density, high cycle efficiencies and long cycling times. But they still have low energy density and are not able to store a large amount of charge. Because of these characteristics, they are considered suitable for those applications in which power bursts are needed, but high energy storage capacity is not required, like UPS (uninterruptible power supply) systems, photographic flashes, regenerative braking, electric vehicle acceleration etc. ${ }^{16}$

\subsection{Performance Comparison of Energy Storage Systems}

The two main attributes of any EES system is its energy density and its power density. Conventional capacitors have a very high-power density but poor energy density, whereas the opposite applies to batteries. Supercapacitors manage to obtain a relatively high energy density as compared to conventional capacitors, while still maintaining the high-power output found in conventional capacitors. But 
their energy density is still lower than that supplied by a battery. Hence, supercapacitors serve as a gap between conventional capacitors and batteries. The variation of energy density versus the power density of these EES systems are illustrated using the Ragone plot shown in Figure 1.4.

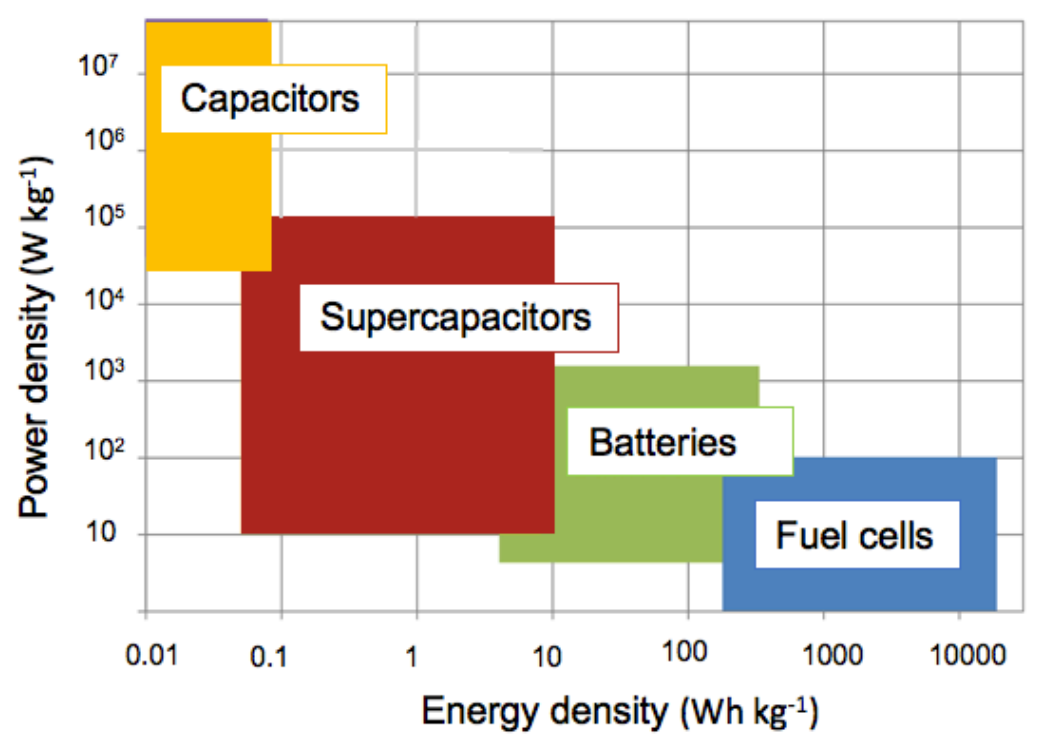

Figure 1.4 Ragone plot of energy density vs power density for various energy storage systems. Adapted with permission from Winter, M.; Brodd, R. J. What are Batteries, Fuel cells, and Supercapacitors. Chem. Rev. 2004, 104, 42454269. ${ }^{17}$ Copyright 2004 American Chemical Society.

It is clear from the plot that capacitors have a very high-power density $\left(>10^{6}\right.$ $\mathrm{W} \mathrm{kg}^{-1}$ ) compared to batteries and supercapacitors, but relatively low energy density. On the other hand, batteries have high energy-density $\left(>50 \mathrm{Wh} \mathrm{kg}^{-1}\right)$ but a poor power density, meaning it can store a large amount of energy but cannot dissipate it quickly. Supercapacitors occupy an important position in terms of power density as well as energy density. The detailed performance differences between these devices are revealed in Table 1.1.17,18 
Table 1.1 Performance Comparison Table.

\begin{tabular}{|c|c|c|c|}
\hline Parameters & Capacitors & Supercapacitors & Batteries \\
\hline $\begin{array}{c}\text { Energy density } \\
\left(\mathrm{Wh} \mathrm{kg}{ }^{-1}\right)\end{array}$ & $<0.1$ & $0.1-10$ & $10-100$ \\
\hline $\begin{array}{c}\text { Power density } \\
\left(\mathrm{W} \mathrm{kg}^{-1}\right)\end{array}$ & $>100,000$ & $10-100,000$ & $10-1000$ \\
\hline Charge time & $10^{-6}$ to $10^{-3} \mathrm{sec}$ & $1 \mathrm{sec}$ to $1 \mathrm{~min}$ & 0.3 to 3 hours \\
\hline Discharge time & $10^{-6}$ to $10^{-3} \mathrm{sec}$ & $1 \mathrm{sec}$ to $1 \mathrm{~min}$ & 1 to 5 hours \\
\hline Cycle-life & Almost infinite & $>500,000$ & About 1000 \\
\hline
\end{tabular}

Supercapacitors have more energy density than conventional capacitors because they store charge not only at the electrode surfaces but also in the bulk near the surface of the electrodes. They have higher power density than batteries because the charge-discharge process is not limited by ionic-conduction into the electrode bulk. They also exhibit good cycling efficiency, and longer lifetime than batteries because their charge storage mechanism does not involve any oxidation-reduction reactions. But due to the absence of redox reactions they have much lower energy density compared to batteries. ${ }^{19,20}$

The low energy density issue of supercapacitors has limited their widespread use. To overcome this major obstacle, many enterprises have invested time and money in exploring, researching, and developing supercapacitors with a high energy density that is close to currently used rechargeable batteries while maintaining their high-power density and extended cycle life. 


\subsection{Research Motivation and Objective}

To address the issue of low energy density of supercapacitors, intensive research is being carried out to develop new electrode materials for supercapacitors. Currently, carbon-based materials are mostly used due to their high surface area for charge storage and favorable chemical properties. But, in spite of these properties, the charges physically stored on them are unfortunately limited. To solve this issue, many advanced approaches are being developed. The electrode materials are hybridized by adding redox active materials like metal oxides $\left(\mathrm{RuO}_{2}, \mathrm{MnO}_{2}, \mathrm{Co}_{3} \mathrm{O}_{4} \text {, etc. }\right)^{21-23}$, metal hydroxides $\left(\mathrm{Ni}(\mathrm{OH})_{2}\right.$, $\mathrm{Co}(\mathrm{OH})_{2}$, etc.) to carbon-based electrodes or by completely replacing the carbon electrodes with redox active materials like conducting polymers (polypyrrole, PANI, etc. $)^{24,25}$ The SCs with redox active materials as electrodes are called redox enhanced SCs or hybrid supercapacitors. These hybrid supercapacitors have been reported to yield much higher specific capacitance and energy density than conventional supercapacitors and are being considered as promising next generation energy storage systems. ${ }^{8}$

In recent decades, different electrode materials have been developed to enhance the performance of SCs, but only a few materials are explored as redox additives in electrolytes for SC applications. In this regard, the objective of this research project was to develop an oxidation half-cell of a hybrid supercapacitor using a redox additive gel-polymer electrolyte and single-walled carbon nanotube (SWCNT) electrodes. $N, N$-disubstituted-4,4-bipyridinium (also referred to as 
viologen or $\mathrm{V}^{2+}$ ) species were used as the redox additives in poly(ethylene glycol) MW=400 (PEG)-lithium perchlorate gel-polymer electrolyte. The viologen centers were incorporated in the PEG backbone to form a V-PEG copolymer, which was then tethered to single-walled carbon nanotube electrodes to enhance the energy density via redox reactions at the electrode-electrolyte interface.

The oxidation half-cell was then coupled with a reduction half-cell containing ferrocene dicarboxylic acid, to form a hybrid supercapacitor. The reduction halfcell was developed and characterized by Shalaka Rahangdale. ${ }^{26}$ The capacitance and energy density of this hybrid SC is expected to be greater than conventional SCs, due to the reversible Faradaic reactions related to viologens and ferrocene dicarboxylic acid in the corresponding half-cells. 


\section{Chapter 2 : MATERIALS FOR THE OXIDATION HALF-CELL OF THE HYBRID SUPERCPACITOR}

\subsection{Introduction}

In the oxidation half-cell of the proposed hybrid supercapacitor, viologenpolyethylene glycol (V-PEG) polymer was used as the cationic polyelectrolyte and single-walled carbon nanotubes (SWCNTs) as electrode materials. The oxidation half-cell was coupled with a reduction half-cell having ferrocene dicarboxylic acid in it, to compensate for electrochemical reductions of viologens during charging, as illustrated in Figure 2.1. Porous polycarbonate membranes were used as separators, to allow the transfer of ions, but prevent electron flow through them.

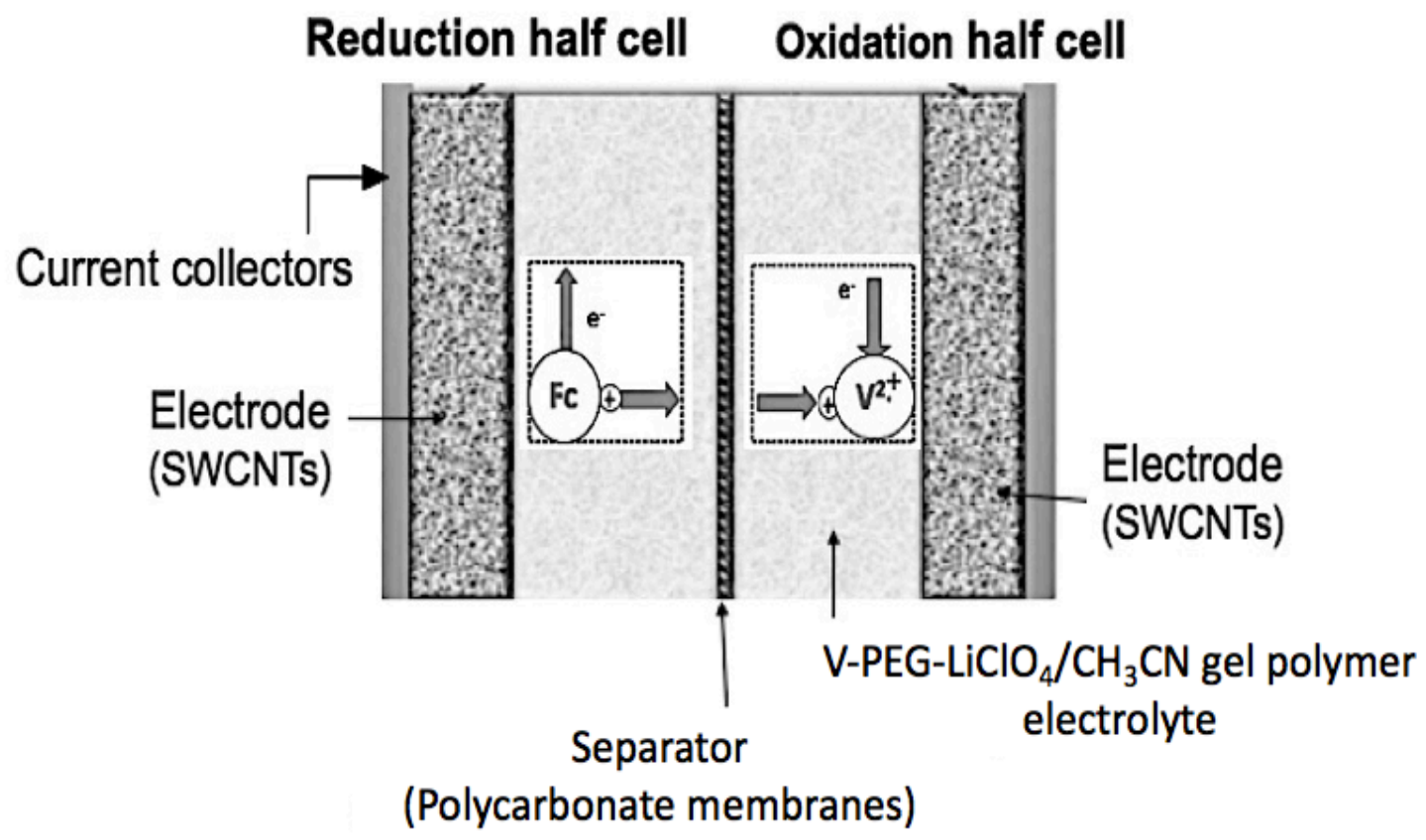

Figure 2.1 Proposed hybrid supercapacitor in a sandwich-type configuration. 
In the oxidation half-cell, the electrode is expected to be the source of double layer capacitance and the viologen centers in the gel-polymer electrolyte are expected to be the source of redox capacitance. The oxidation-half cell materials and their advantages are discussed in detail in the following sections.

\subsection{Electrode Materials}

The electrode materials for supercapacitors are required to have high chemical stability for higher cyclic stability, a high specific surface area for higher specific capacitance, and high electronic conductivity for high power density. ${ }^{1,18,27}$ In this respect, single-walled carbon nanotubes can be regarded as appealing electrode materials, as they possess all the above properties. ${ }^{14,28}$

Carbon nanotubes (CNTs) were discovered in 1993 by lijima et al. ${ }^{29}$ They can be defined as one atom thick sheets of graphene rolled up into cylinders with a diameter in the order of 3-30 nm, as shown in Fig 2.2. All carbon atoms in single-walled CNTs (SWCNTs) are covalently bonded with $\mathrm{sp}^{2}$ geometry to neighboring carbon atoms with no unpaired electrons on their surface, due to which they show a high level of chemical stability. They also exhibit a good thermal conductivity along their axis as they are highly crystalline. ${ }^{28,29}$ Because of these reasons, they were used as electrode materials in this project.

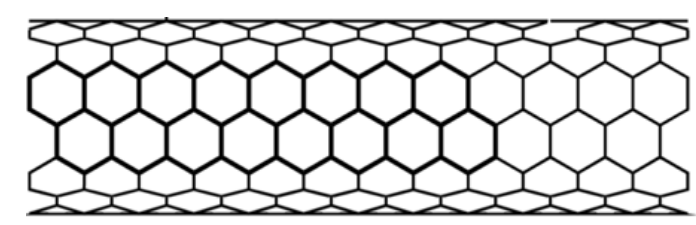

Figure 2.2 Structure of single-walled carbon nanotubes. 
Despite all the appealing properties of SWCNTs, there are certain challenges associated with them for their application as electrode materials in supercapacitors (SCs). They are hydrophobic in nature and tend to aggregate into bundles, rafts, and ropes due to extensive van der Waals interaction between their sidewalls and the availability of easy packing. This results in their poor solubility in most of the organic and aqueous solvents. ${ }^{30}$ To overcome these limitations of SWCNTs, various chemical groups can be attached on their surface to improve their solubility by interrupting the van der Waals interaction between the tubes. ${ }^{31,32}$

In this project, to improve the solubility of the SWCNTs, they were oxidized using $13 \mathrm{M}$ nitric acid. The nitric acid-oxidation process is discussed in detail in Chapter 3. Furthermore, in an attempt to improve the exposed surface area of oxidized-SWCNTs for enhanced specific capacitance, they were functionalized with $\mathrm{PEG}_{400}$. The viologen centers were also covalently incorporated into polyethylene networks to increase their co-solubility with the PEG-derivatized SWCNTs. The incorporation of viologen species in polyethylene glycol backbone to form a V-PEG polymer is discussed in Chapter 4 and the derivatization of SWCNTs with V-PEG polymer is discussed in detail in Chapter 5.

\subsection{Electrolyte Materials}

\subsubsection{Electrolyte Salt and Solvent}

Electrodes having a high surface area and high electronic conductivity are considered critical to enhance the performance of SCs. But besides the two 
electrodes, research has revealed that their performance depends on the electrolyte as well. ${ }^{33}$ The electrolyte provides ionic conductivity, and facilitates the charge-discharge processes on each electrode. Therefore, it is required to have a wide voltage window, high electrochemical stability, high ionic concentration, low resistivity, low solvated ionic radius, low viscosity, low toxicity, and low volatility. ${ }^{33,34}$ Three types of electrolytes that are currently used in SC research are aqueous, organic, and ionic liquid electrolytes.

Aqueous electrolytes such as $\mathrm{H}_{2} \mathrm{SO}_{4}, \mathrm{Na}_{2} \mathrm{SO}_{4}$, and $\mathrm{KOH}$ have small ionic radii and can provide high ionic concentrations and lower resistance. However, their decomposition voltage is about $1.23 \mathrm{~V}$, and this limits the energy density and power density of SCs. ${ }^{35}$ Ionic liquids (ILs) such as N-methyl-N-propylpyrrolidinium bis(fluorosulfonyl)imide have a wide voltage window, high thermal, and chemical stability. Despite the difficulties in designing ILs to have a wide potential range, their performance metrics such as high conductivity in a wide temperature range makes them attractive candidates. Organic electrolytes, such as tetraethylammonium tetrafluoroborate $\left(\mathrm{TEABF}_{4}\right)$ dissolved in acetonitrile or propylene carbonate, can provide a wide voltage window as high as $3.5 \mathrm{~V}$ as well as a wide range of operating temperature. ${ }^{35}$

In this project, lithium perchlorate $\left(\mathrm{LiClO}_{4}\right)$ was used as the electrolyte salt and $\mathrm{PEG}_{400}$ as the electrolyte solvent. Lithium perchlorate was selected because of its good solubility and high conductivity in liquid $P E G_{400}$. Compared with other lithium salts, it is less hygroscopic, stable to ambient moisture, economical, and 
very easy to handle. ${ }^{36}$ PEG was used not only due to the solubility factor but also due to the fact that polymer electrolytes offer a number of advantages compared to their liquid counterparts. They offer excellent processability, broad electrochemical stability, they are less reactive, and safer due to their low flammability ${ }^{36}$ In addition, $\mathrm{PEG}_{400}$ is non-toxic, easy to handle, and exhibits ion conduction at room temperature. The lithium-ion conduction in PEG is illustrated in Scheme 2.1. The lithium ions are coordinated by ether oxygen atoms on the segments of PEG chains. They get displaced by the continuous segmental rearrangements accompanied by the gradual replacement of ligands in the solvation sheath of lithium ions.

Scheme 2.1 Schematic illustration of lithium-ion conduction in PEG.

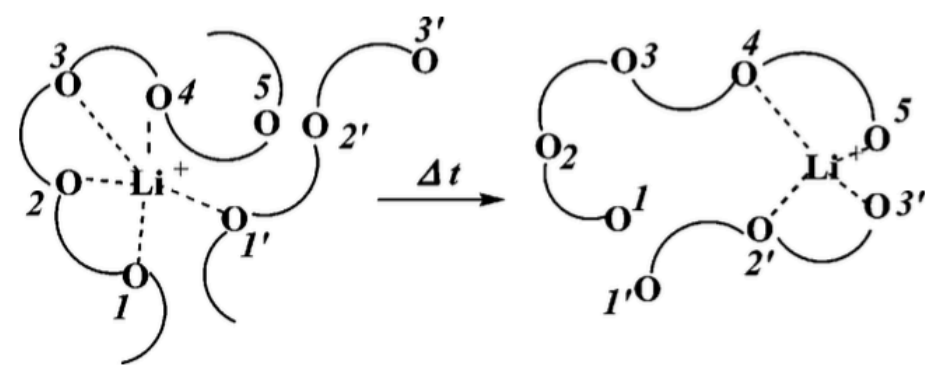

\subsubsection{Redox Additive}

In hybrid SCs, redox additives can be incorporated in the electrolyte to improve their energy density. Redox additives are directly involved in the electron transfer redox reactions and they improve the performance of SCs by their redox capacitance contribution at the electrode-electrolyte interface.$^{34}$ In this regard, $\mathrm{N}, \mathrm{N}$-disubstituted-4,4-bipyridinium (also referred to as viologen or $\mathrm{V}^{2+}$ ) species 
were used as the redox additives for the oxidation half-cell of the proposed hybrid SC. They were incorporated into the backbone of the polymer electrolyte $\left(\mathrm{PEG}_{400}\right)$ to form viologen-PEG (V-PEG) polymers. The different V-PEG polymer products that can be formed are shown in Figure 2.3. The synthesis of V-PEG polymer is discussed in detail in Chapter 4. The $\mathrm{PEG}_{400}$ was used for multiple purposes in the oxidation half-cell. It was not only used to incorporate viologen species, but also to dissolve lithium perchlorate and functionalize SWCNTs to increase their exposed surface area, as discussed in the above sections.

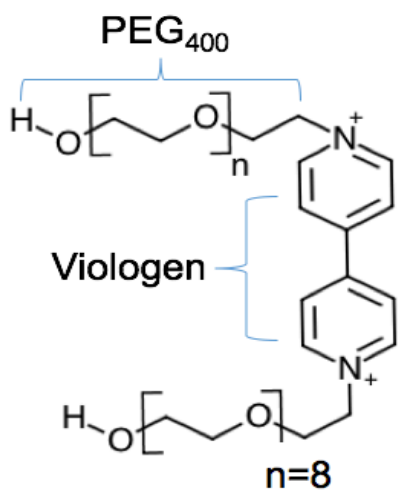

2.30

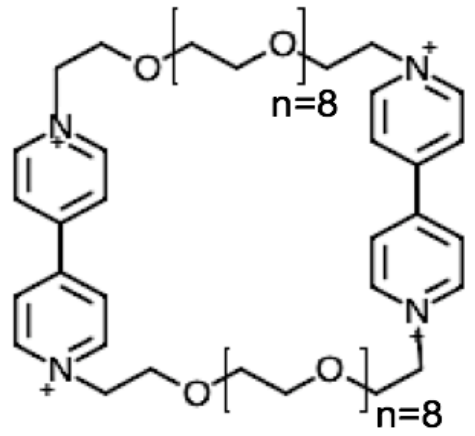

2.31<smiles>[B]OCCOC[Nb]1([B][O-])C=CC(c2ccncc2)=CC1</smiles>

2.32

Figure 2.3 Possible structures of V-PEG polymer.

The viologen species were selected because they are strong electron acceptors, possess three redox states $\left(\mathrm{V}^{0}, \mathrm{~V}^{+}\right.$, and $\left.\mathrm{V}^{2+}\right)$ states, and exhibit fast and reversible rates of electron transfer. ${ }^{37,38}$ On charging, viologens $\left(\mathrm{V}^{2+}\right)$ undergo one-electron reduction to form the stable but air sensitive cation radicals 
$\left(\mathrm{V}^{+}\right)$, which further undergo one-electron reduction to form the neutral reduced form $V^{0}$, illustrated in Scheme 2.2. After the introduction of viologen species in the polymer electrolyte of the oxidation half-cell, the energy density and capacitance value of the proposed hybrid SC is expected to increase due to reversible Faradaic reactions between viologen species and ferrocene dicarboxylic acid present in the reduction-half cell of the SC. The chemical processes involved to store charge in the proposed hybrid supercapacitor are discussed in detail in Chapter 6.

Scheme 2.2 Redox behavior of viologen species.

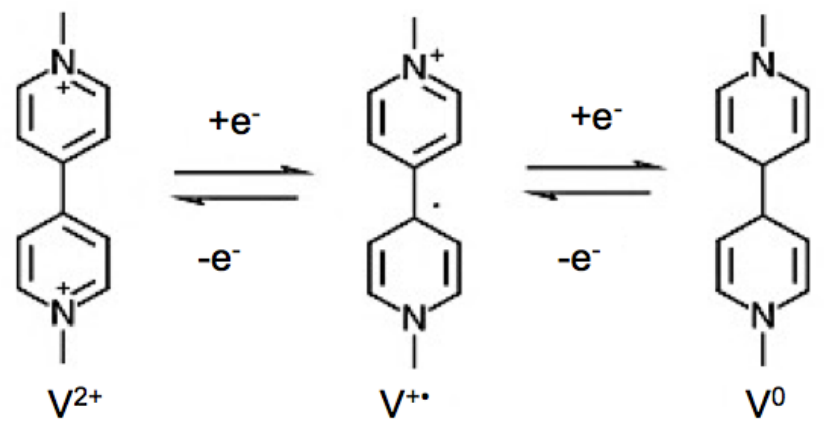

\subsection{Separator}

The separator is located between the two electrodes in a SC, to prevent the conduction of electrons between them, while permitting the facile transfer of electrolyte ions. In SCs, the separators are required to have minimum resistance for the ion transfer within the electrolyte, strong electronic insulating capability, high electrochemical stability in the electrolyte, and good mechanical strength for durability. ${ }^{35}$ Considering all these factors, porous polycarbonate filter membranes were used as separators in this project. 


\section{Chapter 3 : FUNCTIONALIZATION OF SINGLE-WALLED CARBON NANOTUBES}

\subsection{Introduction}

Carbon nanotubes (CNTs) are inert and insoluble in most aqueous and organic solvents, but their reactivity and solubility can be improved by functionalizing them with different chemical groups. The chemical functionalization can be done either covalently or non-covalently at the ends, on the sidewall, or inside of CNTs. In an effort to increase the reactivity and solubility of single-walled carbon nanotubes (SWCNTs), three different approaches were attempted to covalently functionalize them with hydrophilic groups. The first approach was to use UV-ozone for oxidatively breaking C-C double bonds in pristine-SWCNTs and introducing functional groups like carboxylic acids, esters, and quinones on their sidewalls. It has been proved that UV light excites oxygen molecules from their spin-triplet state to a spin-singlet state and this excitation lowers the activation energy of molecular oxygen for chemisorption reactions.

This results in easy charge transfer from the SWCNTs to oxygen molecules. ${ }^{39-41}$

The second approach was to attach maleic anhydride groups on the surface of pristine-SWCNTs via a Diels-Alder reaction, as shown in Scheme 3.1. The Diels-Alder reaction is a cycloaddition reaction between a conjugated diene (electron rich) and a dienophile (electron poor). The SWCNTs were used as dienes in this reaction due to the presence of extensive conjugated double bonds. Maleic anhydride (MA) was used as dienophile, due to the presence of 
two carbonyl groups which are strong electron withdrawing groups and make the $\mathrm{C}=\mathrm{C}$ bond of maleic anhydride electron deficient. ${ }^{42}$

Scheme 3.1 Diels-Alder reaction mechanism.

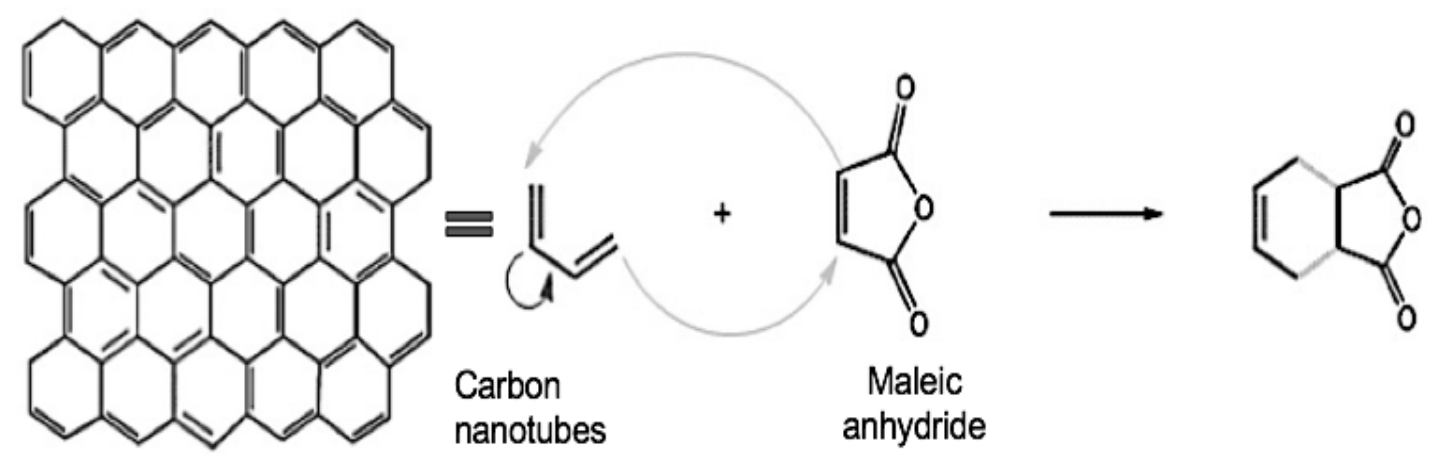

The third approach was to oxidize SWCNTs using a 3:1 mixture of sulfuric acid (98 wt\%) and nitric acid (16M), or in a closely related approach, to oxidize them using $13 \mathrm{M}$ nitric acid. The acid oxidation has been reported to break the carbon-carbon double bonded network of p-SWCNTs allowing the introduction of oxygen atoms in the form of carboxylic $(-\mathrm{COOH})$, carbonyl (-CO), and hydroxyl ($\mathrm{OH}$ ) functional groups, as shown in Scheme 3.2. ${ }^{43-45}$ The experimental conditions for all the four methods used to covalently functionalize SWCNTs with hydrophilic groups are described in detail in the following section. 
Scheme 3.2 Acid treatment of SWCNTs.

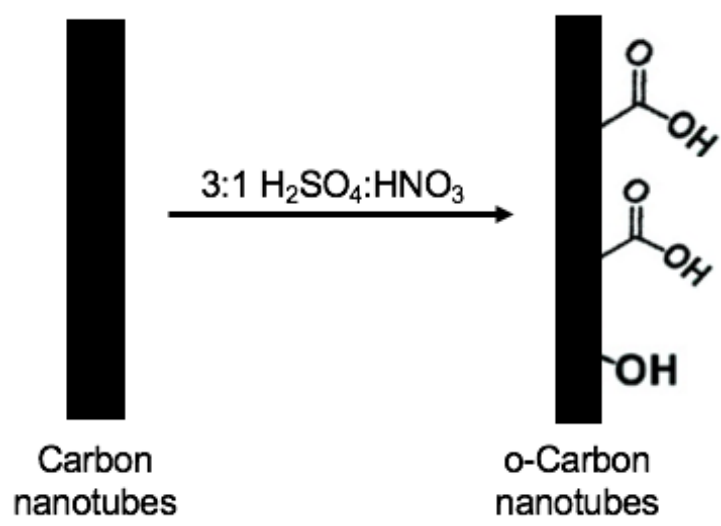

\subsection{Experimental Section}

\subsubsection{Materials}

Single-walled carbon nanotubes were purchased from Cheap Tubes Inc. They were used as received without further purification. These SWCNTs have an average diameter between 1-2 $\mathrm{nm}$ and purity above $90 \%$. All other reagents were purchased from Sigma-Aldrich Inc. and were used as received.

Polycarbonate membranes with $0.6 \mu \mathrm{m}$ pore size and nylon membranes with $0.45 \mu \mathrm{m}$ pore size were purchased from Sigma-Aldrich Inc. as well.

\subsubsection{Experimental Procedures}

\subsubsection{Ozonolysis}

$50 \mathrm{mg}$ of SWCNTs was treated with ozone gas, which was generated onsite using a low-pressure mercury UV lamp. The ozone gas was introduced continuously into a two port (with one gas inlet and one gas outlet) $100-\mathrm{mL}$ plastic bottle containing the SWCNTs. The ozone treatment was carried out for 2 hours at room temperature and the bottle was shaken after every 10 minutes to 
provide a uniform ozone exposure to tubes. The residual ozone gas coming out from the outlet was scrubbed into $0.5 \mathrm{M}$ potassium iodide solution before its discharge to the atmosphere. The treated tubes were collected from the bottle and stored in a glass vial for characterization.

\subsubsection{Maleic Anhydride Treatment}

In an oven dried three-neck flask, $30 \mathrm{mg}$ of SWCNTs was suspended in 20 $\mathrm{mL}$ of $\mathrm{N}$-methyl-2-pyrrolidone. The resulting mixture was stirred for 10 minutes

and sonicated in a water bath for 90 minutes. After degassing, $0.15 \mathrm{~g} \mathrm{~mL}^{-1}$ maleic anhydride was added to the mixture, which was then stirred for 48 hours at 170 ${ }^{\circ} \mathrm{C}$ under an inert nitrogen atmosphere. After 48 hours, the reaction mixture was first cooled down to room temperature, then diluted with deionized (DI) water for its filtration through a $0.6 \mu \mathrm{m}$ polycarbonate membrane filter. After filtration, no product was retained on the membrane filter.

\subsubsection{Concentrated $\mathrm{H}_{2} \mathrm{SO}_{4} / \mathrm{HNO}_{3}$ Mixture (3:1) Treatment}

In an oven dried $50 \mathrm{~mL}$ round bottom flask, $20 \mathrm{mg}$ of SWCNTs was suspended in $20 \mathrm{~mL}$ of a $3: 1$ mixture of concentrated $\mathrm{H}_{2} \mathrm{SO}_{4}(98$ $\mathrm{wt} \%) / \mathrm{HNO}_{3}(16 \mathrm{M})$. The resulting mixture was sonicated in a water bath for 30 hours. After 30-hour sonication, the resulting reaction mixture was diluted with $200 \mathrm{~mL}$ of DI water and filtered through a $0.6 \mu \mathrm{m}$ pore size polycarbonate membrane filter. The retained tubes were repeatedly washed with DI water and dried at $80^{\circ} \mathrm{C}$ overnight in an oven. 


\subsubsection{Nitric Acid Oxidation}

In an oven dried $100 \mathrm{~mL}$ round bottom flask, $200 \mathrm{mg}$ of SWCNTs was refluxed in $55 \mathrm{~mL}$ of $13 \mathrm{M}$ nitric acid for four days. The refluxed tubes were collected on a $0.6 \mu \mathrm{m}$ - pore membrane filter and rinsed with DI water. Then the tubes were dried at $80^{\circ} \mathrm{C}$ overnight in an oven.

\subsection{Characterization Techniques}

\subsubsection{Raman Spectroscopy}

Raman spectroscopy is a non-destructive light scattering technique, which allows analysis of a wide variety of opaque, colored, transparent, and translucent samples including solutions, suspensions, and solids. ${ }^{46}$ This technique is named in honor of its inventor, C. V. Raman, an Indian scientist, and is based on the Raman effect. ${ }^{47}$ The Raman effect, is the inelastic scattering of incident radiation through its interaction with vibrating molecules. The inelastic scattering of light is used to identify and interrogate vibrational and rotational modes of molecules.

In this technique, when a sample is illuminated with a monochromatic laser beam (typically in the UV-NIR range), the laser beam interacts with the molecules present in it and is scattered in all directions. The frequency of the scattered radiation, is measured, for example, at right angles to the incident radiation. If the frequency of the scattered radiation is equal to the frequency of the incident radiation, then it's called Rayleigh scattering, but if the frequency of the scattered radiation is different from the frequency of the incident radiation, then it may be Raman scattering. The majority of the scattered light follows the 
Rayleigh scattering mechanism, roughly one in $10^{6}$ of incident photons, and only a much smaller fraction (again, roughly one in $10^{6}$ ) shows Raman scattering. The scattered light showing Raman scattering is used to construct a Raman spectrum. If the frequency of the incident radiation is higher than the frequency of the scattered radiation, the radiation is referred to as Stokes lines and if the frequency of the incident radiation is lower than the frequency of the scattered radiation, then it is termed anti-Stokes. In a Raman spectrum, both Stokes and anti-Stokes lines are present. The difference in frequency between the incident and scattered radiation is called as the Raman shift. Raman's insight was to predict the existence of these bands, and to assign them to inelastic scattering wherein the incident photon mixes with the vibrational energy of the molecule. This results in Stokes/anti-Stokes bands appearing at a frequency shift equal to the vibrational frequency of the bond in question. Stokes bands are more intense than anti-Stokes bands because they involve transitions from lower to higher energy vibrational levels and hence are measured in conventional Raman spectroscopy. ${ }^{47,48}$ The different types of transitions involved in Rayleigh and Raman scattering are demonstrated in Figure 3.1. 


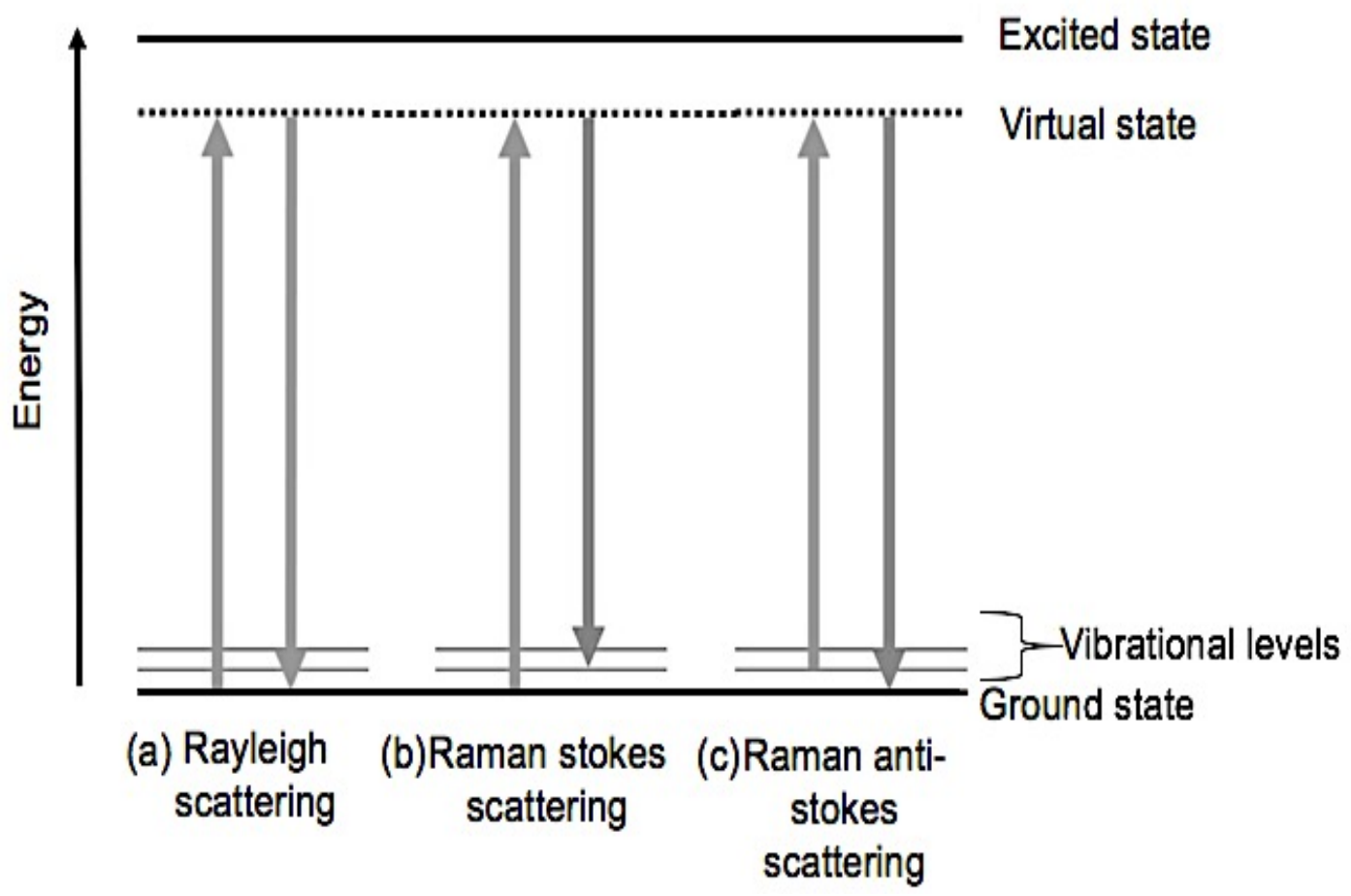

Figure 3.1 A schematic view of the energy transitions involved in (a) Rayleigh scattering, (b) Raman scattering (stokes scattering) and (c) Raman scattering (anti-stokes).

This technique is used for both quantitative and qualitative analysis and is well known for its minimum requirement for sample preparation and handling. A Raman spectrum is presented as intensity vs wavelength. Qualitative analysis can be done by measuring the frequency of scattered radiations while quantitative analysis can be done by measuring the intensity of scattered radiations. ${ }^{49}$ The magnitude of wavelength shifts (frequency values) is independent of the wavelength of incident radiation, but the intensity of Raman scattering depends on the wavelength of incident radiation. ${ }^{47}$

Over the last four decades. Raman spectroscopy has played an important role in the characterization of carbon nanotubes and identifying the covalent 
functionalization of SWCNTs. It is used to detect the presence of any defects or $\mathrm{sp}^{3}$ hybridization within the CNTs. Typically, three types of modes are often observed with CNTs, referred to as radial breathing mode (RBM), disorder mode ( $\mathrm{D}$ band), and tangential mode (G-band). The radial breathing mode between $100-300 \mathrm{~cm}^{-1}$ is dependent on CNT's diameter. This region shows much variation with different samples. The tangential mode or the G-band is characteristic of $\mathrm{sp}^{2}$ hybridized carbon atoms present in p-SWCNTs. This band indicates the presence of highly ordered CNT sidewalls and it appears between 1500$1600 \mathrm{~cm}^{-1}$. The disorder mode or the $\mathrm{D}$ band is characteristic of $\mathrm{sp}^{3}$ hybridized carbon atoms. It appears between $1200-1350 \mathrm{~cm}^{-1}$, indicating the presence of some disorder in $\mathrm{sp}^{2}$-hybridized $\mathrm{p}$-CNTS. It is correlated with the extent of sidewall functionalization of CNTs. The intensity of the $D$ band relative to the intensity of the $G$ band is expressed as $I_{D} / l_{G}$. It provides information regarding the structural changes as a result of covalent functionalization of the SWCNTs. The higher $I_{D} / I_{G}$ ratio indicates higher degree of covalent functionalization. ${ }^{50,51}$ However, the Raman spectroscopy does not help in studying the chemistry of sidewalls of CNTs. The functional groups present on the tube walls cannot be identified using this technique. To identify the functional groups, present on the tube walls, infrared spectroscopy is used, which is discussed in the following section. 


\subsubsection{Attenuated Total Reflection Fourier-Transform Infrared (ATR-FTIR) Spectroscopy}

Fourier-transform infrared spectroscopy is a fast, non-destructive analytical technique which helps to indicate the presence or absence of specific functional groups in a sample. It is based on triggering molecular vibrations through irradiation with infrared (IR) light and detecting the absorption of light by the sample. It commonly utilizes the mid IR region $\left(4000 \mathrm{~cm}^{-1}\right.$ to $\left.400 \mathrm{~cm}^{-1}\right)$. In this technique, when a sample is illuminated with a beam of IR light, the bonds present in the molecules absorb the energy of IR radiation. The absorption of IR light only occurs if the frequency of the incident IR radiation is identical to the vibrational frequency of the mode in question, i.e. of the specific functional groups in the molecule. The wavelengths at which the sample absorbs IR light is characteristic of its molecular structure. For the radiation measured in infrared frequencies, an interferometer is typically used for spectral dispersion, hence the need for a Fourier to convert from the time to frequency domain. Thus, from an FTIR spectrum, the chemical components present in the sample can be determined. ${ }^{52}$

In FTIR spectroscopy, the transmission of light is typically used, and IR light is passed through a sample sandwiched between two IR transparent windows. In this approach, it is crucial to adjust the sample thickness because the longer path lengths result in more absorption of incident IR radiation, and potentially none reaching the detector. The attenuated total reflection (ATR) offers an alternative sampling technique to overcome the sample thickness limitation of transmission. 
ATR is a surface sensitive technique, and generally it prevents strong attenuation of the IR signal in highly absorbing media. In this method, a beam of IR light is passed through a crystal made of IR transparent material with high refractive index. The IR beam is totally internally reflected as it passes through the crystal, reflected at an angle of incidence greater than the critical angle for the crystal material-organic material interface. This reflection forms the evanescent wave which extends into the sample and decays exponentially with distance from the surface as shown in Figure 3.2. It protrudes only a few microns beyond the crystal surface and interacts with the sample on the top surface of the prism or ATR crystal. In the regions of the IR spectrum where the sample absorbs energy, the evanescent wave is attenuated and the attenuated beam is recorded by the detector to generate a IR spectrum.$^{53}$ Additionally, this technique allows samples to be directly deposited onto the ATR crystal with very little sample preparation.

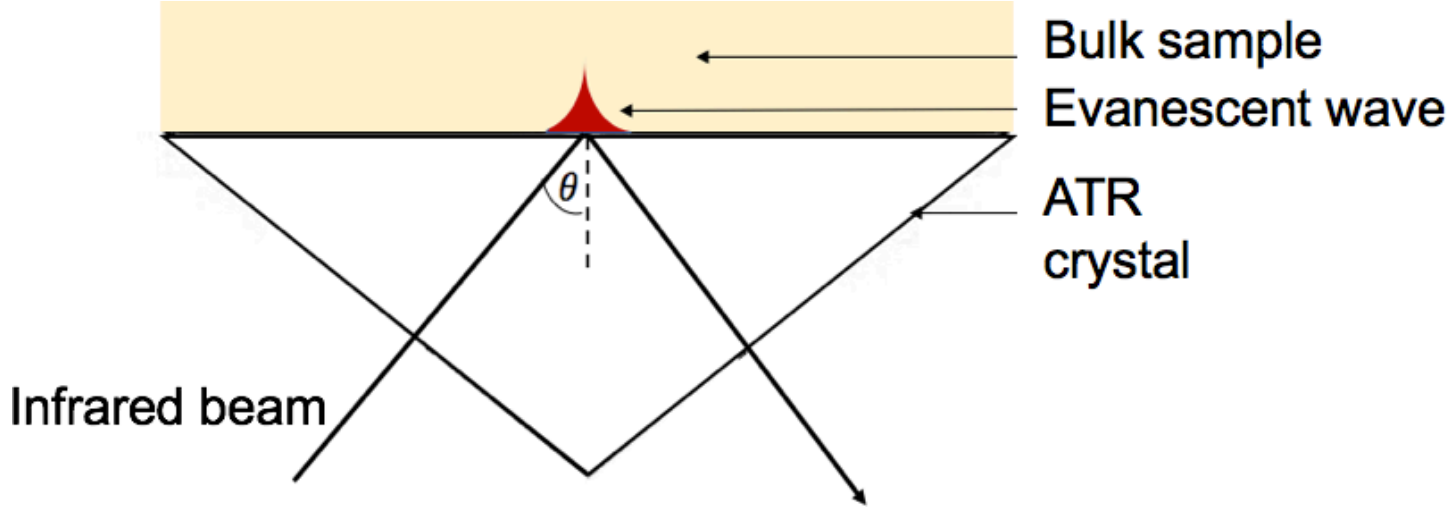

Figure 3.2 Schematic representation of infrared beam path length through the ATR crystal. 
ATR-FTIR plays an important role in studying the sidewall chemistry of nanotubes. It can help to identify functional groups like $-\mathrm{COOH},-\mathrm{OH}$, and other oxygen containing groups attached on the sidewalls of CNTs after their functionalization. In a typical ATR-FTIR spectra, bands due to $C=O$ stretch are observed in the range $\sim 1700 \mathrm{~cm}-1$ for the carboxylated SWCNTs. The bands due to $\mathrm{O}-\mathrm{H}$ stretch are observed in the range $\sim 3300 \mathrm{~cm}-1$ for the hydroxylated SWCNTs. ${ }^{54}$ The presence of these bands can indicate successful functionalization of SWCNTs with hydroxyl and carboxyl groups.

\subsection{Results and Discussion}

\subsubsection{Ozonolysis}

The unfunctionalized SWCNTs are expected to aggregate and be completely insoluble in water due to their hydrophobic nature. But, the SWCNTs functionalized with hydrophilic groups through ozonolysis are expected to be soluble in water. But, when the treated SWCNTs were dispersed in DI water, they still showed aggregation, indicating their unsuccessful functionalization. The unsuccessful functionalization can be attributed to a paucity of reaction time or non-uniform ozone exposure to tubes. To ensure this was the case, the ozone treatment time was increased and the SWCNTs were suspended in DI water for uniform ozone exposure. Even after four hours of ozone exposure and constant stirring, similar results were obtained, and this method was abandoned. 


\subsubsection{Maleic Anhydride Treatment}

The maleic anhydride treatment described above yielded SWCNTs that were difficult to filter through a $0.6 \mu \mathrm{m}$ polycarbonate membrane filter. During filtration, most of the tubes passed through the filter membrane along with the reaction mixture indicating excessive shortening of SWCNTs due to maleic anhydride treatment. The filtrate obtained was black in color, which suggested improved solubility of the tubes due to functionalization. In an effort to separate the tubes from the reaction mixture, the obtained black solution was again filtered through a $0.45 \mu \mathrm{m}$ pore size nylon membrane. But filtration was again not successful and no product was retained on the membrane filter.

After failed filtration attempts, centrifugation was used as an alternative approach to separate the tubes from the reaction mixture. Small volumes of the reaction mixture were centrifuged using a Labnet mini centrifuge C-1200 $(115 \mathrm{~V} / 60 \mathrm{~Hz})$ at a speed of $2000 \mathrm{rpm}$ for an hour, but no two distinct phases were obtained. This procedure was repeated multiple times and still tubes did not settle and stayed dispersed in the reaction mixture. This failure may be attributable to the low rpm value of the instrument.

\subsubsection{Concentrated $\mathrm{H}_{2} \mathrm{SO}_{4} / \mathrm{HNO}_{3}$ Mixture (3:1) Treatment}

The acid treated SWCNTs were expected to have improved solubility but when they were dispersed in DI water, the expected result was not observed. Even after sonicating the SWCNT-water suspension, the tubes still aggregated in the aqueous environment. This indicated that this method did not incorporate 
much hydrophilic functional groups on the CNT surface. This may be due to lack of heating during sonication which could have lowered the reaction rate. So, considering all these factors a reflux method was developed to oxidize SWCNTs.

\subsubsection{Nitric Acid Oxidation}

To check the solubility of acid refluxed tubes, they were dispersed in water and sonicated for five minutes. After sonication, they were found to be soluble in water resulting in a black colored solution illustrated in Figure 3.3. This indicated successful functionalization of SWCNTs.

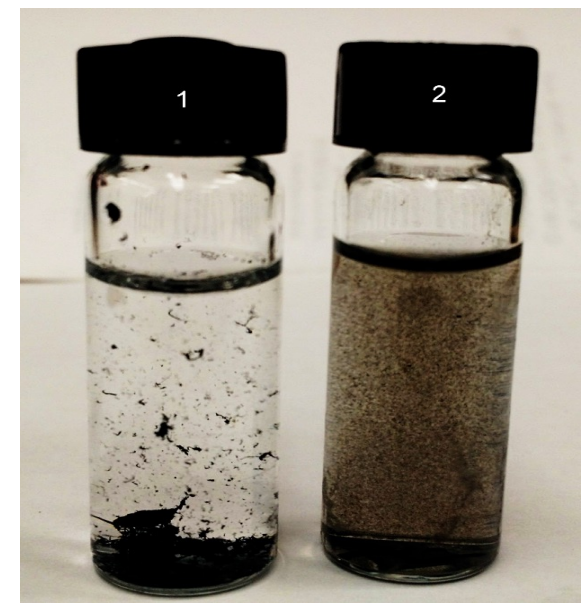

Figure 3.3 Solubility test of CNTs, (1) p-SWCNTs in water and (2) acid treated SWCNTs in water.

After obtaining positive results from the solubility test, the refluxed tubes were further characterized using FTIR and Raman spectroscopy. The Raman spectra of p-SWCNTs and acid treated SWCNTs were recorded at room temperature on an Enwave Optronics Raman spectrometer using a laser beam of the wavelength of $785 \mathrm{~nm}$. These spectra are overlapped for comparison, as illustrated in Figure 3.4. In the Raman spectrum of p-SWCNTs (Fig 3.4a), a prominent G-band at 
$1615 \mathrm{~cm}^{-1}$ and a very small D-band at $1300 \mathrm{~cm}^{-1}$ is observed, indicating the presence of mostly $\mathrm{sp}^{2}$ hybridized carbon-atoms and very few $\mathrm{sp}^{3}$ hybridized carbon-atoms. However, in the Raman spectrum of acid treated SWCNTs (Fig $3.4 \mathrm{~b}$ ), a distinct D-band is observed at $1316 \mathrm{~cm}^{-1}$, indicating the presence of some defects caused by acid treatment. The $I_{D} / I_{G}$ ratio of $p$-SWCNTs and acid treated were calculated to be 0.08 and 0.15 . The higher $I_{D} / l_{G}$ ratio of acid treated SWCNTs indicated successful activation of tubes as $I_{D} / l_{G}$ ratio is sensitive to $\mathrm{sp}^{3}$ hybridized carbon atoms.

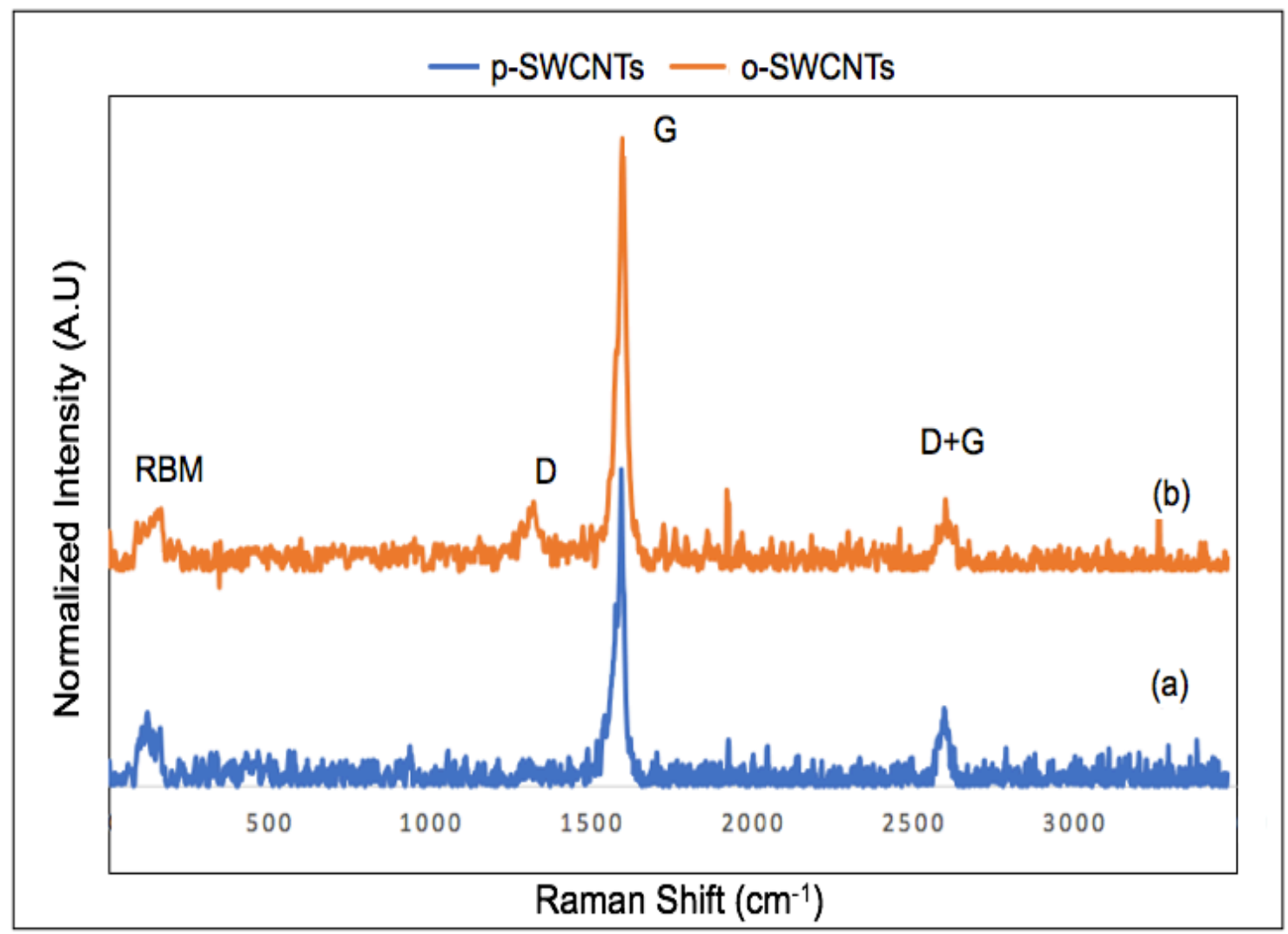

Figure 3.4 Raman spectra of (a) p-SWCNTs and (b) acid treated SWCNTs. 
The FTIR spectra of acid treated and pristine tubes were taken using Thermo Nicolet 6700 FT-IR spectrometer, to further confirm the functionalization of SWCNTs. These spectra are overlapped for comparison, as illustrated in Figure 3.5. In FTIR spectra of both p-SWCNTs and acid treated tubes, a sharp absorption band at $2100 \mathrm{~cm}^{-1}$ is observed, which arises due to $C=C$ stretch mode in the SWCNTs. However, in the FTIR spectrum of acid treated SWCNTs (Fig $3.5 b)$, additional absorption bands at $3300 \mathrm{~cm}^{-1}(\mathrm{O}-\mathrm{H}$, hydroxyl group) and 1650 $\mathrm{cm}^{-1}$ (carboxyl group) are observed, which are consistent with the known vibrational frequencies of the hydroxyl and carboxyl functional groups. Consequently, due the presence of these absorption bands $(\mathrm{O}-\mathrm{H}$ and $\mathrm{C}=\mathrm{O})$ in the FTIR spectrum of acid treated SWNTs, it can be confirmed that the tubes were successfully oxidized or activated by nitric acid treatment.

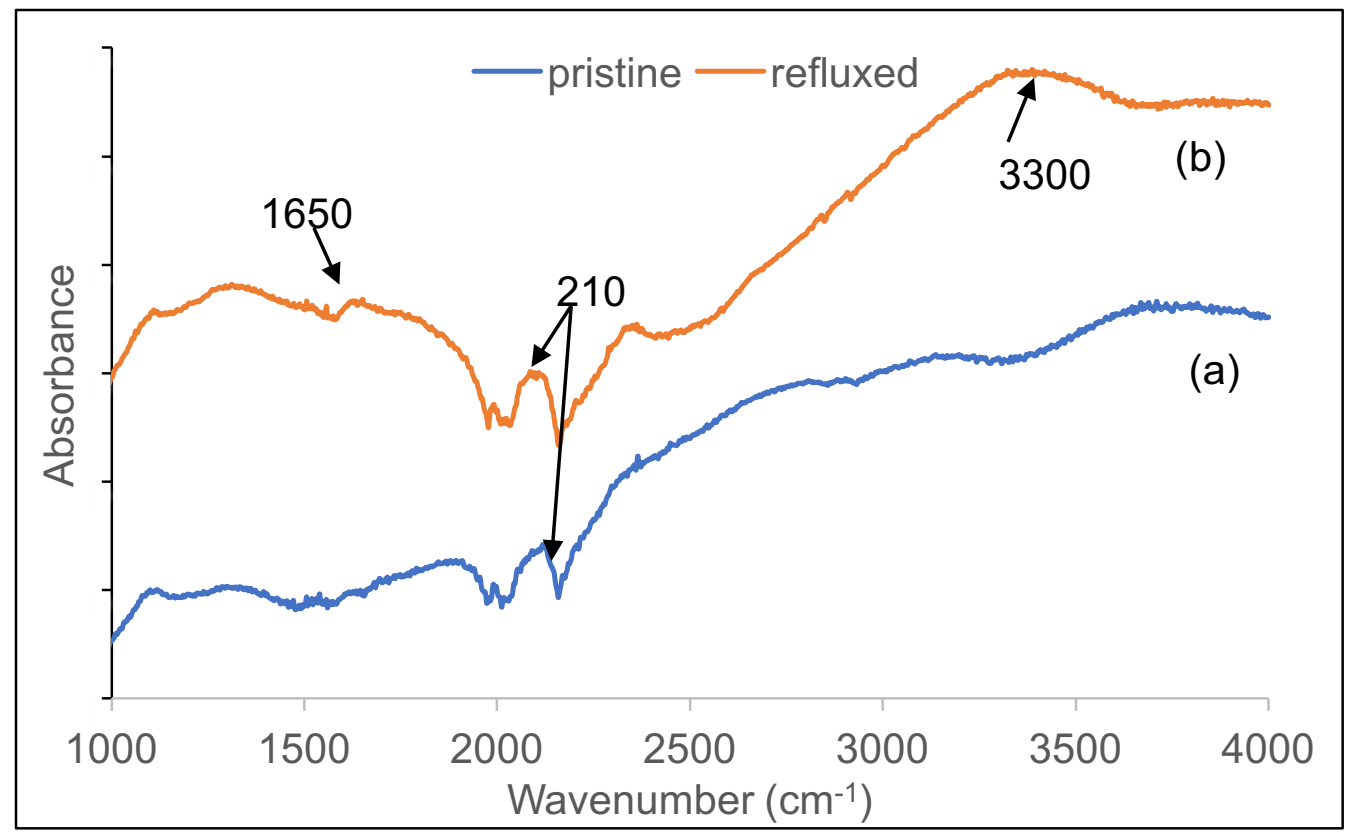

Figure 3.5 FTIR spectra of (a) p-SWCNTs and (b) acid treated SWCNTs. 


\subsection{Conclusions}

On the basis of above results, it can be concluded that the most simple and effective method to introduce hydrophilic groups on the surface of p-SWCNTs is the nitric acid treatment. The data from Raman spectroscopy confirmed that nitric acid treatment successfully oxidized them by creating some defects in their structure. The presence of hydroxyl and carboxylic acid groups on the walls of SWCNTs, was confirmed by the data from FTIR spectroscopy. The oxidized SWCNTs also revealed good solubility in water. To sum up, CNTs possess limited solubility and are inert to most of the chemicals, but can be activated by treating them with nitric acid for a prolonged period of time. These activated tubes were further functionalized with a V-PEG polymer to increase their exposed surface area. The functionalization of activated SWCNTs with V-PEG polymer is discussed in Chapter 5. 


\section{Chapter 4 : SYNTHESIS OF VIOLOGEN-POLYETHYLENE GLYCOL (V-PEG) POLYMER}

\subsection{Introduction}

The salts of 1,1'-disubstituted-4,4'-bipyridinium are commonly known as viologens. They were discovered in 1993 and since then they have been widely investigated due to their electrochemical properties. ${ }^{55}$ These properties include two reductions corresponding to the three redox forms $\left(\mathrm{V}^{2+}, \mathrm{V}^{+}\right.$, and $\left.\mathrm{V}^{0}\right)$, fast electron response, and good chemical reversibility. Because of these unique electrochemical properties, they were originally investigated as redox indicators in biological studies. Subsequently, they were used as herbicides (paraquat). ${ }^{38}$ Recently, viologen-based polymers have received much attention as electrode materials for batteries. ${ }^{37,56}$

Viologen moieties can be incorporated along the backbone of a polymer chain to form main-chain viologen polymers. ${ }^{57}$ This improves the solubility of the viologen moieties and prevents their crystallization. In 1974, the first viologen polymer was synthesized using a dihaloarylalkane and 4,4'-bipyridine. Since then, different polymers with viologen moieties as a part of the polymer backbone have been studied. ${ }^{57}$ Because of the presence of viologens, they exhibit a wide range of properties like electrical conductivity, electrochromism, photochromism, thermochromism, and photomechanical behavior. ${ }^{58,59}$ In this project, viologen moieties were incorporated in the polymer backbone of polyethylene glycol (PEG-400), to form a cationic polyelectrolyte (V-PEG) for the proposed hybrid supercapacitor. V-PEG polymer was synthesized by reacting tosylated 
polyethylene glycol (PEG-400) with 4,4'-bipyridine. First, the tosylation was carried out to convert the two hydroxyl groups at the end positions of PEG into tosylates, as illustrated in Scheme 4.1. This step is carried out because tosylates are excellent leaving groups compared to hydroxyl groups and can be used as precursors for nucleophilic substitution reactions..$^{59-61}$

Scheme 4.1 Tosylation of (a) PEG-400 using (b) p-toluenesulfonyl chloride.

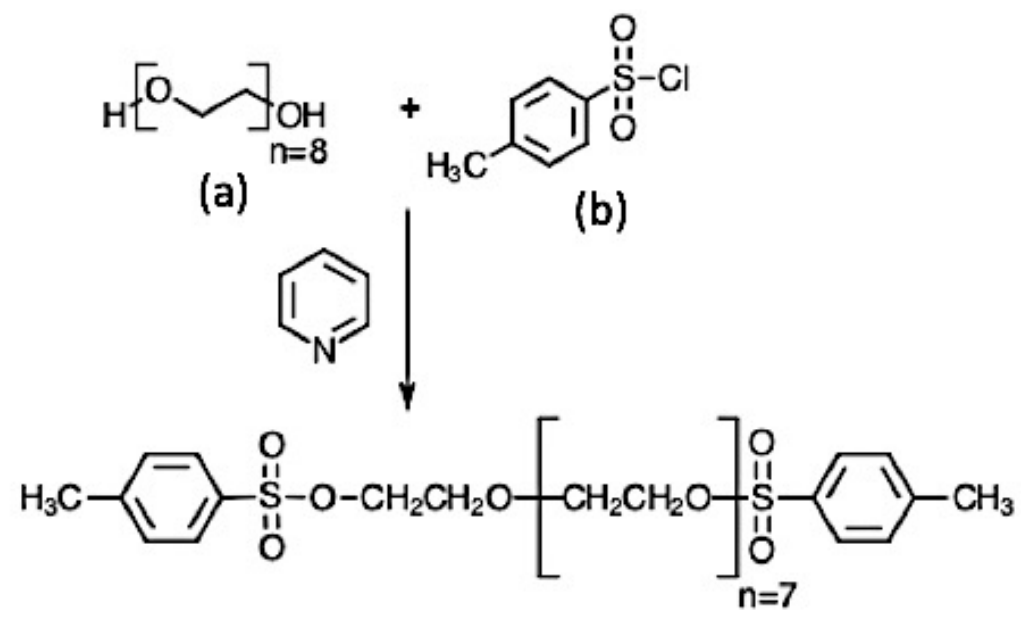

The reaction conditions for the tosylation reaction are discussed in detail in the following section. After this step, the ditosylated PEG chains were used as prepolymers for the preparation of the corresponding main-chain viologen copolymers, V-PEG. The ditosylated PEG chains were reacted with 4,4'-bipyridine for about 48 hours. These two species react in a SN2 fashion, 4,4'-bipyridine acts as a nucleophile and replaces the two tosylate groups at the end positions of PEG, as demonstrated in Scheme 4.2. The departure of tosylate groups occurs simultaneously with the backside attack of 4,4'-bipyridine, one bond is broken and one bond is formed synchronously. ${ }^{58,62}$ 
Scheme 4.2 Synthesis of viologen-polyethylene glycol polymer using (a) ditosylated PEG and (b) 4,4-bipyridine.<smiles>Cc1ccc(S(=O)(=O)OCCOC(C)(C)CCOS(=O)(=O)c2ccc(C[n+]3ccc(-c4ccncc4)cc3)cc2)cc1</smiles>

(a)

(b)

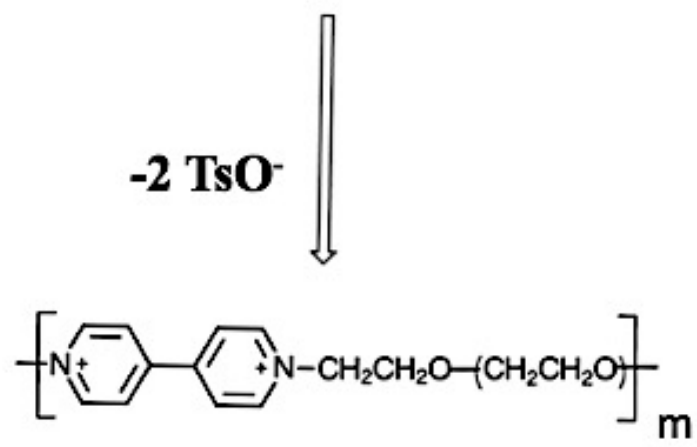

\subsection{Experimental Section}

\subsubsection{Materials}

All the chemicals and solvents were purchased from Sigma-Aldrich Inc. All reactions were carried out under an inert $\mathrm{N}_{2}$ (nitrogen) atmosphere in oven-dried glassware fitted with rubber septa. Teflon-coated magnetic stir bars were used for stirring and the dry liquid reagents and solvents were transferred using glass syringes.

\subsubsection{Experimental Procedures}

\subsubsection{Tosylation of PEG-400}

For tosylating PEG, two different approaches were attempted. In the first approach, $p$-toluenesulfonyl chloride was used as the tosylating agent and triethylamine as the base. In tosylation, usually a non-nucleophilic base is used because it can readily react with $p$-toluenesulfonyl chloride instead of removing 
$\mathrm{HCl}$ formed during the reaction. In the second approach, triethylamine was switched with pyridine, and all the liquid solvents and reagents were dried under vacuum and stored over molecular sieves before using them.

\subsection{Tosylation of PEG using Triethylamine}

PEG-400 (1 eq, $2 \mathrm{~g}, 1.77 \mathrm{~mL}, 5 \mathrm{mmol}$ ) was first dissolved in $20 \mathrm{~mL}$ of dichloromethane (DCM). This solution was mechanically stirred and cooled in an ice bath. Then $p$-toluenesulfonyl chloride $(1.8 \mathrm{eq}, 1.72 \mathrm{~g}, 9 \mathrm{mmol})$ and $2 \mathrm{~mL}$ of triethylamine were added to it under continuous stirring. The resulting mixture was stirred in an ice bath for two hours and then stirred for 6 hours at room temperature. To obtain the product, the reaction mixture was added dropwise into $100 \mathrm{~mL}$ of cold diethyl ether, but no precipitates were obtained indicating unsuccessful tosylation of PEG.

\subsection{Tosylation of PEG using Pyridine}

In a three-necked $\mathrm{N}_{2}$-flushed flask, $p$-toluenesulfonyl chloride $(1.8 \mathrm{eq}, 1.72 \mathrm{~g}$, $9 \mathrm{mmol}$ ) was first dissolved in $10 \mathrm{~mL}$ of dry DCM and then $0.5 \mathrm{~mL}$ of pyridine (previously dried by vacuum distillation and stored over molecular sieves) was added to it. This solution was mechanically stirred and cooled in an ice bath. To this rapidly stirred solution, PEG-400 (1 eq, $2 \mathrm{~g}, 1.77 \mathrm{~mL}, 5 \mathrm{mmol}$, dried by vacuum distillation and stored over molecular sieves) was added very slowly dropwise. The reaction mixture was kept in the ice bath for 3 hours and then stirred at room temperature for 12 hours. After 12 hours, a white polymer was obtained by pouring the reaction mixture into cold diethyl ether. The ditosylated 
polymers were purified by reprecipitation from dichloromethane and cold diethyl ether. The purified polymers were dried under vacuum and then stored at $-30^{\circ} \mathrm{C}$ for later use.

\subsubsection{Synthesis of Viologen-Polyethylene Glycol Polymer}

A mixture of ditosylated PEG (3.10 g, $4.38 \mathrm{mmol})$ and 4,4'-bipyridine $(0.68 \mathrm{~g}$, $4.38 \mathrm{mmol}$ ) was heated at $60-70^{\circ} \mathrm{C}$ in $50 \mathrm{~mL}$ of $\mathrm{N}, \mathrm{N}$-dimethylformamide (DMF) for 48 hours. After 48 hours, the reaction mixture was stirred at room temperature for two more days. Unreacted 4,4'-bipyridine, excess polyethylene glycol and partially reacted 4,4'-bipyridine were removed by extractions with cold diethyl ether and DCM. After drying under the vacuum, light brown highly viscous liquid polymer was obtained.

\subsection{Characterization Techniques}

The structures of tosylated PEG and novel viologen-polyethylene glycol polymer were identified using ${ }^{1} \mathrm{H}^{-} \mathrm{NMR},{ }^{13} \mathrm{C}-\mathrm{NMR}$, and FTIR spectroscopy. The ${ }^{1} \mathrm{H}-\mathrm{NMR}$ and ${ }^{13} \mathrm{C}-\mathrm{NMR}$ spectra were recorded on Varian $400 \mathrm{MHz}$ spectrometer and the solvent (DMSO- $\mathrm{d}_{6}$ ) signal was used as the internal standard. FTIR spectra were measured on Nicolet 6700 FT-IR spectrometer. The electrochemical properties of the V-PEG polymer were investigated by the method of cyclic voltammetry (CV). All the CV experiments were performed using a $\mathrm{CH} 660$ or PAR 263A electrochemical analyzer. The basic principles and advantages of NMR and cyclic voltammetry are discussed briefly in sections below. 


\subsubsection{Nuclear Magnetic Resonance Spectroscopy (NMR)}

NMR is a non-destructive analytical technique which exploits the magnetic properties of atomic nuclei to determine the chemical structure of different molecules. This technique is based on the interaction of radio frequency pulses with unpaired nuclear spins (NMR active nuclei) in an external magnetic field. The NMR active nuclei are first exposed to a strong and constant magnetic field, then they are excited by a radiofrequency pulse sequence. After the excitation, the nuclei undergo relaxation and emit electromagnetic signals. These signals are recorded and converted into a frequency spectrum. From the spectrum, parameters like chemical shift, splitting pattern, the number of signals, and the area under each signal provide structural information about a given sample ${ }^{63-65}$

In ${ }^{1} \mathrm{H}-\mathrm{NMR}$, the signals arise due to the interaction of radio frequency pulses with different protons in a sample under study, as a function of chemical shift. The chemical shift values or position of the signals gives information regarding the chemical environment of protons. If two or more protons are in an equivalent environment, then they will have the same chemical shift and will appear as one signal. The number of signals provide information about the number of chemically inequivalent protons and the area under each signal gives information about the relative number of protons that are giving rise to that signal. Integration can be used for the measurement of the area under each signal. For a given peak, the splitting pattern provides information about the number of neighboring inequivalent protons. Splitting of signals is caused by protons bonded to adjacent 
carbon atoms, and it follows the so called $(\mathrm{N}+1)$ rule, where $\mathrm{N}$ is the number of equivalent protons that are bonded to the adjacent carbon atoms. ${ }^{63-65}$ For example, if a proton has no neighboring proton, it manifests a single NMR peak and if it has two neighboring protons, it yields a triplet.

Similar to ${ }^{1} \mathrm{H}-\mathrm{NMR}$, the ${ }^{13} \mathrm{C}-\mathrm{NMR}$ the signals arise due to the interaction of radio frequency pulses with different carbon atoms in a sample under study. It relies on the magnetic properties of ${ }^{13} \mathrm{C}$ nuclei. The number of signals gives information about the different carbon atoms or sets of equivalent carbon atoms present in the sample. The chemical shift values provide information regarding the chemical environment and hybridization of carbon atoms $\left(\mathrm{sp}^{3}, \mathrm{sp}^{2}\right.$ or $\left.\mathrm{sp}\right)$. However, in ${ }^{13} \mathrm{C}$ spectra, C-C splitting is rarely observed because only about $1.1 \%$ of naturally occurring carbon is ${ }^{13} \mathrm{C}$ and the chances of two ${ }^{13} \mathrm{C}$ next to each other is very rare. Integration is also not useful in ${ }^{13} \mathrm{C}$ NMR because the carbon intensities don't accurately reflect the relative number of $\mathrm{C}$-atoms ${ }^{65}$ But the signals are spread over a much wider range (0-250 ppm) compared to ${ }^{1} \mathrm{H}$ NMR spectra, making it easier to identify and count the different types of nuclei.

\subsubsection{Electrochemical Analysis}

Cyclic voltammetry is a versatile and widely used electrochemical analysis technique. It is used for the characterization of electroactive chemical species. It can provide information about the number and stability of redox states, kinetics of electron transfers, and diffusion properties. In CV, the voltage is swept at a 
constant rate, positively and negatively relative to a reference electrode while monitoring the resulting electrochemical current. ${ }^{66}$

CV experiments are mostly conducted in a three-electrode electrochemical cell. These cells are required to have provisions for an inert gas purge, a working electrode (WE), a reference electrode (RE), and a counter (auxiliary) electrode $(A E)$. The electrodes are connected to a potentiostat that controls the potential of the WE and determines resulting current. The working electrode is the critical component of the cell, as it is where the key reaction under study takes place. It can act as the anode or cathode, depending on the direction of current flow. This electrode is usually made of an inert material, that has good conductivity and good thermodynamic stability, such as platinum, gold, and glassy carbon. The counter electrode is the $A E$, it functions as a cathode when the working electrode is operating as an anode and vice versa. The potential of the $A E$ in an active feedback loop provides the programmed potential at RE, and therefore drives current at the WE. Platinum wires are mostly used as counter electrodes due to their inert nature. The RE is used as a half cell, to measure the potential of the WE. The potentiostat isolates the RE and does not allow any current to pass through it. The most common reference electrodes used in the laboratories are silver-silver chloride electrodes and saturated calomel electrodes (SCE). ${ }^{67,68}$ In CV experiments, an initial potential is applied to the cell and then a linear voltage ramp (at a fixed sweep rate, $\mathrm{V} \mathrm{s}^{-1}$ ) is applied first toward one cusp potential, and then toward the final potential. During the potential sweep, the 
current response is measured. The current that flows through the working electrode is plotted against the applied voltage to give a cyclic voltammogram, as shown in Figure 4.1. In the forward scan, a Faradic current peak is observed for any analyte that can be reduced within the initial and final potential range. As the potential applied to the WE approach the reduction potential of the analyte, the current increases. But then tails off due to the depletion of the analyte at or near the WE's surface. In the reverse scan, the applied potential reaches a value where the product formed in the first reduction reaction gets re-oxidized. This produces a Faradic current of reverse polarity from the forward scan. This oxidation peak has similar shape to the reduction peak, and from these peaks, redox potentials and electrochemical reaction rates of the analytes can be obtained. The reversibility of any electroactive chemical species can be measured by changing the scan direction and its stability can be characterized by repeating the $\mathrm{CV}$ scans continuously. ${ }^{67,68}$

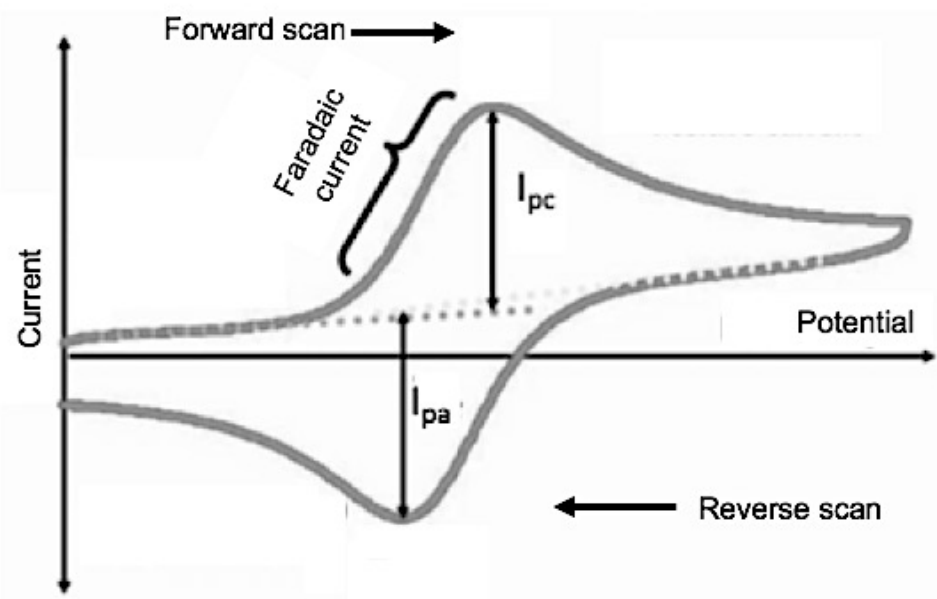

Figure 4.1 A cyclic voltammogram. 
The room temperature voltammetric peak current for a reversible process is given by the Randles-Sevcik equation:

$$
i_{p}=\left(2.69 \times 10^{5}\right) n^{3 / 2} A D^{1 / 2} C v^{1 / 2} \quad \text { Equation } 1.10
$$

Where ip is the peak current, $n$ is the number of electrons transferred in the redox event, $A$ is the area of the microelectrode $\left(\mathrm{cm}^{2}\right), D$ is the diffusion coefficient $\left(\mathrm{cm}^{2} \mathrm{sec}^{-1}\right), C$ is the concentration $\left(\mathrm{mol} \mathrm{cm}^{-3}\right)$, and $v$ is the scan rate $(\mathrm{V}$ $\left.\sec ^{-1}\right)$. As per this equation, a reaction may be considered kinetically reversible if the peak current (ip) increases linearly as a function of square root of the scan rate. $^{66}$

To study the redox behavior of V-PEG polymer in the liquid and semi-solid phases, CV experiments were performed using both micro- (3mm diameter) and ultramicro- $(10 \mu \mathrm{m})$ working electrodes. The ultramicroelectrodes were used because they are suitable to perform electrochemical investigations on polyelectrolytes because their low current defeats the high electrical resistance of polymers. In addition, they permit measurements on limited quantities and exhibit relatively faster response time. ${ }^{69}$ The $\mathrm{CV}$ graphs obtained with a microelectrode is very different from the one obtained with a ultramicroelectrode. This is due to the differences in mass transport at the electrode surface. At larger electrodes, mass transport occurs mostly perpendicular to the surface, resulting in a typical peak-shaped voltammogram. But at ultramicroelectrodes, mass transport takes on a hemispherical profile, resulting in a sigmoidal, steady state voltammogram. Unlike microelectrodes, current generated at ultramicroelectrodes are dependent 
on their geometry. The limiting plateau current from ultramicroelectrodes is given by Equation (1.11), shown below. ${ }^{62,69}$

$$
i_{l i m}=4 n F r D C \quad \text { Equation } 1.11
$$

Where $i_{\text {lim }}$ is the limiting current (amps), $F$ is Faraday's constant $\left(C \mathrm{~mol}^{-1}\right)$, and $r$ is electrode radius $(\mathrm{cm})$. The experimental details of both liquid and semi-solid phase characterization are discussed below.

\subsubsection{Liquid Phase Characterization}

The liquid phase experiments were performed to analyze the electrochemical behavior of 4,4'-bipyridine (starting material) and synthesized viologen-PEG polymer. In all the experiments, a high surface area Pt wire was used as the AE and silver/silver chloride was used as the RE. The analysis of 4,4'-bipyridine was first carried out using a Pt microelectrode of diameter $3 \mathrm{~mm}$ and then using a Pt ultramicroelectrode of diameter $10 \mu \mathrm{m}$. The apparatus setup for analysis of 4,4'bipyridine is depicted in Figure 4.2. All the electrodes were dipped in a cell containing an electrolyte. The cell lid had holes for the insertion of electrodes and for nitrogen gas to be bubbled through the solution. Before every experiment, the working electrode was polished using 1.0, 0.3 and 0.05-micron alumina powder. A nylon polishing pad was used for the 1.0 and 0.3 -micron alumina and a microcloth polishing pad was used for 0.05 -micron alumina powder. The electrolyte solution was also purged off oxygen by bubbling solvent-saturated nitrogen in the jar for 5 minutes and a nitrogen blanket was maintained throughout all electrochemical measurements. 


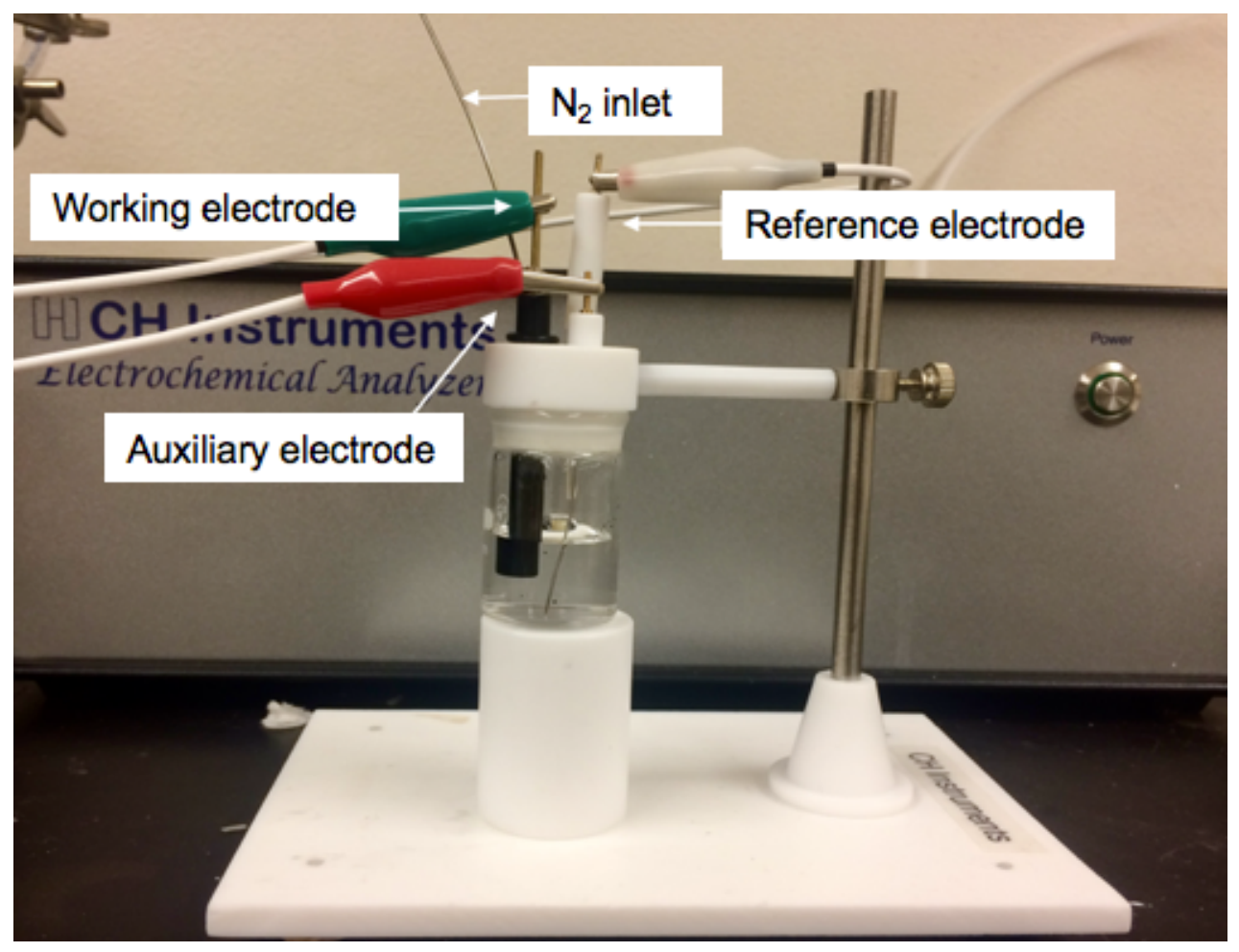

Figure 4.2 Three-electrode electrochemical cell setup for analysis of 4,4'bipyridine.

Similarly, the viologen polymer was analyzed using both Pt micro- and ultramicroelectrode. For the analysis, a thin layer of the polymer was deposited on the surface of the WE due to its poor solubility in the electrolyte. The working electrode was also wrapped with a polycarbonate membrane (of diameter 0.45 $\mu m$ ) to prevent the polymer from leaking. The apparatus setup for analysis of the viologen polymer is depicted in Figure 4.3. 


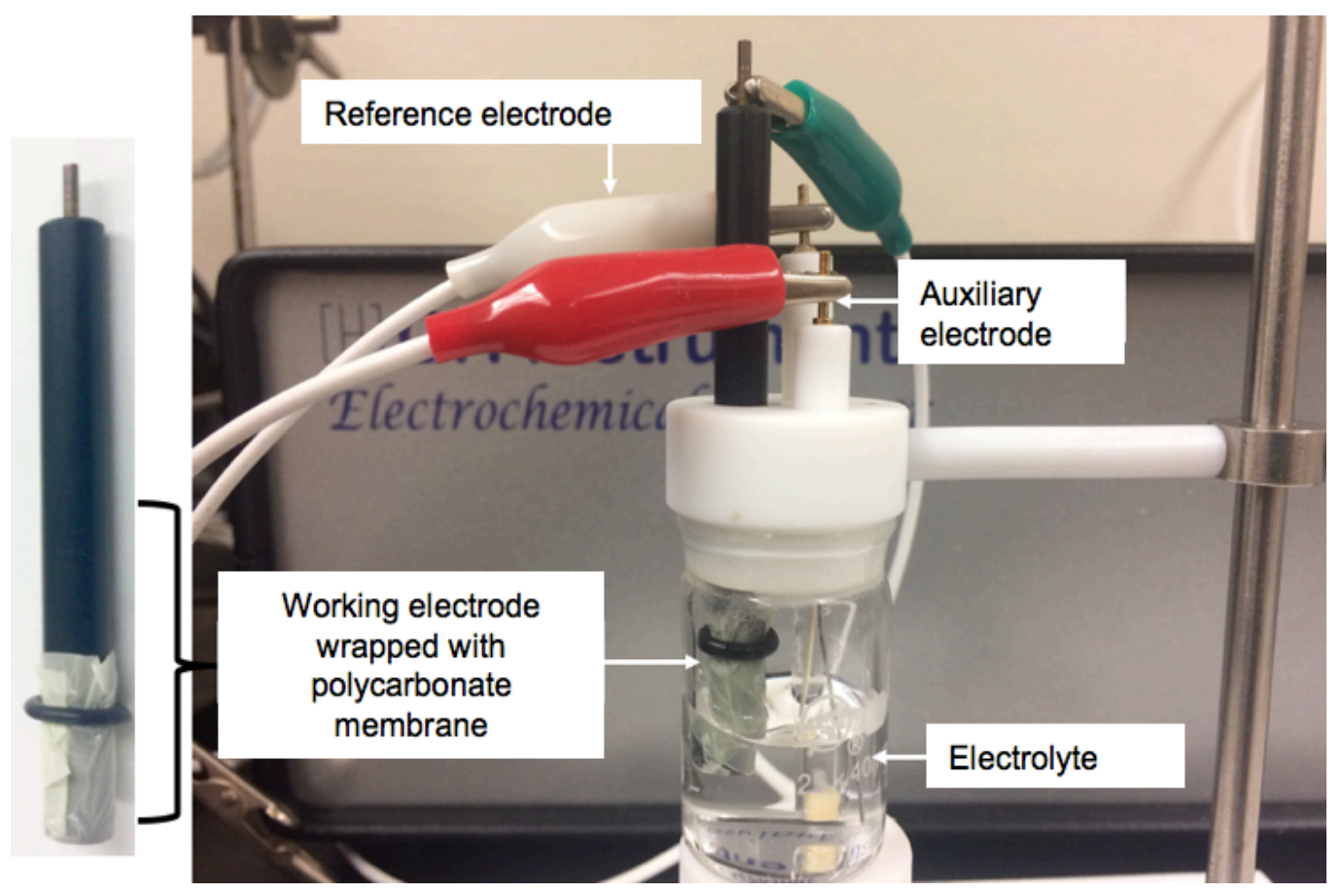

Figure 4.3 Three-electrode electrochemical cell setup for analysis of viologen polymer.

\subsubsection{Semi-Solid Phase Characterization}

In addition to liquid phase characterization, semi-solid phase characterization of the viologen polymer was also performed using a $10 \mu \mathrm{m}$ Pt ultramicroelectrode (WE) and a thin silver plate as both AE and RE. The experimental setup is depicted in Figure 4.4. A Teflon block was used to hold the WE on top of the silver plate with the polymer between them. A few drops of electrolyte were also added to the polymer before conducting $\mathrm{CV}$ experiments. 


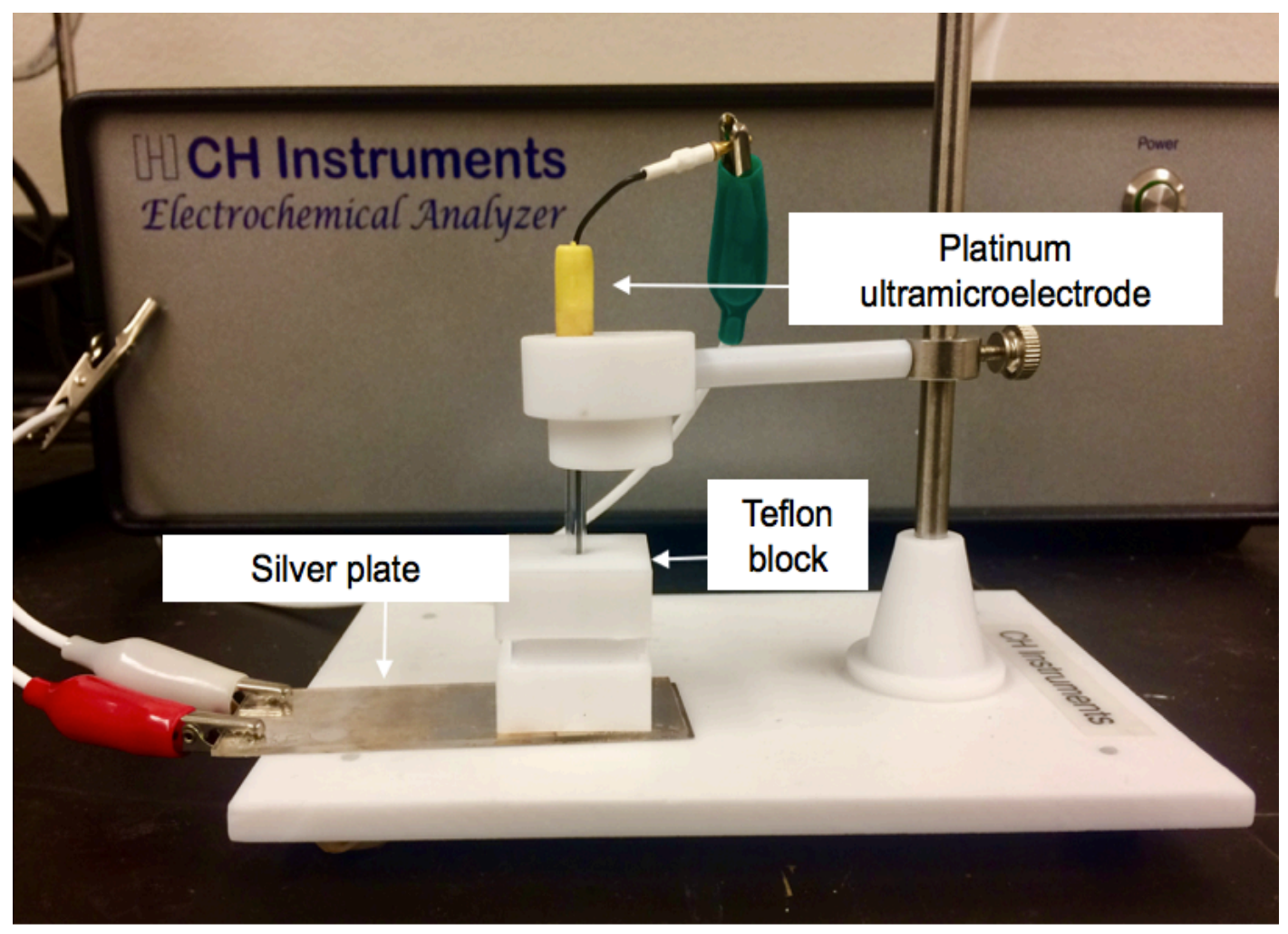

Figure 4.4 Semi-solid phase characterization setup for viologen polymer.

\subsection{Results and Discussion}

\subsubsection{Nuclear Magnetic Resonance Spectroscopy (NMR) Results}

The molecular structures of ditosylated PEG and viologen polymer were identified using both ${ }^{1} \mathrm{H}$ and ${ }^{13} \mathrm{C}$ NMR. The chemical shifts $(\delta)$ are reported in ppm relative to the residual solvent signal (DMSO: $\delta=2.2$ for ${ }^{1} \mathrm{H}$ NMR and $\delta=$ 40.0 for ${ }^{13} \mathrm{C}$ NMR). The abbreviations used are as follows: s (singlet), $d$ (doublet), $\mathrm{t}$ (triplet), $\mathrm{m}$ (multiplet).

\subsubsection{Ditosylated PEG}

The ${ }^{1} \mathrm{H}$ NMR spectrum of ditosylated PEG in DMSO, including peak assignments is shown in Figure 4.5. ${ }^{1} \mathrm{H}$ NMR $\left(400 \mathrm{MHz}, \mathrm{DMSO}-\mathrm{d}_{6}\right): \delta$ (ppm) 36 
(s, 6H, - $\left.\mathrm{CH}_{3}\right), 3.35 \sim 3.69\left(\mathrm{~m}, 32 \mathrm{H},-\mathrm{CH}_{2}-\mathrm{O}-\right), 4.05$ (t, 4H, $\left.-\mathrm{CH}_{2}-\mathrm{OTs}-\right), 7.45$ and $7.99\left(\mathrm{~m}, 8 \mathrm{H},-\mathrm{C}_{6} \mathrm{H}_{4^{-}}\right)$. The spectrum was consistent with previously published work. ${ }^{62}$ It can be noticed that there is a small amount of impurity detected, corresponding to the unassigned peaks.

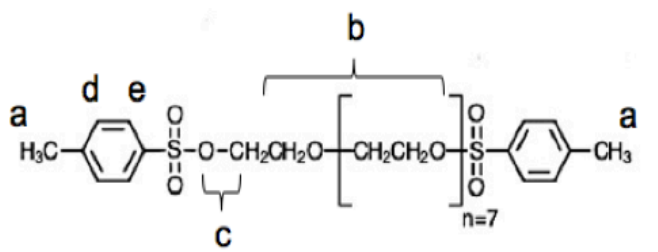

C

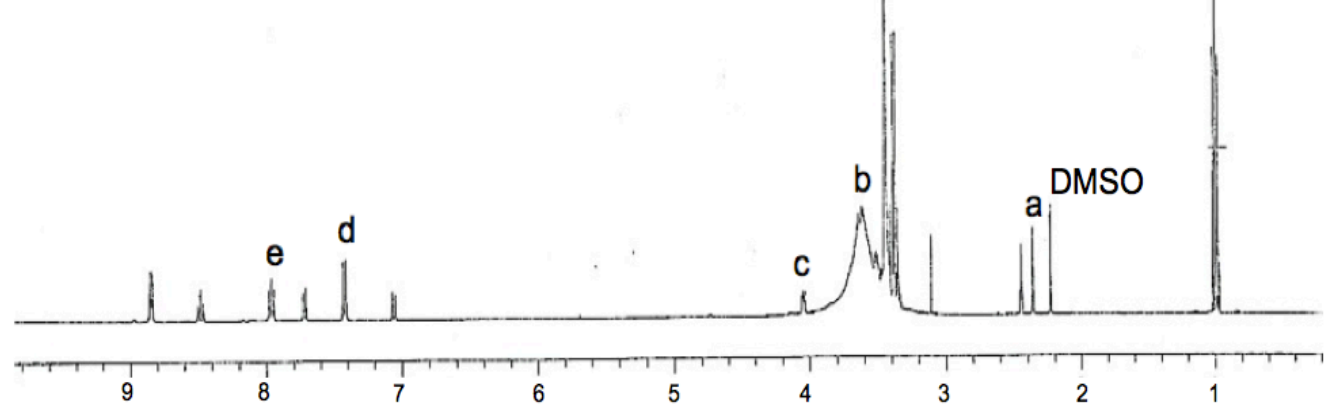

Figure 4.5 ${ }^{1} \mathrm{H}$ NMR spectrum of ditosylated PEG in DMSO and structural identification.

The ${ }^{13} \mathrm{C}$ NMR of ditosylated PEG in DMSO, is shown in Figure $4.6 .{ }^{13} \mathrm{C}$ NMR (400 MHz, DMSO-d 6 ): $\delta(p p m) ~ 21.72,60.84,68.51,70.64,72.96,126.14$, $128.75,130.78,146.24$. The $\mathrm{C}$-atoms giving rise to peaks at $60.84 \mathrm{ppm}$ and $72.96 \mathrm{ppm}$ are not labelled because these peaks arise from the C-atoms of nontosylated polymer ends. This spectrum was consistent with previously published work. $^{70}$ 


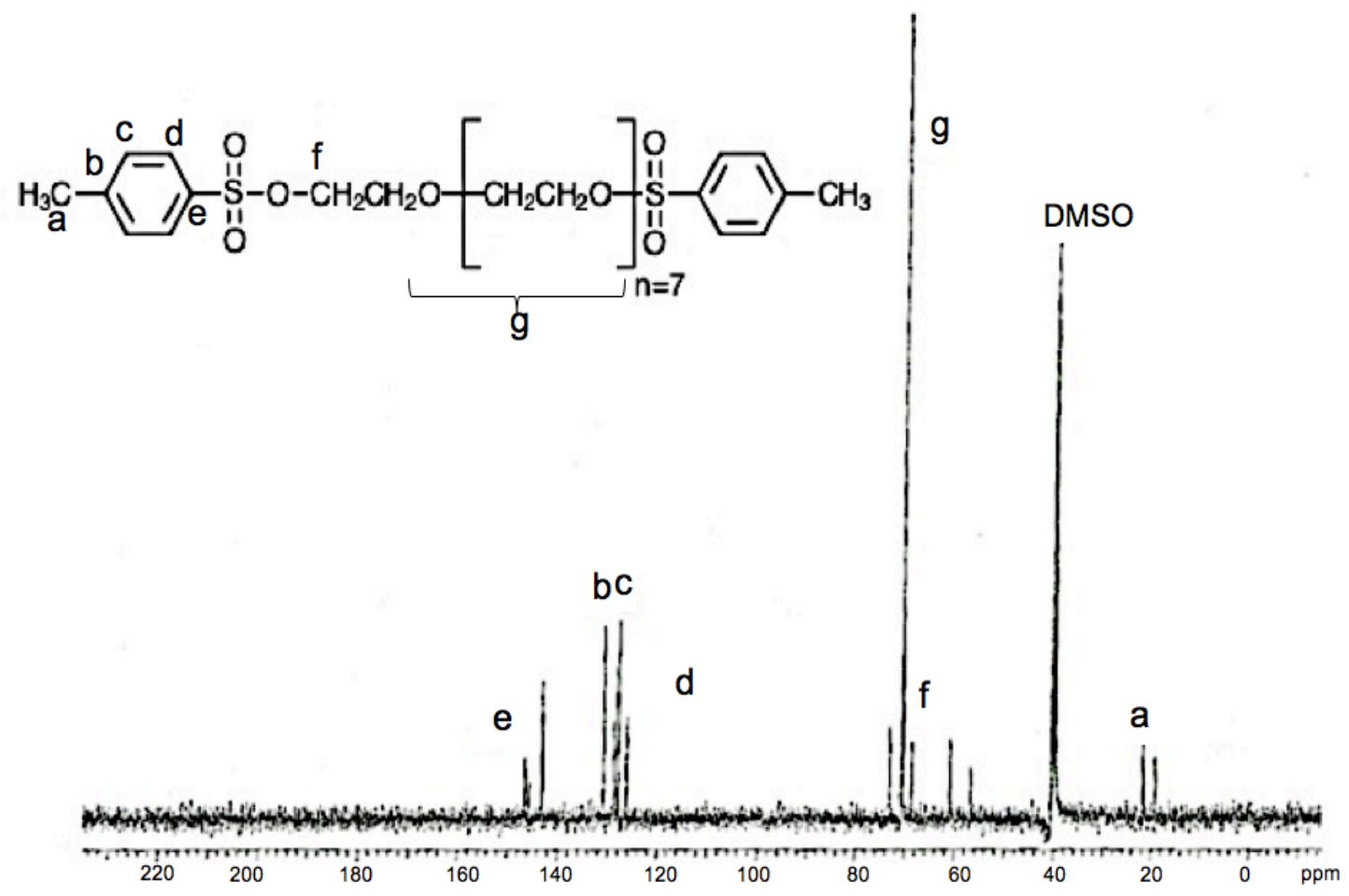

Figure 4.6 ${ }^{13} \mathrm{C}$ NMR spectrum of ditosylated PEG in DMSO and structural identification.

\subsubsection{Viologen Polymer:}

The ${ }^{1} \mathrm{H}$ NMR spectrum of viologen polymer in DMSO is shown in Figure 4.7. ${ }^{1} \mathrm{H}$ NMR (400 MHz, DMSO-d6): $\delta(p p m) 2.43$ (s, 6H, $\left.\mathrm{CH}_{3}-\mathrm{Ph}\right), 3.6-3.84(\mathrm{~m}, 32 \mathrm{H}$, $\left.\mathrm{CH}_{2} \mathrm{O}-\right), 4.79\left(\mathrm{~m}, 4 \mathrm{H},-\mathrm{CH}_{2}-\mathrm{N}^{+}-\right), 7.06$ and $7.4\left(\mathrm{~m}, 8 \mathrm{H},-\mathrm{C}_{6} \mathrm{H}_{4}-\right), 8.6$ and $8.9(\mathrm{~m}$, $\left.8 \mathrm{H},-\mathrm{N}^{+} \mathrm{C}_{5} \mathrm{H}_{4}-\right)$. These chemical shift values were consistent with previously published work. ${ }^{62}$ 


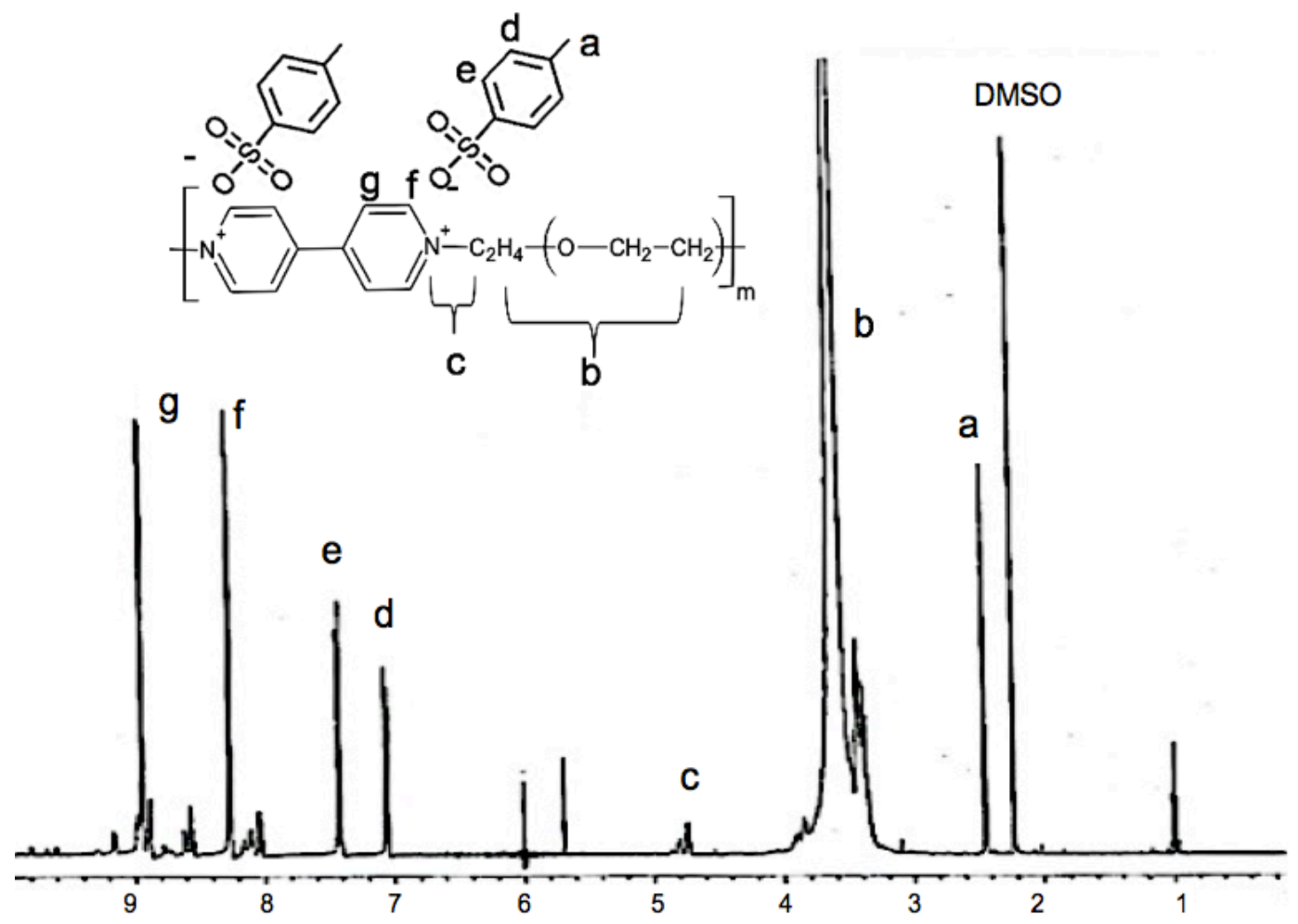

Figure 4.7 ${ }^{1} \mathrm{H}$ NMR spectrum of viologen polymer in DMSO and structural identification.

The ${ }^{13} \mathrm{C}$ NMR of viologen polymer in DMSO is shown in Figure $4.8 .{ }^{13} \mathrm{C}$ NMR (400 MHz, DMSO-d $\left.\mathrm{d}_{6}\right): \delta$ (ppm) 21.39, 31.29, 44.28, 61.01, 70.41, 124.37, $126.14,128.75,138.48,142.604,145.89$. The $\delta=61.01-72.9$ ppm signals are due to the inner $\mathrm{C}$-atoms of the polymer. This spectrum was consistent with previously published work. ${ }^{58}$ 


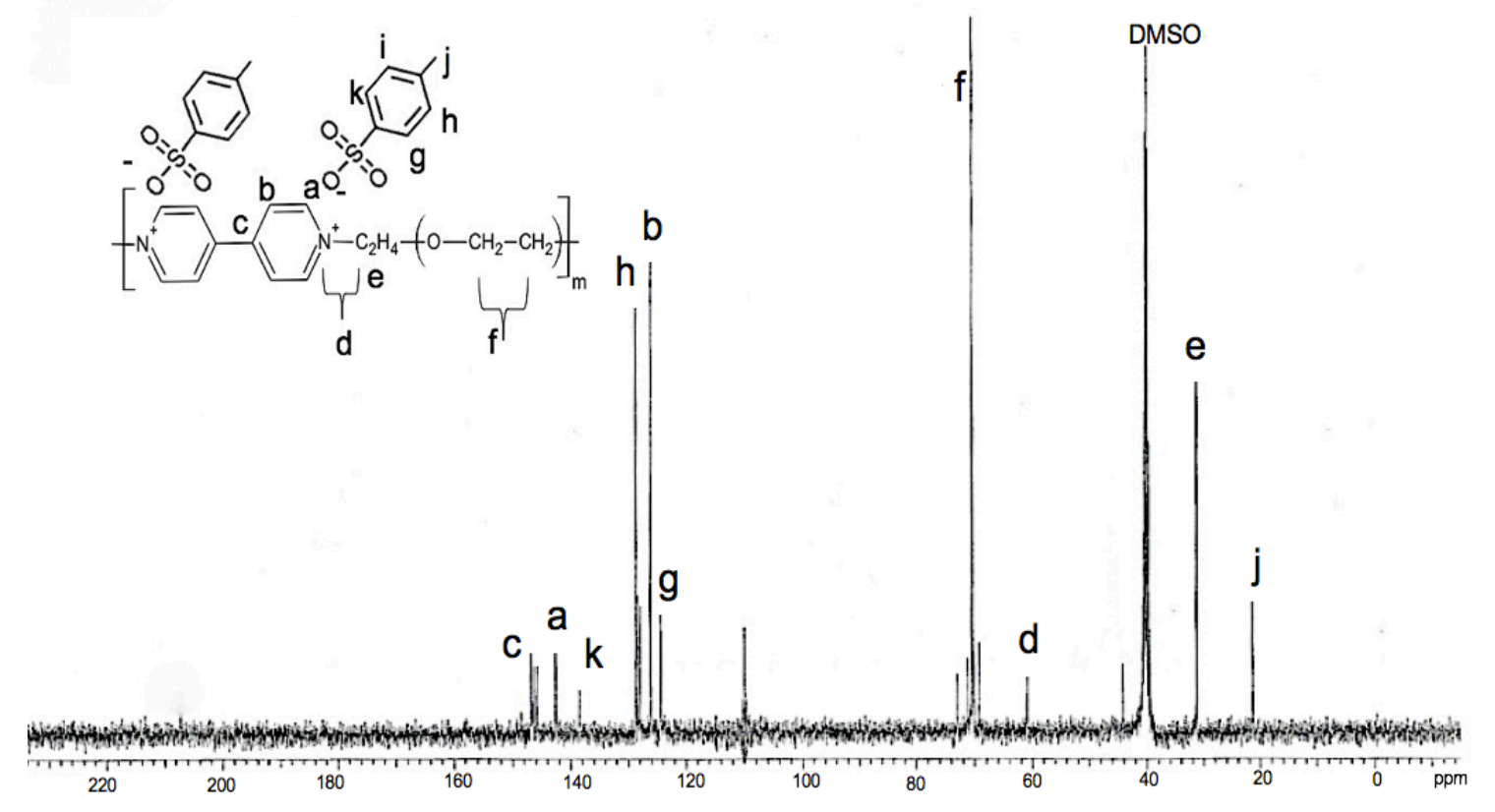

Figure $4.8{ }^{13} \mathrm{C}$ NMR spectrum of viologen polymer in DMSO and structural identification.

\subsubsection{Cyclic Voltammetry Results}

\subsubsection{Liquid Phase Characterization}

\subsection{Analysis of 4,4'-bipyridine using Micro- and Ultramicroelectrode \\ Cyclic voltammetry of nitrogen-degassed solution of 4,4'-bipyridine in $0.1 \mathrm{M}$} lithium perchlorate/acetonitrile ( $\mathrm{ACN}$ ) was done using a platinum $(\mathrm{Pt})$ microelectrode. The potential of the Pt microelectrode was swept between $-0.2 \mathrm{~V}$ and $-1.2 \mathrm{~V} v \mathrm{Ag} / \mathrm{AgCl}$ at a scan rate of $0.1 \mathrm{~V} \mathrm{~s}^{-1}$. The resulting cyclic voltammogram did not show any redox peaks, as shown in Figure 4.9. The absence of redox peaks indicated that 4,4-bipyridine is not electroactive. A similar result was obtained when the cyclic voltammetry analysis of 4,4-bipyridine was done using a platinum ultramicroelectrode. The potential of the $\mathrm{Pt}$ 
ultramicroelectrode was swept between $-0.2 \mathrm{~V}$ and $-1.0 \mathrm{~V} \mathrm{vs} \mathrm{Ag} / \mathrm{AgCl}$ at a scan rate of $0.03 \mathrm{~V} \mathrm{~s}^{-1}$. Figure 4.10 shows the resulting voltammogram with no redox peaks.

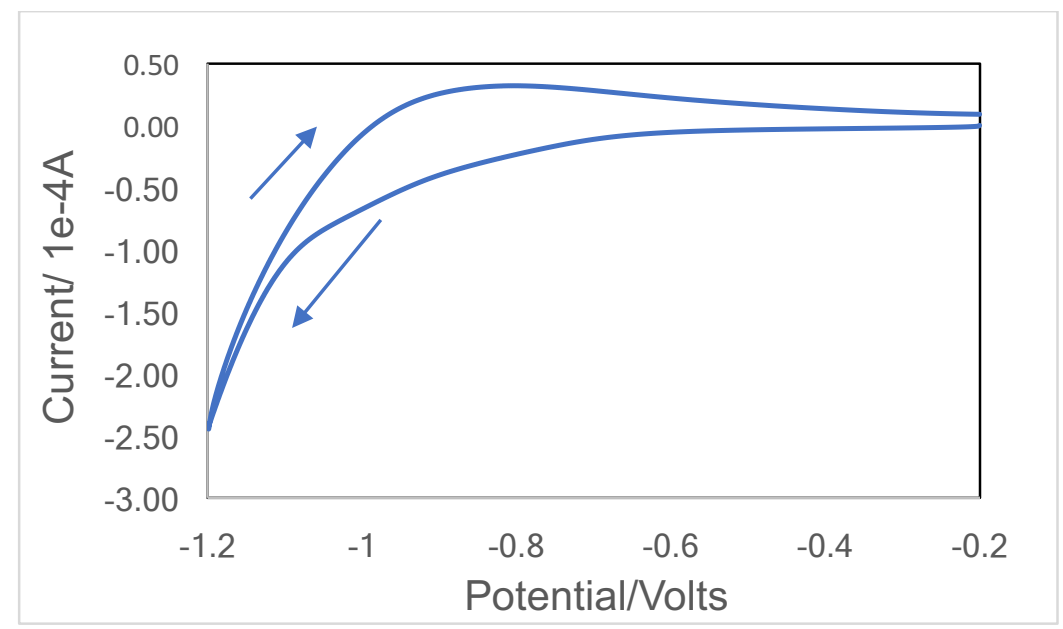

Figure 4.9 Cyclic voltammogram of 4,4'-bipyridine using Pt microelectrode.

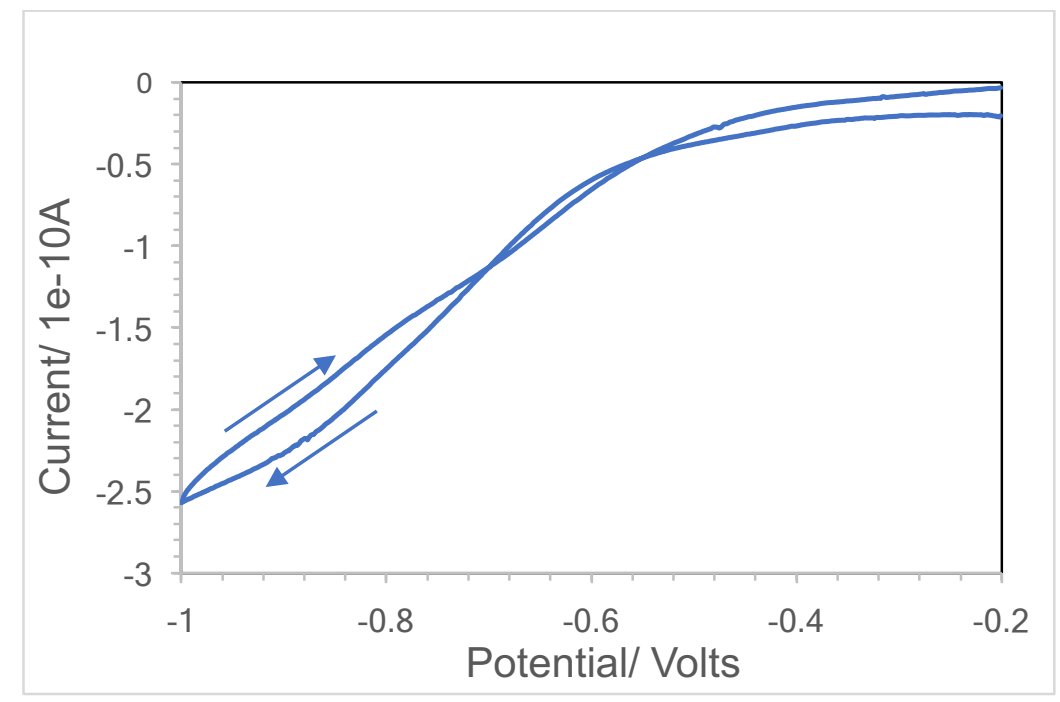

Figure 4.10 Cyclic voltammogram of 4,4'-bipyridine using Pt ultramicroelectrode. 


\subsection{Analysis of Viologen Polymer using Micro- and Ultramicroelectrode}

Cyclic voltammetry of viologen polymer, deposited on the surface of a $\mathrm{Pt}$ microelectrode and dipped in $0.1 \mathrm{M} \mathrm{LiClO}_{4} / \mathrm{ACN}$ was done at room temperature. The potential of the Pt electrode was swept between $-0.2 \mathrm{~V}$ and $-1.0 \mathrm{~V}$ vs $\mathrm{Ag} / \mathrm{AgCl}$ at a scan rate of $0.25 \mathrm{~V} \mathrm{~s}^{-1}$. In the resulting $\mathrm{CV}$ graph (Fig.4.11), two distinct peaks both on the reduction and oxidation cycles were observed, corresponding to redox couples $\mathrm{V}^{2+} \mathrm{N}^{+\bullet}$ and $\mathrm{V}^{+\bullet} / \mathrm{V}^{0}$. The redox potential $\left(\mathrm{E}_{0}\right)$ or midpoint potential for $\mathrm{V}^{2+} \mathrm{N}^{+\cdot}$ was $-0.42 \mathrm{~V}$ and $\mathrm{E}_{0}$ for $\mathrm{V}^{+\bullet} / \mathrm{V}^{0}$ was $-0.76 \mathrm{~V}$. This confirmed the quaternization of nitrogen atoms of 4,4'-bipyridine by its covalent linkage to PEG chains, hence making it electroactive. The peak separations of these two redox couples was approximately $0.1 \mathrm{~V}$ for $\mathrm{V}^{2+} / \mathrm{V}^{+\cdot}$ and $0.12 \mathrm{~V}$ for $\mathrm{V}^{+\bullet} / \mathrm{V}^{0}$, indicating that $\mathrm{V}^{2+} / \mathrm{V}^{+\cdot}$ is a more reversible redox couple than $\mathrm{V}^{+\bullet} / \mathrm{V}^{0}$.

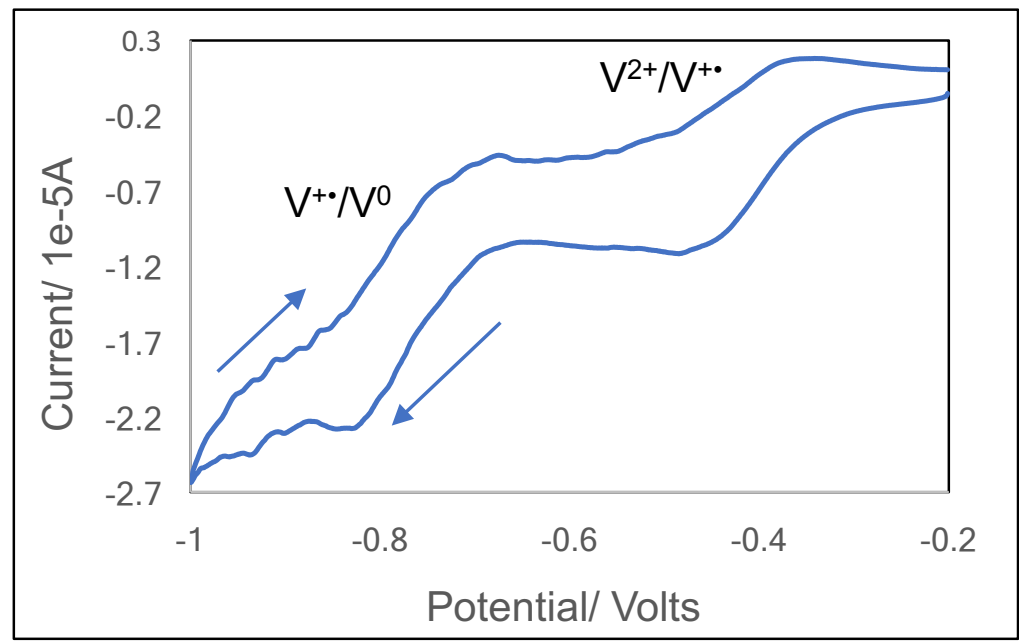

Figure 4.11 Cyclic voltammogram of viologen polymer using Pt microelectrode. 
Similarly, the potential of the Pt ultramicroelectrode was swept between -0.2 $\mathrm{V}$ and $-1.0 \mathrm{~V}$ vs $\mathrm{Ag} / \mathrm{AgCl}$ at a scan rate of $0.03 \mathrm{~V} \mathrm{~s}^{-1}$. The $\mathrm{CV}$ graph showed two sigmoidal curves corresponding to $\mathrm{V}^{2+} \mathrm{V}^{+\cdot}$ and $\mathrm{V}^{+\bullet} / \mathrm{V}^{0}$, as shown in Figure 4.12. The results obtained using both micro- and ultramicroelectrodes were consistent with previously published work. ${ }^{56,71}$

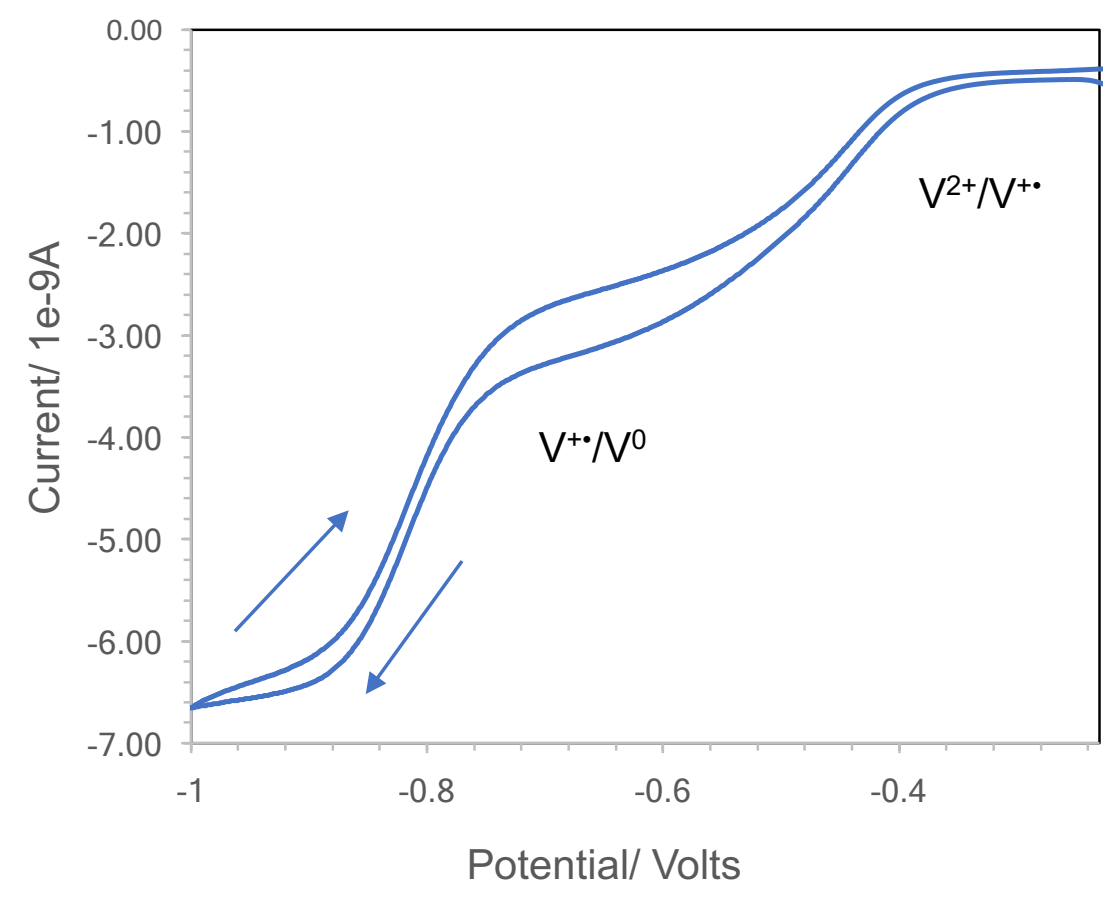

Figure 4.12 Cyclic voltammogram of viologen polymer using $\mathrm{Pt}$ ultramicroelectrode.

\subsubsection{Semi-Solid Phase Characterization}

Cyclic voltammetry of the viologen polymer deposited over the silver plate with few drops of $0.1 \mathrm{M} \mathrm{LiClO} / \mathrm{ACN}$ in it, was performed at room temperature. The potential of the Pt ultramicroelectrode was swept between $-0.2 \mathrm{~V}$ and $-1.0 \mathrm{~V}$ vs $\mathrm{Ag} / \mathrm{AgCl}$ at a scan rate of $0.03 \mathrm{~V} \mathrm{~s}^{-1}$. In the resulting $\mathrm{CV}$ graph (Fig.4.13), two 
distinct peaks both on the reduction and oxidation cycles were observed, corresponding to redox couples $\mathrm{V}^{2+} \mathrm{N}^{+\cdot}$ and $\mathrm{V}^{+\cdot} / \mathrm{V}^{0}$. The redox potential $\left(\mathrm{E}^{0}\right)$ for $\mathrm{V}^{2+} \mathrm{N}^{+\cdot}$ was $-0.37 \mathrm{~V}$ and $\mathrm{E}^{0}$ for $\mathrm{V}^{+\bullet} / \mathrm{V}^{0}$ was $-0.73 \mathrm{~V}$. This again confirmed the quaternization of nitrogen atoms of 4,4'-bipyridine by its covalent linkage to PEG chains. The peak separations for these two redox couples were approximately $0.09 \mathrm{~V}$ for $\mathrm{V}^{2+} \mathrm{V}^{+\bullet}$ and $0.11 \mathrm{~V}$ for $\mathrm{V}^{+\bullet} \mathrm{N}^{0}$, indicating that $\mathrm{V}^{2+} \mathrm{N}^{+\bullet}$ is a more reversible redox couple than $\mathrm{V}^{+\cdot} \mathrm{V}^{0}$. The potential values obtained for both redox couples were consistent with the previously published work. ${ }^{71}$

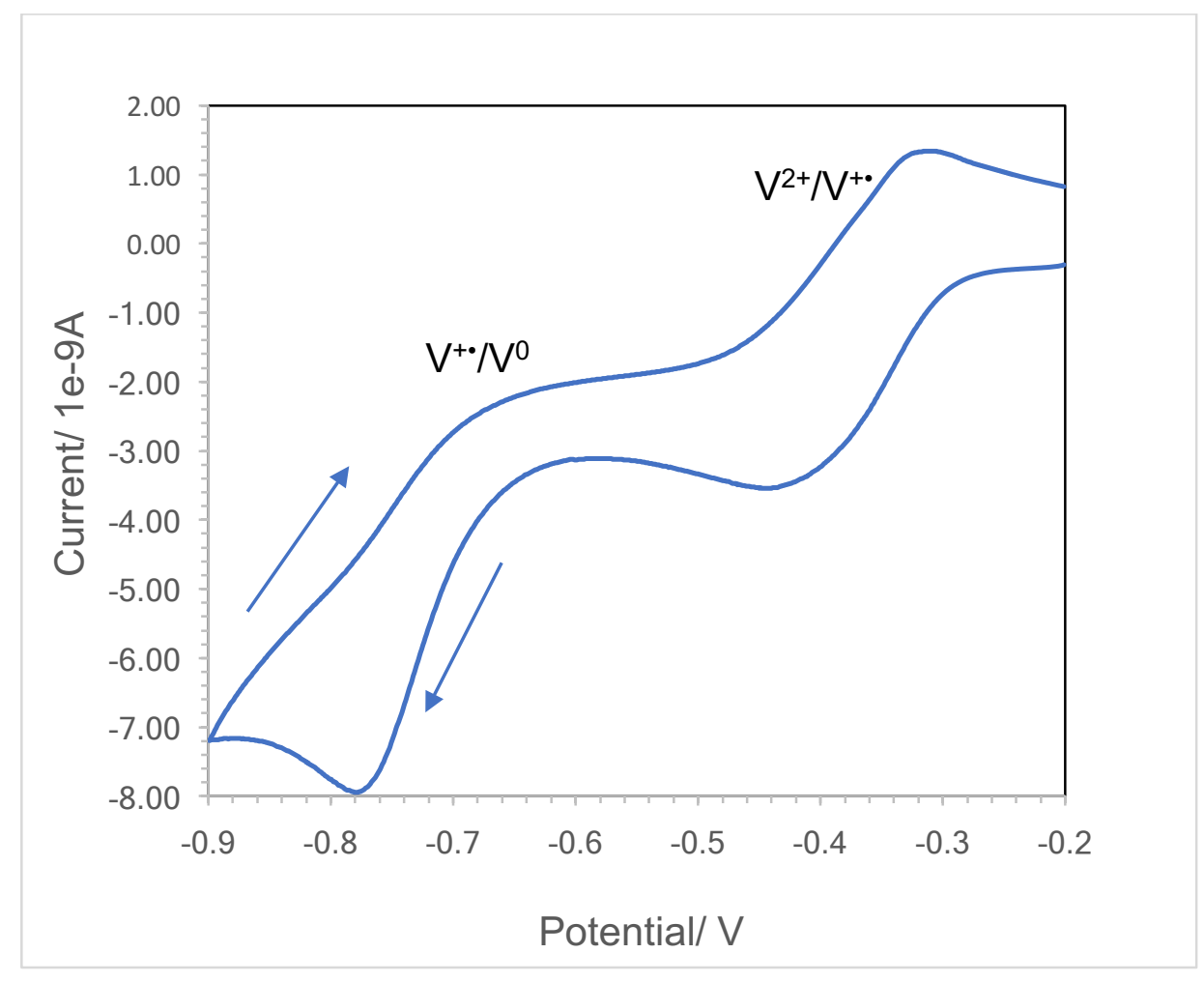

Figure 4.13 Cyclic voltammogram of viologen polymer using Ag plate as $\mathrm{AE}$ and $\mathrm{RE}$, and $\mathrm{Pt}$ as the working electrode. 


\subsubsection{FTIR Spectroscopy Results}

The structure of the viologen-PEG polymer was also determined by FTIR spectroscopy. The overlapped FTIR spectra of 4,4'-bipyridine, PEG-400, and viologen polymer are shown in Figure 4.14. The spectra of both PEG (Fig. 4.14a, b) and viologen polymer show absorption bands at $1094 \mathrm{~cm}^{-1}$ and at $2865 \mathrm{~cm}^{-1}$. The band at $1094 \mathrm{~cm}^{-1}$ corresponds to the $\mathrm{C}-\mathrm{O}$ stretch mode of the ether group of PEG and band at $2865 \mathrm{~cm}^{-1}$ corresponds to $\mathrm{sp}^{3}$ hybridized $\mathrm{C}-\mathrm{H}$ symmetric bond stretch of PEG backbone. The FTIR spectra of both viologen polymer and 4,4'bipyridine (Fig. 4.14b, c) show absorption band at $3024 \mathrm{~cm}^{-1}$ corresponding to $\mathrm{sp}^{2}$ hybridized $\mathrm{C}-\mathrm{H}$ bond stretch due to pyridine rings. In addition, the FTIR spectrum of viologen polymer (Fig 4.14b) shows absorption bands at $1192\left(\mathrm{R}-\mathrm{N}^{+}\right)$ and $1008 \mathrm{~cm}^{-1}(\mathrm{~S}-\mathrm{O})$, corresponding to R-N stretch mode of the linkage (between PEG and viologen moieties) and sulfonate group of tosylates. All these values were consistent with previously published work..$^{58,62,72}$ Consequently, it was confirmed that the viologen moieties were covalently attached to PEG chains. 


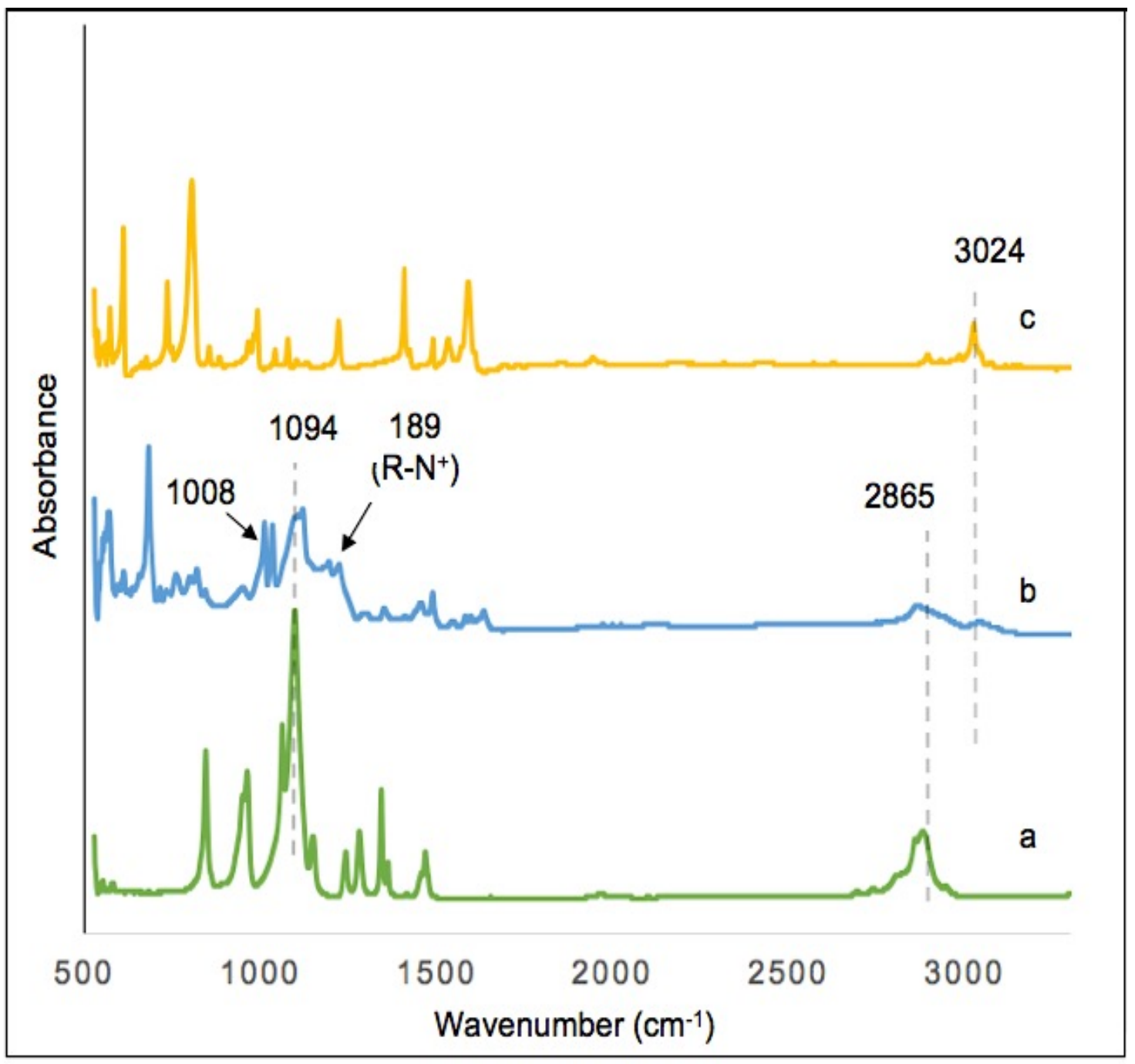

Figure 4.14 FTIR spectra of (a) PEG-400, (b) viologen polymer and (c) 4,4'bipyridine.

\subsection{Conclusions}

The viologen-polyethylene glycol polymer was successfully synthesized using tosylated PEG and 4,4'-bipyridine. It was observed that the tosylation reaction is the most sensitive and critical step in the synthesis of viologen polymer. The tosylation was only achieved using pyridine and dry chemical reagents, indicating that tosylation step is moisture sensitive and requires a weaker base. The 
moisture can lead to the hydrolysis of $p$-toluenesulfonyl chloride and any strong base, including water and hydroxide can readily react with $p$-toluenesulfonyl chloride.

The redox properties of the V-PEG polymer were also successfully analyzed using cyclic voltammetry, as CV graphs showed clear two sets of oxidation/reduction peaks. Based on these results, this polymer was used as a redox additive polyelectrolyte in the proposed oxidation-half cell of the hybrid supercapacitor. It was also tethered to the oxidized-SWCNTs, to increase their exposed surface area. The functionalization of oxidized-SWCNTs with V-PEG polymer is discussed in the following chapter. 


\section{Chapter 5 : FUNCTIONALIZATION OF OXIDIZED SINGLE-WALLED CARBON NANOTUES WITH V-PEG POLYMER}

\subsection{Introduction}

As discussed in Chapter 2, carbon nanotubes (CNTs) possess limited solubility and processability due to their association in bundles, which is caused by the van der Waals interactions between their sidewalls. To circumvent these issues, the CNTs are commonly functionalized with different chemical groups. Grafting polymers on the surface of CNTs not only improves their solubility, but also increases their exposed surface area, even at a low degree of functionalization..$^{73,74}$ So, in an effort to increase the exposed surface area of the oxidized single-walled carbon nanotubes (o-SWCNTs), they were covalently functionalized with V-PEG polymer.

To carry out this functionalization, the surface-bound carboxylic groups on oxidized-SWCNTs were first modified into reactive acyl chlorides using oxalyl chloride and N,N-Dimethylformamide (DMF), as shown in Scheme $5.1 .^{75,76}$ This reaction is critical because acyl chlorides are very reactive and can be used to form ester linkages between oxidized-SWCNTs and V-PEG polymer. The mechanism of acyl chloride formation using oxalyl chloride is shown in Scheme 5.2. In this reaction, DMF (5.20) reacts with oxalyl chloride (5.21) to give an iminium intermediate (5.22), which in turn reacts with the carboxylic acid to form an acyl chloride (5.23). ${ }^{77}$ 
Scheme 5.1 Acyl chlorination of oxidized-SWCNTs.

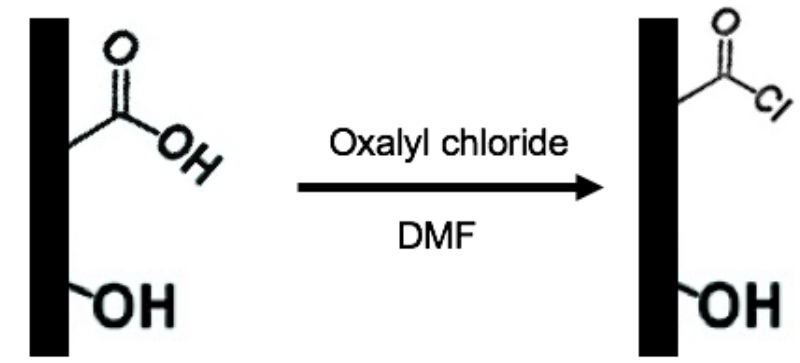

Scheme 5.2 Mechanism of acyl chloride formation using oxalyl chloride.
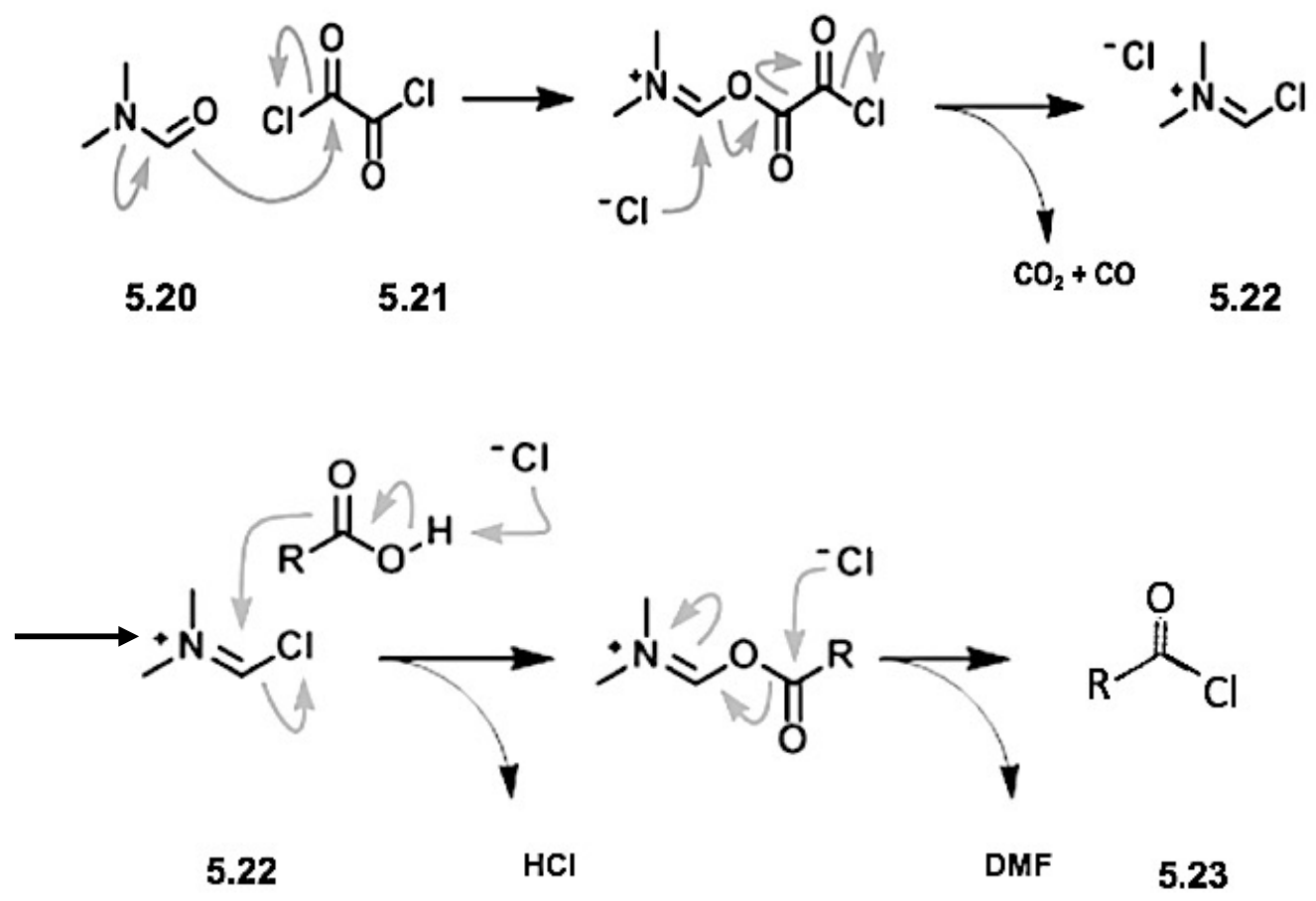

After the acyl chlorination, the oxidized-SWCNTs were mixed with V-PEG polymer, so that the acyl groups can react with the end hydroxyl groups $(-\mathrm{OH})$ of V-PEG polymer, to form ester linkages, as shown in Scheme 5.3. The experimental conditions for these reactions are discussed in detail in the following section. 
Scheme 5.3 Grafting of viologen polymer to acyl-chlorinated SWCNTs.

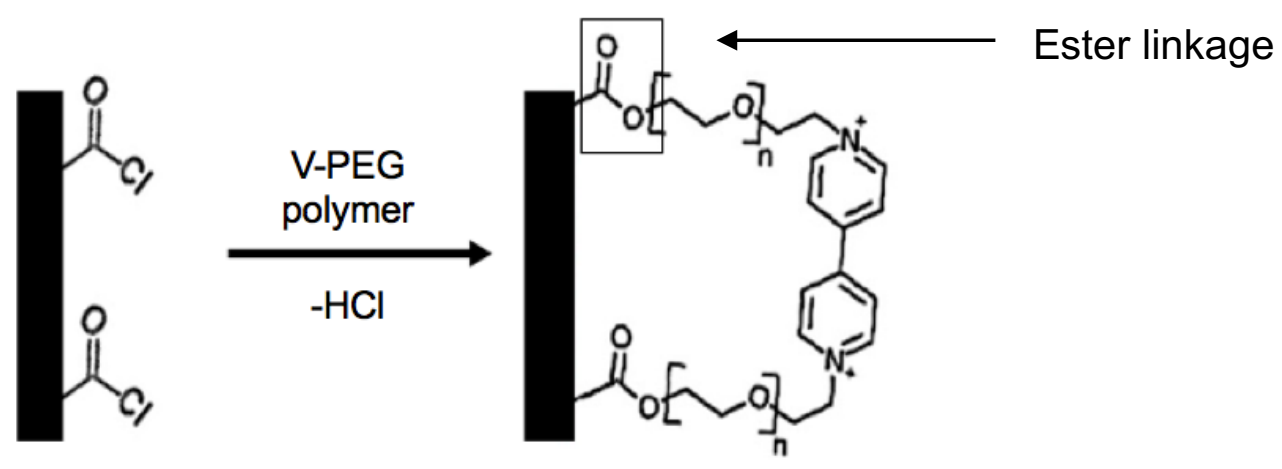

\subsection{Experimental Section}

\subsubsection{Materials}

Oxalyl chloride and DMF were purchased from Sigma-Aldrich Inc. All reactions were carried out under an inert nitrogen atmosphere in an oven-dried three-neck glassware fitted with rubber septa. Teflon-coated magnetic stir bars were used for stirring and dry liquid reagents and solvents were transferred using glass syringes

\subsubsection{Experimental Procedures}

\subsubsection{Grafting SWCNTs with V-PEG Polymer}

$70 \mathrm{mg}$ of oxidized-SWCNTs was first dispersed in $30 \mathrm{~mL}$ of dimethylformamide (DMF) by a 15-minute sonication treatment. Then the resulting mixture was stirred in an ice-bath for 30 minutes. Next, $2 \mathrm{ml}$ of oxalyl chloride was added dropwise to the dispersion of oxidized-SWCNTs. The reaction mixture was stirred in an ice bath for 3 hours and then at room temperature for 12 hours. Finally, the temperature was raised to $80^{\circ} \mathrm{C}$ and the mixture was stirred overnight to remove excess oxalyl chloride. Next, the 
previously prepared V-PEG polymer $(0.08 \mathrm{mmol}, 70 \mathrm{mg})$ was dissolved in DMF and added to the SWCNT suspension. The mixture was stirred at $100{ }^{\circ} \mathrm{C}$ for 5 days. After cooling to room temperature, the solvent was evaporated using a rotary evaporator. The remaining black solid was dried under vacuum and used without further purification.

\subsection{Characterization Techniques}

The presence of ester linkages between SWCNTs and V-PEG polymer was analyzed using FTIR spectroscopy. The FTIR spectrum was measured on a Nicolet 6700 FT-IR spectrometer. The electrochemical behavior of the obtained product was investigated using cyclic voltammetry (CV). CV experiments were performed using $\mathrm{CH} 660$ or PAR 263A electrochemical analyzer. The apparatus setup for CV analysis is depicted in Figure 5.1. Analysis was done using a $10 \mu \mathrm{m}$ Pt working electrode (WE) and a thin silver plate as both auxiliary and reference electrode (AE, RE). A Teflon block was used to hold the WE on top of the silver

plate with the V-PEG polymer/SWCNTs composite between them. A few drops of electrolyte were also added to the SWCNT-polymer matrix before conducting CV experiments. 


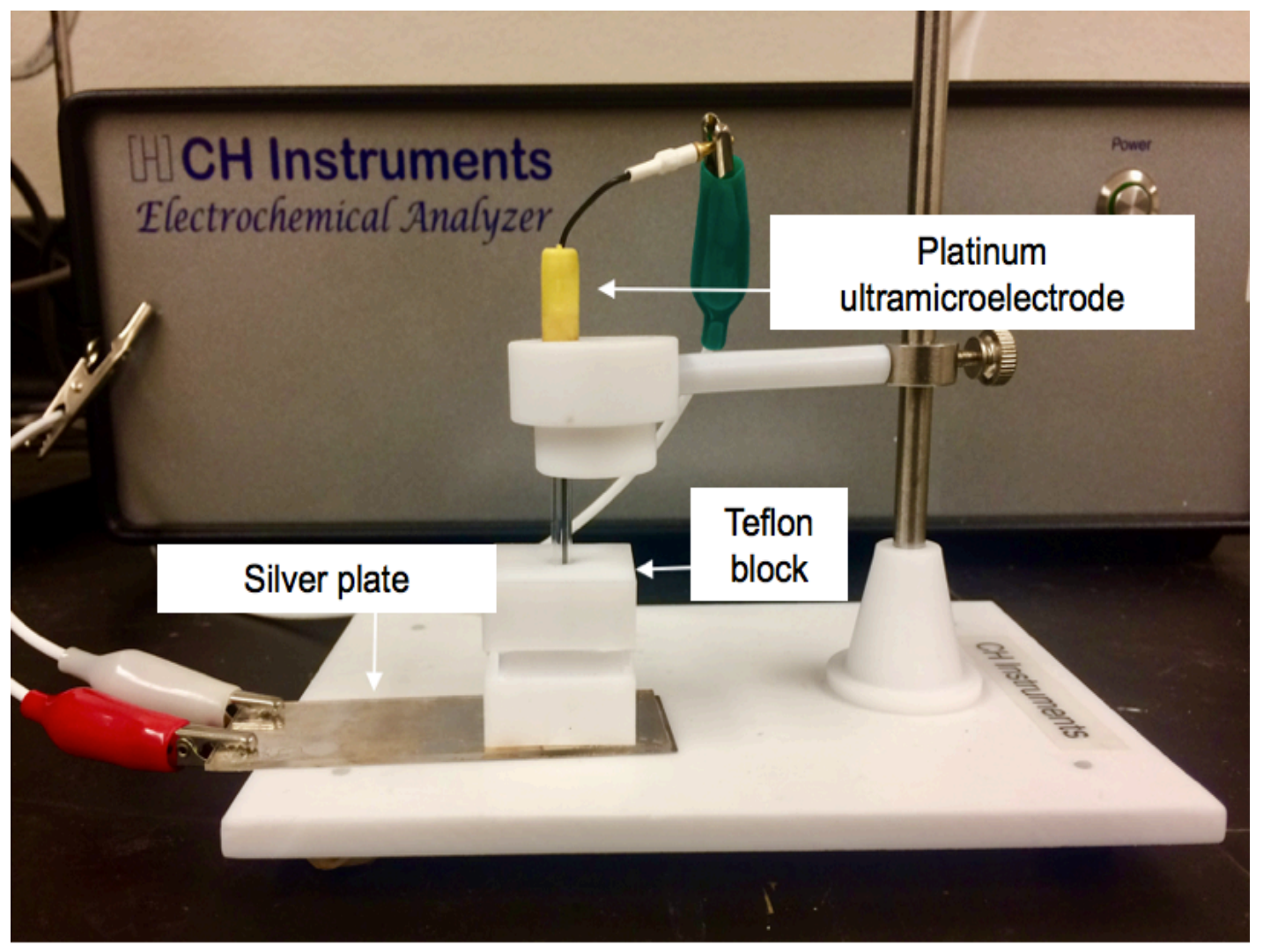

Figure 5.1 CV setup for analysis of the SWCNTs/V-PEG polymer composite.

\subsection{Results and Discussion}

\subsubsection{Cyclic Voltammetry Results}

Cyclic voltammetry of SWCNTs/ V-PEG polymer composite, prepared with a few drops of $0.1 \mathrm{M} \mathrm{LiClO}_{4} /$ Acetonitrile $(\mathrm{ACN})$, was performed at room temperature. The potential of the Pt ultramicroelectrode $(10 \mu \mathrm{m})$ was swept between $-0.2 \mathrm{~V}$ and $-1.0 \mathrm{~V}$, at a scan rate of $0.01 \mathrm{~V} \mathrm{~s}^{-1}$, versus an Ag quasireference plane to which both reference and auxiliary electrodes were connected. This two-electrode experiment is possible because of the low currents at the $10 \mu \mathrm{m}$ working electrode. In the resulting CV graph (Fig. 5.2), one sigmoidal and one half-sigmoidal curve was observed, corresponding to redox 
couples $\mathrm{V}^{+\bullet} / \mathrm{V}^{0}$ and $\mathrm{V}^{2+} / \mathrm{V}^{+\cdot}$. The apparent diffusion coefficients of $\mathrm{V}^{+\bullet} / \mathrm{V}^{0}$ and $\mathrm{V}^{2+} \mathrm{N}^{+\cdot}$ were calculated to be $1.72 \times 10^{-6} \mathrm{~cm}^{2} \mathrm{~s}^{-1}$ and $5.6 \times 10^{-7} \mathrm{~cm}^{2} \mathrm{~s}^{-1}$ using radial diffusion equation (Equation 1.11 in Chapter 4). This redox behavior strongly suggests a continuous SWCNTs/V-PEG composite phase with good ionic and electronic conductivity.

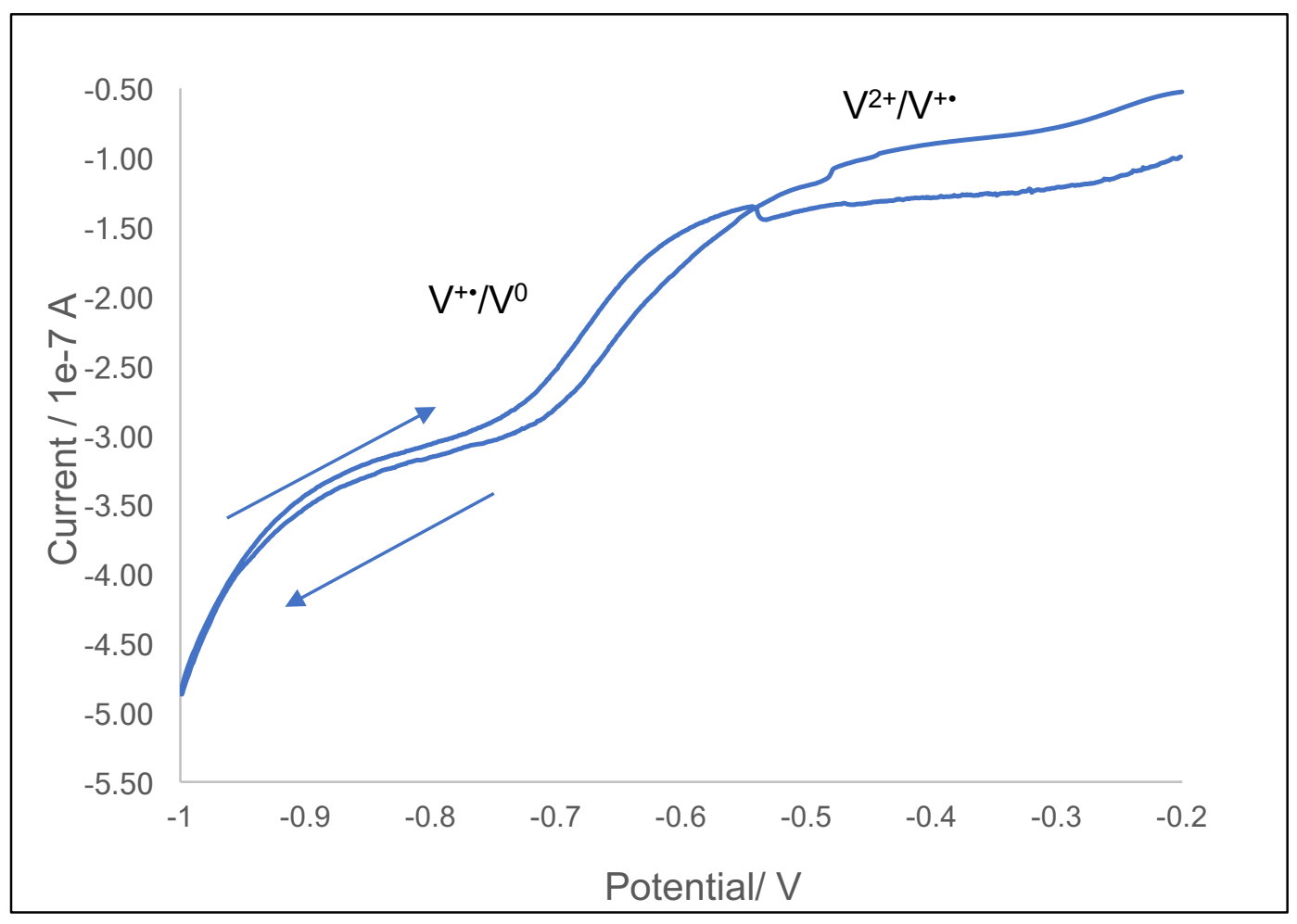

Figure 5.2 Cyclic voltammogram of SWCNTs/V-PEG polymer composite using Pt ultramicroelectrode.

\subsubsection{FTIR Spectroscopy Results}

FTIR spectroscopy was used to confirm the presence of ester linkages between V-PEG polymer and oxidized-SWCNTs. The overlapped FTIR spectra of oxidized-SWCNTs (Figure 5.3a), SWCNT/V-PEG polymer composite (Fig 5.3b), and V-PEG polymer (Fig 5.3c, in the inset) are shown in Figure 5.3. The 
spectrum of oxidized-SWCNTs shows absorption bands at $1650 \mathrm{~cm}^{-1}$ (carboxyl functional group), near $\sim 2100 \mathrm{~cm}^{-1}$ ( $C=C$ stretch mode of carbon nanotubes) and near $3000 \mathrm{~cm}^{-1}(\mathrm{O}-\mathrm{H}$, hydroxyl functional group). The spectrum SWCNTs/V-PEG polymer shows absorption bands near $\sim 2100 \mathrm{~cm}^{-1}$ and $\sim 3000 \mathrm{~cm}^{-1}$, similar to oxidized-SWCNTs. In addition, it shows an absorption band at $1666 \mathrm{~cm}^{-1}$ which might be due to the ester linkages between SWCNTs and V-PEG polymer $(\mathrm{C}=\mathrm{O}$ stretch of ester bonding). But the spectrum of V-PEG polymer also shows an absorption band at $1632 \mathrm{~cm}^{-1}$, which might have blue-shifted in the spectrum of the SWCNTs/V-PEG polymer composite, as shown in the inset (Fig. 5.3b, c). Based on these results, it was difficult to confirm the presence of ester bonds between V-PEG polymer and oxidized-SWCNTs. 


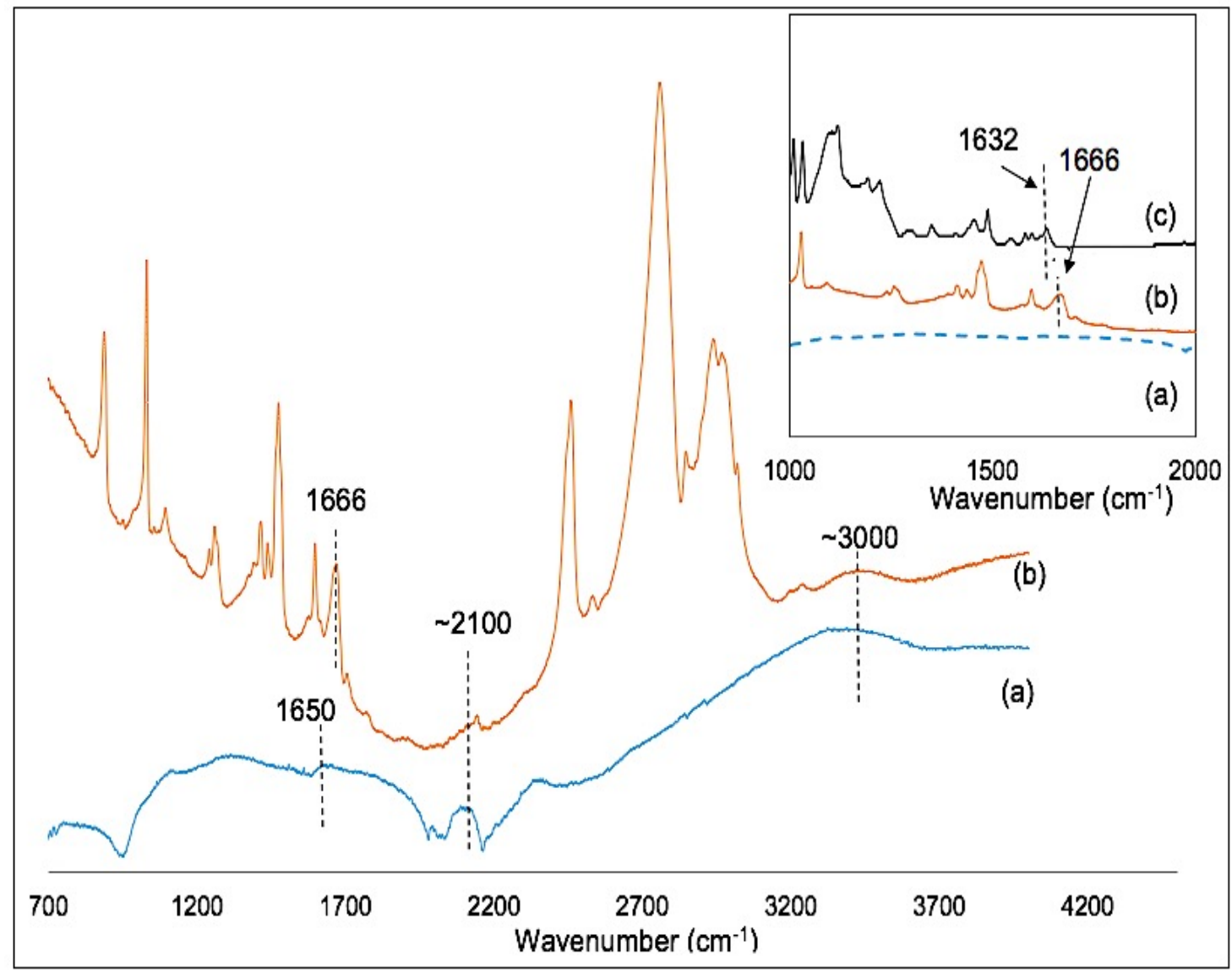

Figure 5.3 FTIR spectra of (a) o-SWCNTs, (b) SWCNTs/V-PEG polymer composite, and (c) V-PEG polymer.

\subsection{Conclusions}

The results obtained from FTIR spectroscopy were ambiguous with respect to confirming the final polymer structure, but the CV graphs showed two sets of oxidation/reduction peaks. Based on these results, the composite of o-SWCNTs and V-PEG polymer was used as such in the oxidation half-cell of the proposed hybrid supercapacitor, without further characterization. As the absence or presence of ester linkages between SWCNTs and V-PEG polymer is not expected to affect the performance of the cell. 


\section{Chapter 6 : CELL FABRICATION AND CHARACTERIZATION}

\subsection{Introduction}

In an attempt to develop a hybrid supercapacitor, the SWCNTs/V-PEG polymer composite was combined with a SWCNTs/ Fc-PEG polymer composite. The SWCNTs/ Fc-PEG polymer composite was synthesized and characterized by Shalaka Rahangdale. In this composite, ferrocene dicarboxylic acid centers were covalently incorporated in the polymer backbone of poly(ethylene glycol) $(M W=400)$ through ester linkages to increase their solubility. ${ }^{26}$ Both of these polymer composites were combined in a sandwich configuration with 19 porous polycarbonate membranes between them to form a two-electrode cell, as shown in Figure 6.1.

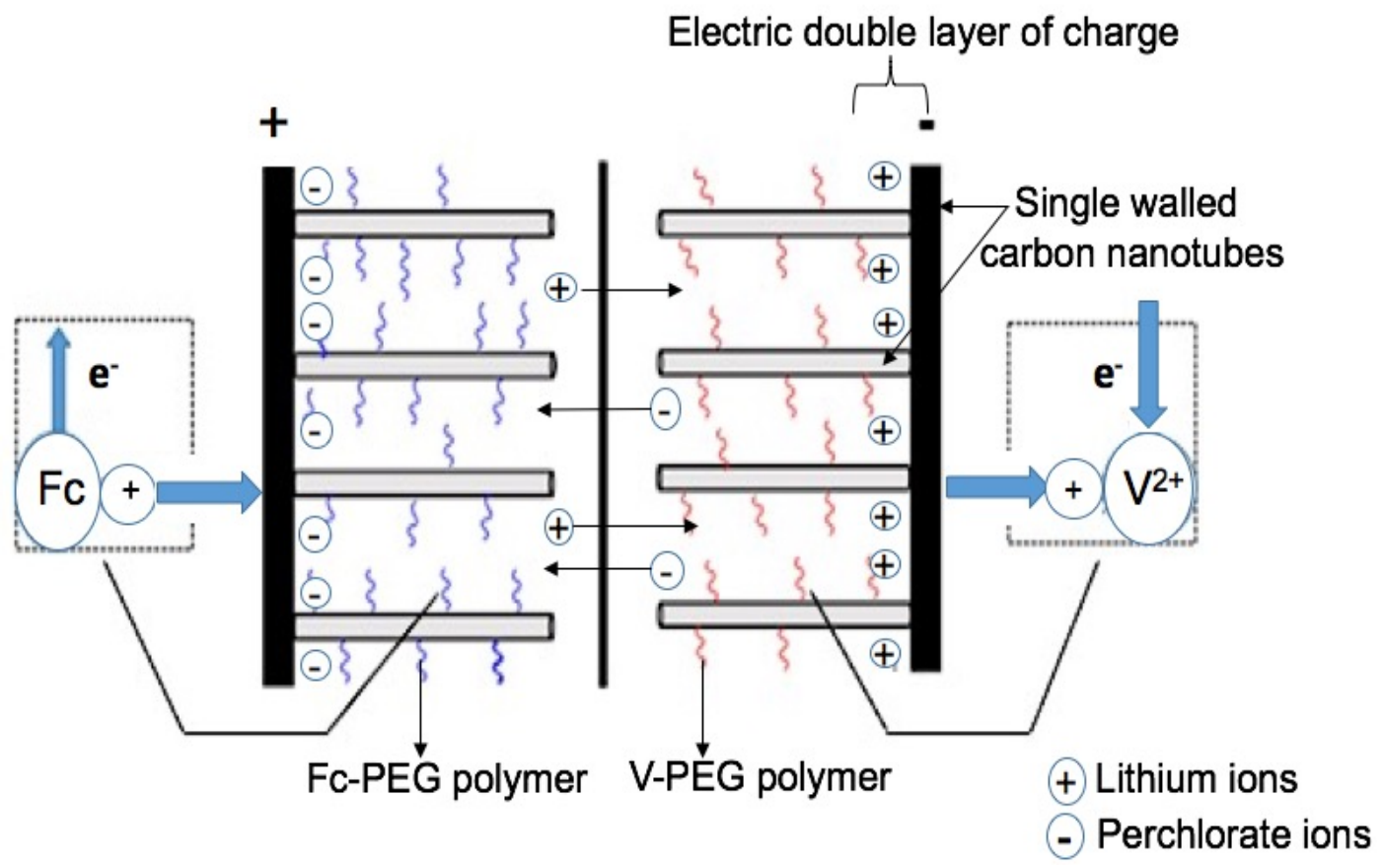

Figure 6.1 The schematic representation of the supercapacitor cell with SWCNTs/Fc-PEG polymer and SWCNTs/V-PEG polymer composites. 
A few drops of $0.1 \mathrm{M}$ solution of lithium perchlorate in dry acetonitrile were also added to both half-cells to ensure sufficient conductivity. During charging, the ferrocene dicarboxylic acid $(\mathrm{Fc})$ centers in the PEG backbone get oxidized and release electrons. These electrons move through an external circuit towards the other half-cell containing viologen species. The SWCNTs conduct these electrons towards the viologen centers, resulting in their reduction. In addition, the charge is also stored at the interface of SWCNTs and polymer electrolytes by electrostatic means, as discussed in Chapter 1. Opposite charges reside on two different layers. In the oxidation half-cell, a positive set resides on the SWCNTs and a negative set of charge due to perchlorate ions in the electrolyte. In the reduction half-cell, a negative set of charge resides on the SWCNTs and a positive set of charge due to lithium ions in the electrolyte as shown in Figure 6.1.

During the discharge process, when the voltage source is removed and the cell is connected to an external load, the role of viologen and Fc gets reversed in the sense that viologen gives up electrons and Fc gets reduced. The process of charging and discharging can be expressed as equations,

During charging, at the positive electrode:

$$
\begin{gathered}
E_{X}+A^{-} \rightarrow E_{X}^{+} / / A^{-}+e^{-} \\
F C \longrightarrow F C^{+}+e^{-}
\end{gathered}
$$

During discharging, at the positive electrode:

$$
\begin{gathered}
E_{X}^{+} / / A^{-}+e^{-} \rightarrow E_{X}+A^{-} \\
F_{C^{+}+e^{-}}^{\longrightarrow} F C
\end{gathered}
$$


During charging, at the negative electrode:

$$
\begin{gathered}
E_{y}+C^{+}+e^{-} \rightarrow E_{y}^{-} / / C^{+} \\
V^{2+}+e^{-} \rightarrow V^{+}
\end{gathered}
$$

During discharging, at the negative electrode:

$$
\begin{gathered}
E_{y}^{-} / / C^{+} \rightarrow E_{y}+C^{+}+e^{-} \\
V^{+} \rightarrow V^{2+}+e^{-}
\end{gathered}
$$

Here $E_{x}$ and $E_{y}$ denotes the SWCNTs, $A^{-}$and $C^{+}$the perchlorate and the lithium ions and // indicates an intimate association between ion and SWCNTelectrode at the electrode/electrolyte interface.

\subsection{Cell Fabrication Procedure}

\subsubsection{Cell Fabrication Materials}

The materials used to assemble the cell included a SWCNTs/V-PEG polymer composite, a SWCNTs/Fc-PEG polymer composite, aluminium current collectors, platinum foil, polycarbonate membrane separators of pore size $0.6 \mu \mathrm{m}$, silicon gaskets, an aluminium C-clamp and a $0.1 \mathrm{M}$ solution of lithium perchlorate in dry acetonitrile.

\subsubsection{Cell Assembly}

To assemble the cell, two square-shaped aluminium current collectors with platinum cavities in the center were used to hold the SWCNTs/V-PEG and SWCNTs/Fc-PEG polymer composites. The platinum cavities were formed by first attaching the silicon gaskets (with square cutouts in the center) to the 
surface of aluminum current collectors, and then inserting platinum foil pieces inside the obtained cavities, as shown in Figure 6.2.

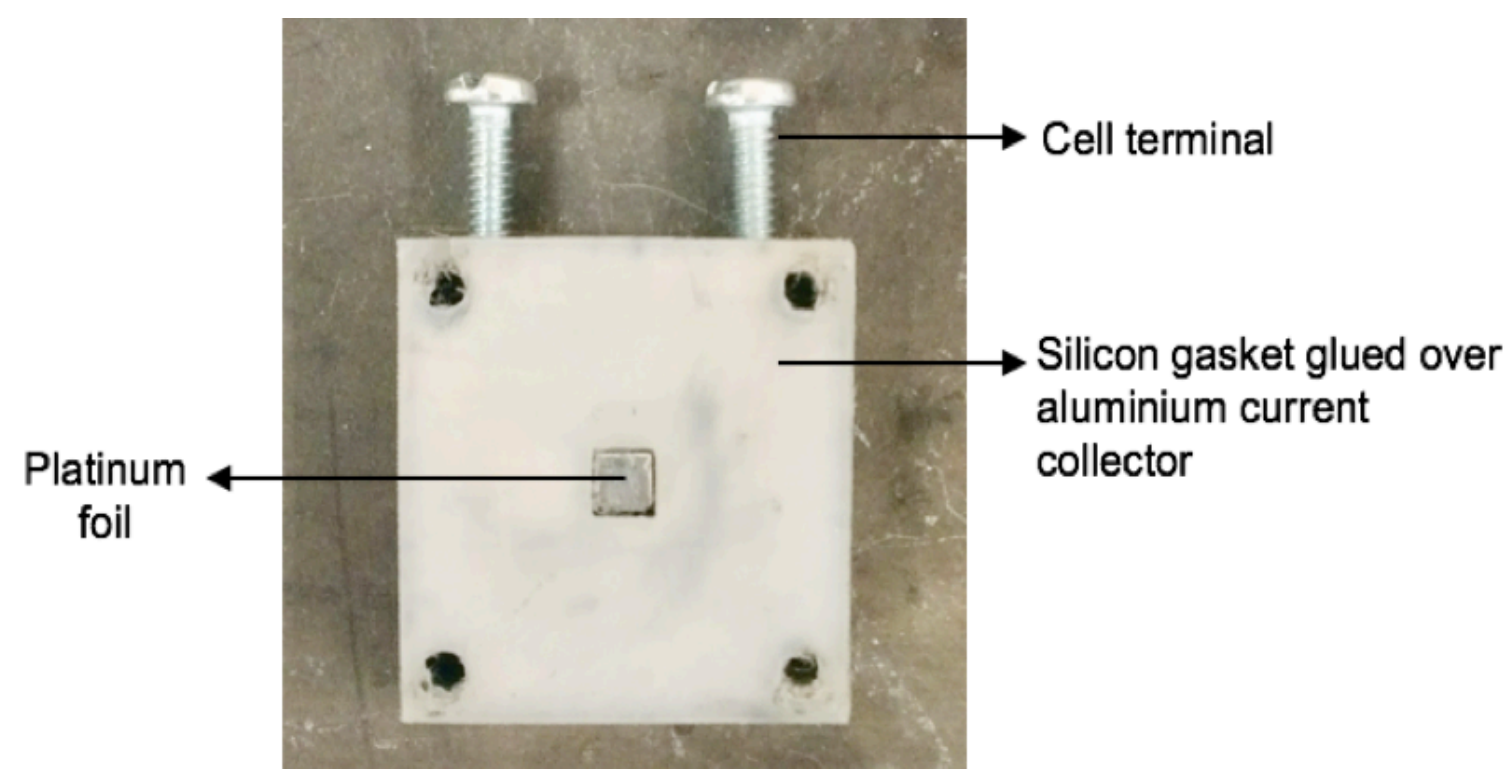

Figure 6.2 Aluminum current collector with a platinum cavity.

The SWCNTs/V-PEG and SWCNTs/Fc-PEG polymer composites were mixed with few drops of $0.1 \mathrm{M}$ solution of lithium perchlorate in dry acetonitrile separately to form two homogeneous mixtures. These two mixtures were deposited in the platinum cavities of two separate aluminum current collectors. These current collectors were then combined in a sandwich configuration with 19 porous polycarbonate membranes between them (pore size $0.6 \mu \mathrm{m}$ ). They were tightly clamped using a C-clamp to form a prototype cell. The whole process of fabrication is demonstrated in Figure 6.3. 


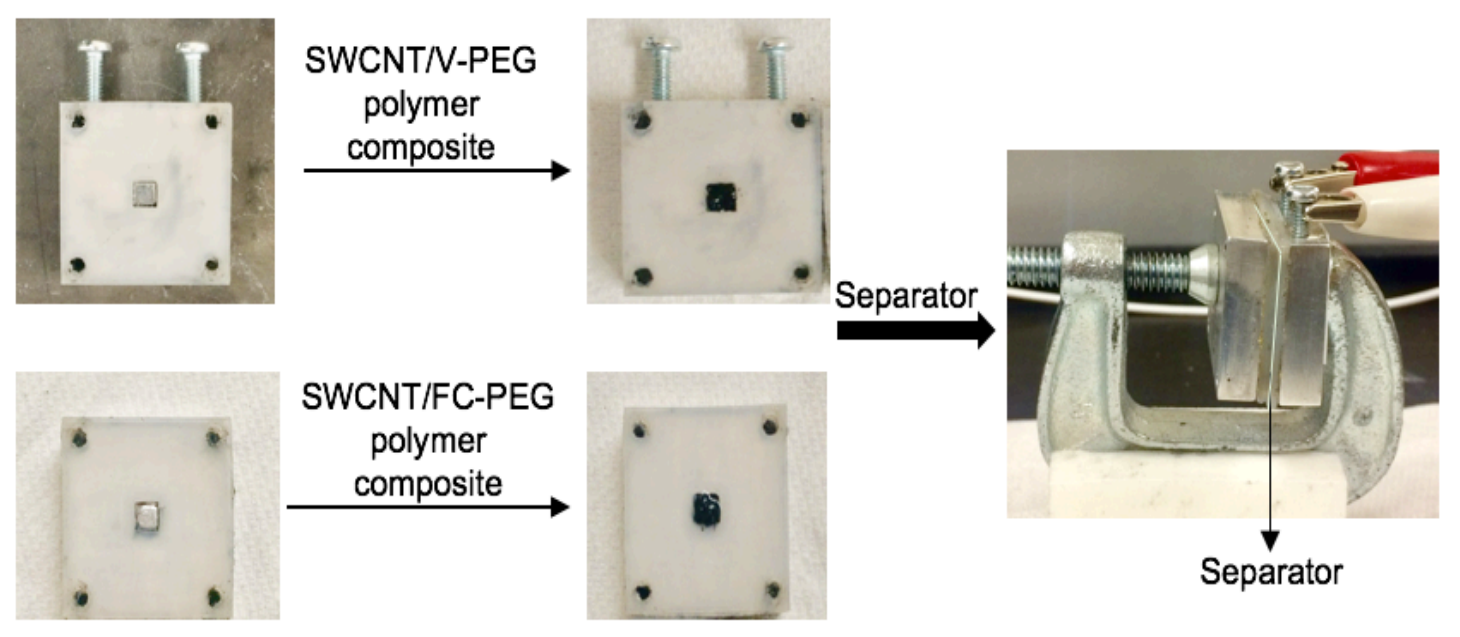

Figure 6.3 Schematic of prototype cell fabrication procedure.

\subsection{Cell Characterization}

The electrochemical characterization of the prototype cell was done using cyclic voltammetry (CV) and chronoamperometry (CA). All the CV experiments were performed using $\mathrm{CH} 660$ electrochemical analyzer and all the $\mathrm{CA}$ experiments were performed using EG\&G 263A potentiostat/Galvanostat. The apparatus setup for both the CV and CA analysis is depicted in Figure 6.4. In all the experiments, the current collector with SWCNTs/Fc-PEG polymer composite in its Pt cavity was connected with the working electrode and the current collector with SWCNTs/V-PEG polymer composite in its Pt cavity was connected to both the auxiliary and reference electrodes. The theoretical aspects of CA are also discussed briefly in the following section. 


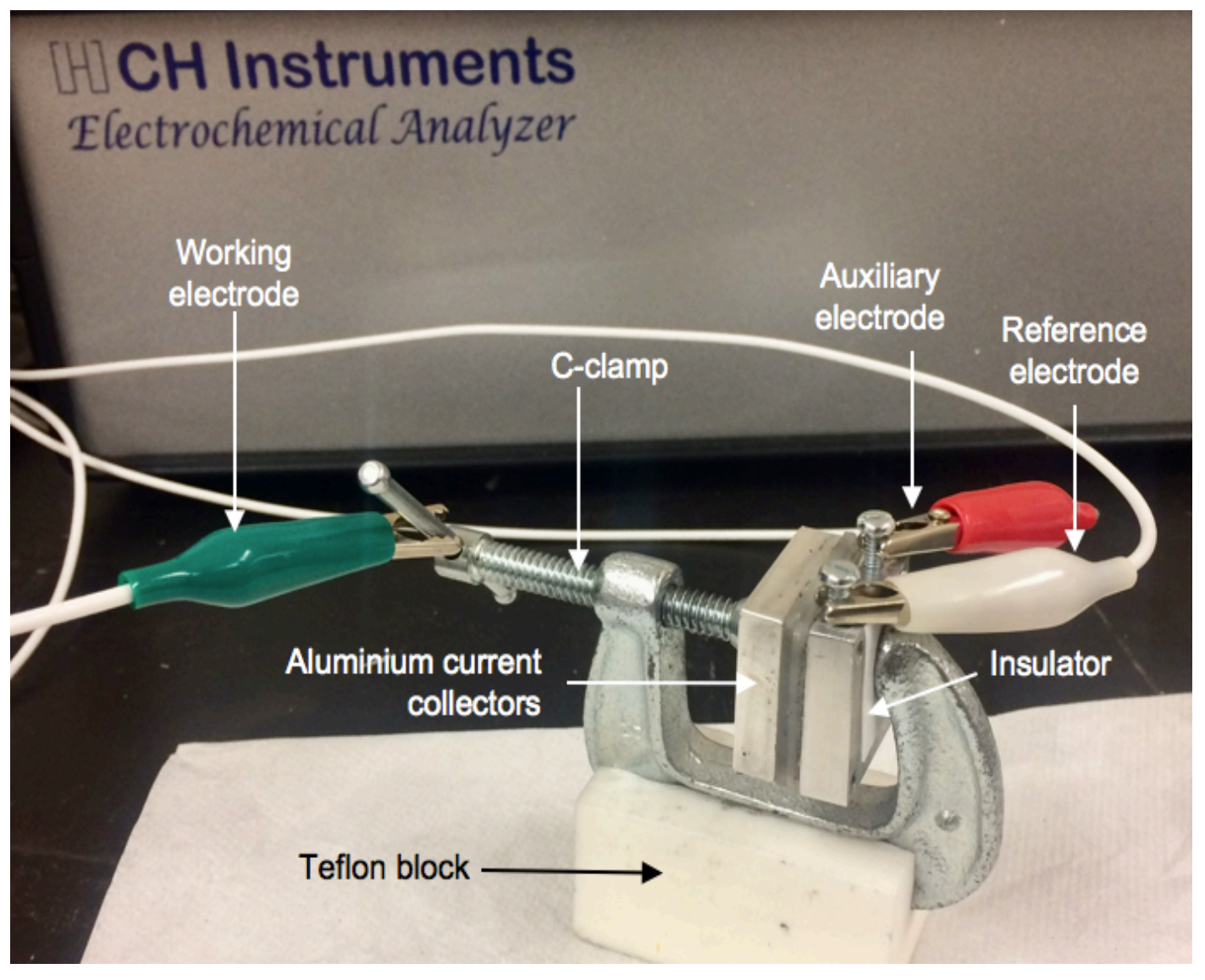

Figure 6.4 Electrochemical setup for analysis of the prototype cell.

\subsubsection{Chronoamperometry}

Chronoamperometry can be defined as the study of the variation of current response with time under potentiostatic control. It is a commonly used electroanalytical technique, useful for determining diffusion coefficients, reaction kinetics and mechanisms. In this technique, the applied potential remains constant over a period of time and afterwards the applied potential is set to a different constant value, either in the potential range of the Faradaic reaction under study or outside this range to recover initial equilibrium conditions. Based on the number of potential pulses applied before recovering the equilibrium 
conditions, this technique is classified as single-, double-, and triple-pulse chronoamperometry. ${ }^{78,79}$ The corresponding current response is recorded at the end of these potential pulses as a function of time, as shown in Figure 6.5.

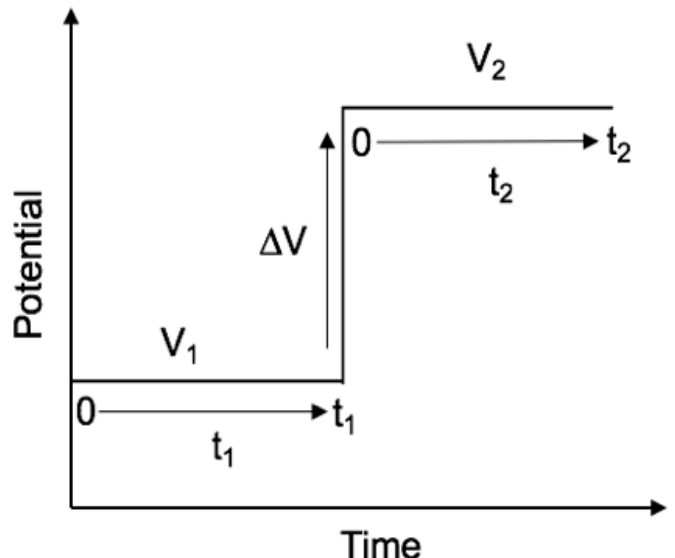

(a)

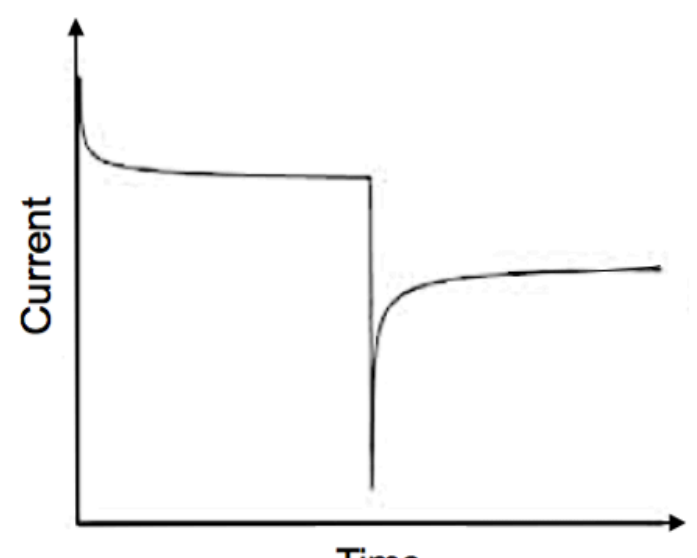

(b)
Time

Figure 6.5 (a) Potential waveform and (b) the signal for double pulse chronoamperometry.

From the current vs the time graph, the concentration gradient at the electrode surface can be studied. A large current is initially observed which then gradually decrease due to the depletion of electroactive species at the electrode surface. This change in current with respect to time is governed by the Cottrell equation:

$$
i=\frac{n F A C \sqrt{D}}{\sqrt{\pi t}}
$$

Where $i$ is the current, $n$ is the number of electrons involved in the redox reaction, $F$ is Faraday's constant, $A$ is the surface area of the (planar) electrode, $C$ is the concentration of the electroactive species, $t$ is time, and $D$ is the diffusion coefficient. As per this equation, the current falls as $t^{-1 / 2}$. But there is always some 
capacitive or non-Faradaic current flowing when the potential of an electrode is

changing and it is dominant at short times. ${ }^{79,80}$ The capacitive current decay with respect to time at a constant applied potential is governed by the equation:

$$
i=\frac{E}{R_{u}} e^{-t / R_{u} C_{d}} \quad \text { Equation } 1.13
$$

Where $R_{u}$ is an uncompensated resistance, $C_{d}$ is the double layer

capacitance. As per this equation, the capacitive current decays exponentially. ${ }^{80}$

\subsection{Results and Discussion}

\subsubsection{Analysis}

During CV analysis of the cell, the potential of the working electrode was swept between 0 Volts to 2 Volts at scan rates of $0.1,0.01$, and $0.005 \mathrm{~V} \mathrm{~s}^{-1}$. The resulting voltammograms are shown in Figure 6.6. From all the CV graphs, similar results were obtained. In the forward scan, a large current was observed, consistent with the charging (oxidation of ferrocene dicarboxylic acid and reduction of viologen sites). However, no reverse, discharging current was observed in the reverse scan. The most likely contribution to this include leakage of electrons through separator membranes between oxidation half-cell and reduction half-cell of the prototype cell. It is also possible that irreversible redox reactions were occurring at the aluminum electrodes, and that they dominated the current response. 

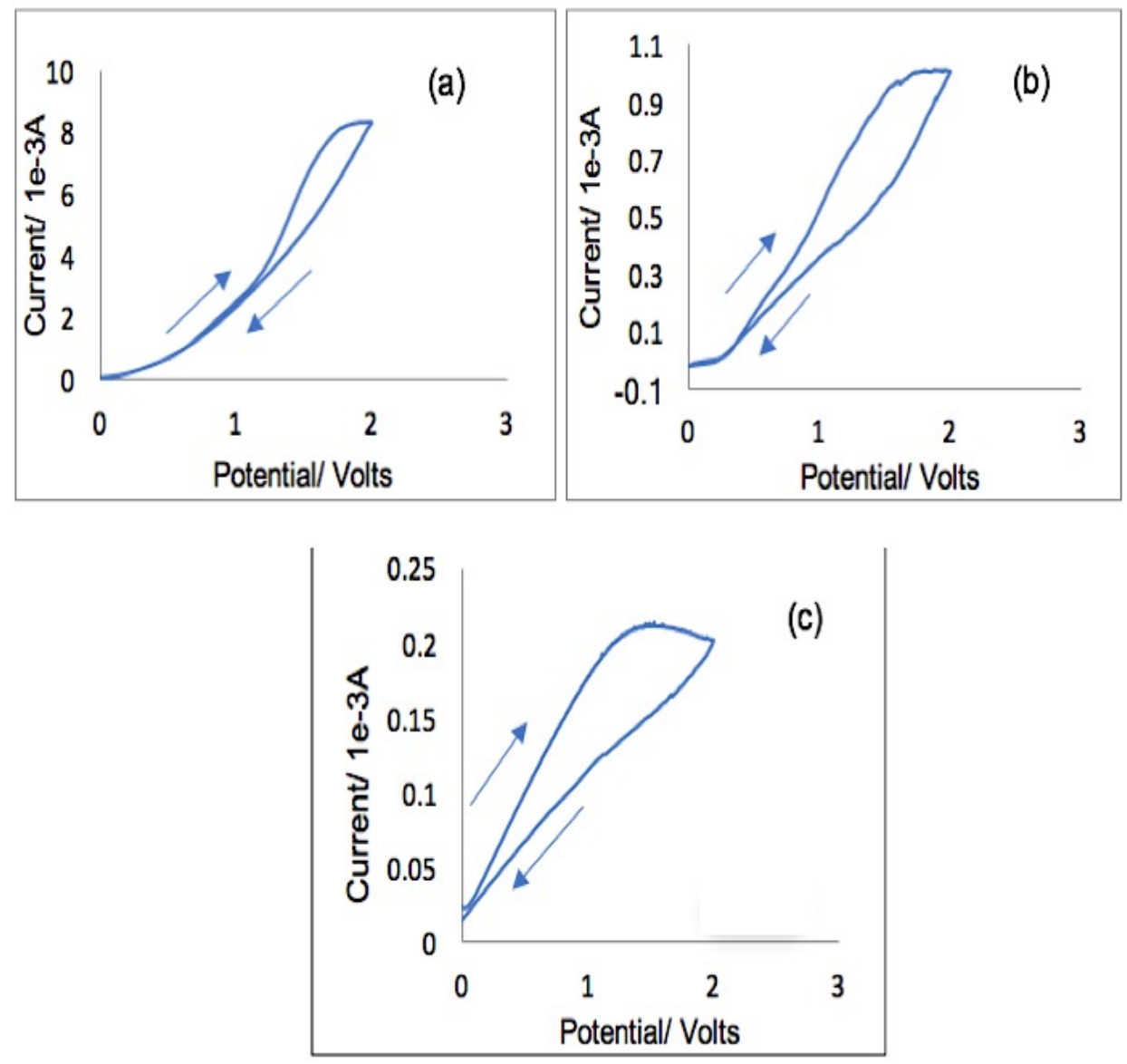

Figure 6.6 Cyclic voltammograms of the prototype cell at scan rate (a) $0.1 \mathrm{~V} \mathrm{~s}^{-1}$, (b) $0.01 \mathrm{~V} \mathrm{~s}^{-1}$ and (c) $0.05 \mathrm{~V} \mathrm{~s}^{-1}$.

\subsubsection{Chronoamperometry Analysis}

To investigate the charging and discharging currents of the prototype cell, four double pulse CA experiments were conducted. During the analysis, two sets of potential pulses were applied to the prototype cell, an anodic pulse set and a cathodic pulse set. In the first experiment, the cell was equilibrated for 0.5 seconds at 0 Volts. After the current reached zero, the applied potential was stepped from $0 \mathrm{~V}$ to $1 \mathrm{~V}$ and was held there for 0.5 seconds. Then the applied potential was stepped down from $1 \mathrm{~V}$ to $0 \mathrm{~V}$ and was held there for 0.5 seconds 
( 0.5 seconds for cathodic pulse and 0.5 seconds for anodic pulse). Similarly, three other double pulse CA experiments were performed in the same potential range for $5 \mathrm{~s}, 50 \mathrm{~s}$, and 500 second time intervals. The resulting CA graphs are shown in Table 6.1

Table 6.1 Chronoamperometry Graphs of the Prototype Cell.

\begin{tabular}{|c|c|c|c|c|c|c|c|c|}
\hline Time & \multicolumn{8}{|c|}{ Chronoamperommetry graphs } \\
\hline 0.5 & 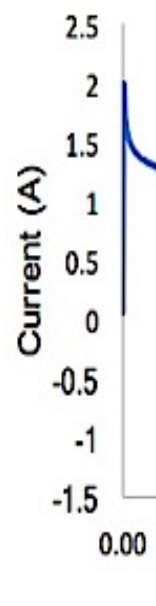 & 0.20 & 0.40 & $\begin{array}{c}0.60 \\
\text { Time (s) }\end{array}$ & 0.80 & 1. & 1 & 1.20 \\
\hline 5 & 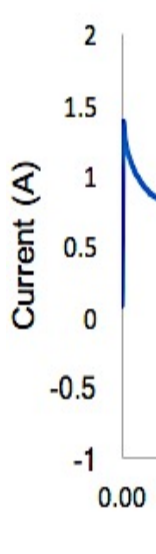 & 2.00 & 4.00 & $\begin{array}{r}6.00 \\
\operatorname{Time}(s)\end{array}$ & & & 10.00 & \\
\hline
\end{tabular}




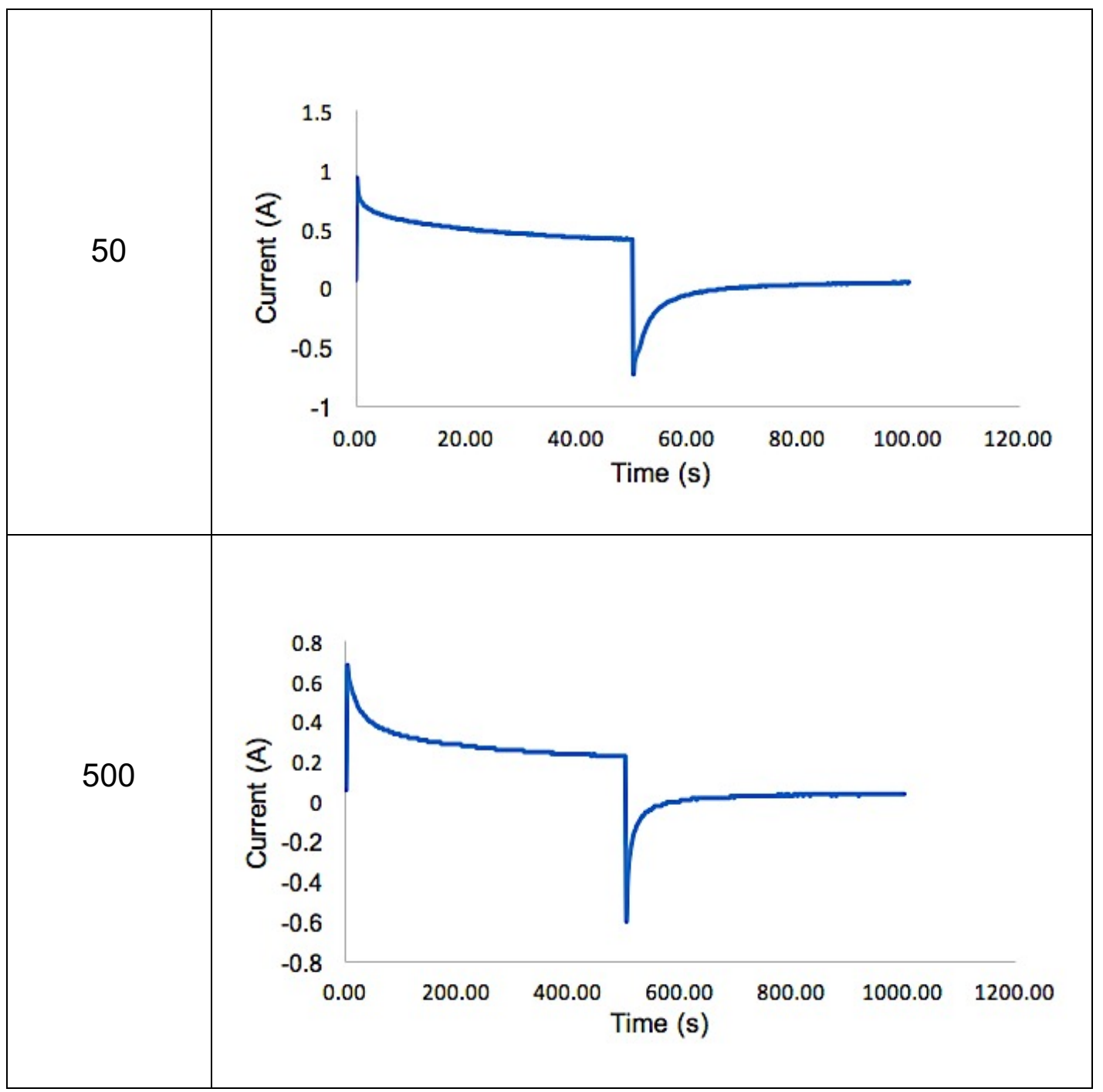

In the resulting CA graphs, the current decreased gradually with increasing time intervals. The CA graph obtained at a time interval of 500 seconds (500 s of cathodic pulse and $500 \mathrm{~s}$ of anodic pulse) shows minimum capacitive current compared to the CA graphs obtained at shorter time intervals $(0.5 \mathrm{~s}, 5 \mathrm{~s}$, and 50 s), as shown in Table 6.1. This occurs because the capacitive current decays exponentially with time as compared to Faradaic current, as discussed in Section 6.3.1. Therefore, at longer time intervals mostly Faradaic current is observed. In 
addition, the charging and discharging currents in all the CA graphs were also observed to be unequal, as tabulated in Table 6.2. This suggested the leakage of electrons through the separator membranes between oxidation half-cell and reduction half-cell of the prototype cell. Also, it's possible that there is leakage of polymer material onto the aluminum current collectors, and that is yielding irreversible currents.

Table 6.2 Charging-Discharging Currents of the Prototype Cell.

\begin{tabular}{|c|c|c|}
\hline $\begin{array}{c}\text { Time interval } \\
\text { (seconds) }\end{array}$ & $\begin{array}{c}\text { Charging current } \\
\text { (Amperes) }\end{array}$ & $\begin{array}{c}\text { Discharging current } \\
\text { (Amperes) }\end{array}$ \\
\hline 0.5 & $1.97 \times 10^{-4}$ & $1.07 \times 10^{-4}$ \\
\hline 5 & $1.36 \times 10^{-4}$ & $0.81 \times 10^{-4}$ \\
\hline 50 & $0.92 \times 10^{-4}$ & $0.72 \times 10^{-4}$ \\
\hline 500 & $0.68 \times 10^{-4}$ & $0.58 \times 10^{-4}$ \\
\hline
\end{tabular}

\subsection{Conclusions and Future Work}

The viologen moieties were successfully covalently incorporated in the poly(ethylene glycol) backbone to form a V-PEG polymer. Cyclic voltammetry analysis of the $\mathrm{V}$-PEG polymer revealed that it has redox potentials at $0.37 \mathrm{~V}$ (vs $\mathrm{Ag} / \mathrm{AgCl}$ ) and at $0.73 \mathrm{~V}(\mathrm{vs} \mathrm{Ag} / \mathrm{AgCl})$ corresponding to $\mathrm{V}^{2+} \mathrm{N}^{+\bullet}$ and $\mathrm{V}^{+\bullet} / \mathrm{V}^{0}$ redox couples, rendering it as a suitable redox additive polyelectrolyte material for a hybrid supercapacitor. Cyclic voltammetry analysis of the composite of singlewalled carbon nanotubes/V-PEG polymer revealed one sigmoidal and one halfsigmoidal curves corresponding to $\mathrm{V}^{+\bullet} \mathrm{N}^{0}$ and $\mathrm{V}^{2+} \mathrm{V}^{+\cdot}$ redox couples, strongly suggesting a continuous SWCNTS/V-PEG polymer composite phase with good ionic and electronic conductivity. Based on all these results, the composite of 
SWCNTS/V-PEG polymer proves to be a suitable electrode/electrolyte phase for its application in the oxidation half-cell of a hybrid supercapacitor.

The SWCNTs/Fc-PEG polymer was also reported to exhibit similar reversible redox behavior as SWCNTS/V-PEG polymer. However, after the coupling of SWCNTS/V-PEG polymer composite with a SWCNTs/Fc-PEG polymer composite to form a prototype cell, expected electrochemical results were not obtained. This failure may be attributable to the leakage of electrons through the separator membranes between the half-cells of the hybrid SC. This can occur because CNTs get shortened after prolonged acid treatment and can pass through the separator membranes, resulting in a short circuit. To prevent this leakage, different separator membranes with smaller pore sizes can be tested in the future work. If the issue of leakage between both the half-cells is eliminated, the energy density of the resulting cell is expected to be greater than conventional supercapacitors, which do not have any redox-active species in them. 


\section{REFERENCES}

(1) Wang, G.; Zhang, L.; Zhang, J. A Review of Electrode Materials for Electrochemical Supercapacitors. Chem. Soc. Rev. 2012, 41, 797-828.

(2) Chen, H.; Cong, T. N.; Yang, W.; Tan, C.; Li, Y.; Ding, Y. Progress in Electrical Energy Storage System: A Critical Review. Prog. Nat. Sci. 2009, 19 (3), 291-312.

(3) Rauda, I. E.; Augustyn, V.; Dunn, B.; Tolbert, S. H. Enhancing Pseudocapacitive Charge Storage in Polymer Templated Mesoporous Materials. Acc. Chem. Res. 2013, 46 (5), 1113-1124.

(4) Luo, X.; Wang, J.; Dooner, M.; Clarke, J. Overview of Current Development in Electrical Energy Storage Technologies and the Application Potential in Power System Operation. Appl. Energy 2015, 137, 511-536.

(5) Akinyele, D. O.; Rayudu, R. K. Review of Energy Storage Technologies for Sustainable Networks. Sustain. Energy Technol. Assessments 2014, 8, 74-91.

(6) Zhang, L. L; Zhao, X. S. Carbon-Based Materials as Supercapacitor Electrodes. Chem. Soc. Rev. 2009, 38, 2520-2531.

(7) Capacitor. https://en.wikipedia.org/wiki/Capacitor (accessed Aug 15, 2017).

(8) Conway, B. E. Electrochemical Supercapacitors: Scientific Fundamentals and Technological Applications; Kluwer-Academic/ Plenum Publisher: New York, 1999; pp 11- 31.

(9) Battery. https://en.wikipedia.org/wiki/Battery_(electricity) (accessed Aug 16, 2017).

(10) Gummow, R. J. $\mathrm{Li}_{2} \mathrm{MnSiO}_{4}$ Nanostructured Cathodes for Rechargeable Lithium-Ion Batteries. In Nanomaterials in Advanced Batteries and Supercapacitors; Ozoemena, K. I.; Chen, S.; Nanostructure Science and Technology; Springer International: Switzerland, 2016; pp 25-54.

(11) Etacheri, V.; Marom, R.; Elazari, R.; Salitra, G.; Aurbach, D. Challenges in the Development of Advanced Li-lon Batteries: A Review. Energy Environ. Sci. 2011, 4, 3243-3262

(12) Liu, C.; Neale, Z. G.; Cao, G. Understanding Electrochemical Potentials of Cathode Materials in Rechargeable Batteries. Mater. Today 2016, 19 (2), 
$109-123$.

(13) Evolution of Supercapacitors.

https://en.wikipedia.org/wiki/Supercapacitor\#Evolution_of_components (accessed Aug 17, 2017).

(14) Obreja, V. V. N. On the Performance of Supercapacitors with Electrodes Based on Carbon Nanotubes and Carbon Activated Material-A Review. Phys. E Low-Dimensional Syst. Nanostructures 2008, 40 (7), 2596-2605.

(15) Frackowiak, E.; Béguin, F. Carbon Materials for the Electrochemical Storage of Energy in Capacitors. Carbon N. Y. 2001, 39 (6), 937-950.

(16) Wang, Y.; Song, Y.; Xia, Y. Electrochemical Capacitors: Mechanism, Materials, Systems, Characterization and Applications. Chem. Soc. Rev. 2016, 45, 5925-5950

(17) Kötz, R.; Carlen, M. Principles and Applications of Electrochemical Capacitors. Electrochim. Acta 2000, 45 (15), 2483-2498.

(18) Gonzalez, A.; Goikolea, E.; Barrena, J. A.; Mysyk, R. Review on Supercapacitors: Technologies and Materials. Renew. Sustain. Energy Rev. 2016, 58, 1189-1206.

(19) Henson, W. Optimal Battery/Ultracapacitor Storage Combination. J. Power Sources 2008, 179 (1), 417-423.

(20) Bubna, P.; Advani, S, G.; Prasad. K. A. Integration of Batteries with Ultracapacitors for a Fuel Cell Hybrid Transit Bus. J. Power Sources 2012 199, 360-366.

(21) Lee, Y. H.; Oh, J. G.; Oh, H. S.; Kim, H. Novel Method for the Preparation of Carbon Supported Nano-Sized Amorphous Ruthenium Oxides for Supercapacitors. Electrochem. commun. 2008, 10 (7), 1035-1037.

(22) Wei, T. Y.; Chen, C. H.; Chang, K. H.; Lu, S. Y.; Hu, C. C. Cobalt Oxide Aerogels of Ideal Supercapacitive Properties Prepared with an Epoxide Synthetic Route. Chem. Mater. 2009, 21 (14), 3228-3233.

(23) Khoo, E.; Wang, J.; Ma, J.; Lee, P. S. Electrochemical Energy Storage in a $\beta-N a 0.33 \mathrm{~V} 2 \mathrm{O} 5$ Nanobelt Network and Its Application for Supercapacitors. J. Mater. Chem. 2010, 20 (38), 8368.

(24) Laforgue, A.; Simon, P.; Sarrazin, C.; Fauvarque, J. F. Polythiophene- 
Based Supercapacitors. J. Power Sources 1999, 80 (1), 142-148.

(25) Senthilkumar, S. T.; Selvan, R. K.; Melo, J. S. Redox Additive/active Electrolytes: A Novel Approach to Enhance the Performance of Supercapacitors. J. Mater. Chem. A 2013, 1 (40), 12386-12394.

(26) Rahangdale, S. Preparation and Characterization of a Ferrocene containing Main-Chain PEG-CNTs Phase for Hybrid Supercapacitor Application. M.S Thesis, San Jose State Univeristy, San Jose, CA, 2017.

(27) Sharma, P.; Bhatti, T. S. A Review on Electrochemical Double-Layer Capacitors. Energy Convers. Manag. 2010, 51 (12), 2901-2912.

(28) Thostenson, E. T.; Ren, Z.; Chou, T.-W. Advances in the Science and Technology of Carbon Nanotubes and Their Composites: A Review. Compos. Sci. Technol. 2001, 61 (13), 1899-1912.

(29) Sarangdevot, K.; Sonigara, B. S. The Wondrous World of Carbon Nanotubes: Structure, Synthesis, Properties and Applications. J. Chem. Pharm. Res. 2015, 7 (6), 916-933.

(30) Hirsch, A. Functionalization of Single-Walled Carbon Nanotubes. Angew. Chemie - Int. Ed. 2002, 41 (11), 1853-1859.

(31) Tasis, D.; Tagmatarchis, N.; Bianco, A.; Prato, M. Chemistry of Carbon Nanotubes. Chem. Rev. 2006, 106 (3), 1105-1136.

(32) Zhao, B.; Hu, H.; Yu, A.; Perea, D.; Haddon, R. C. Synthesis and Characterization of Water Soluble Single-Walled Carbon Nanotube Graft Copolymers. J. Am. Chem. Soc. 2005, 127 (22), 8197-8203.

(33) Béguin, F.; Presser, V.; Balducci, A.; Frackowiak, E. Carbons and Electrolytes for Advanced Supercapacitors. Adv. Mater. 2014, 26 (14), 2219-2251.

(34) Senthilkumar, S. T.; Selvan, R. K.; Melo, J. S. Redox Additive/Active Electrolytes: A Novel Approach to Enhance the Performance of Supercapacitors. J. Mater. Chem. A 2013, 1 (40), 12386.

(35) Zhong, C.; Deng, Y.; Hu, W.; Qiao, J.; Zhang, L.; Zhang, J. A Review of Electrolyte Materials and Compositions for Electrochemical Supercapacitors. Chem. Soc. Rev. 2015, 44 (21), 7484-7539.

(36) Xu, K. Nonaqueous Liquid Electrolytes for Lithium-Based Rechargeable 
Batteries. Chem. Rev. 2004, 104 (10), 4303-4417.

(37) Muench, S.; Wild, A.; Friebe, C.; Haupler, B.; Janoschka, T.; Schubert, U. S. Polymer-Based Organic Batteries. Chem. Rev. 2016, 116 (16), 94389484.

(38) Lieder, M.; Schla"Pfer, C. W. Synthesis and Electrochemical Properties of New Viologen Polymers. J. Appl. Electrochem. 1997, 27 (2), 235-239.

(39) Najafi, E.; Kim, J. Y.; Han, S. H.; Shin, K. UV-Ozone Treatment of MultiWalled Carbon Nanotubes for Enhanced Organic Solvent Dispersion. Colloids Surfaces A Physicochem. Eng. Asp. 2006, 284-285, 373-378.

(40) Li, M.; Boggs, M.; Beebe, T. P.; Huang, C. P. Oxidation of Single-Walled Carbon Nanotubes in Dilute Aqueous Solutions by Ozone as Affected by Ultrasound. Carbon N. Y. 2008, 46 (3), 466-475.

(41) Peng, K.; Liu, L. Q.; Li, H.; Meyer, H.; Zhang, Z. Room Temperature Functionalization of Carbon Nanotubes Using an Ozone/Water Vapor Mixture. Carbon N. Y. 2011, 49 (1), 70-76.

(42) Georgakilas, V.; Kordatos, K.; Prato, M.; Guldi, D. M.; Holzinger, M.; Hirsch, A. Organic Functionalization of Carbon Nanotubes. J. Am. Chem. Soc. 2002, 124, 760-761.

(43) Zhang, J.; Zou, H.; Qing, Q.; Yang, Y.; Li, Q.; Liu, Z. Effect of Chemical Oxidation on the Structure of Single-Walled Carbon Nanotubes. J. Phys. Chem. B 2003, 107(16), 3712-3718.

(44) Yu, H.; Jin, Y.; Peng, F.; Wang, H.; Yang, J. Kinetically Controlled SideWall Functionalization of Carbon Nanotubes by Nitric Acid Oxidation. J. Phys. Chem. C 2008, 112 (17), 6758-6763.

(45) Banerjee, S.; Hemraj-Benny, T.; Wong, S. S. Covalent Surface Chemistry of Single-Walled Carbon Nanotubes. Adv. Mater. 2005, 17 (1), 17-29.

(46) Raman Spectroscopy. https://en.wikipedia.org/wiki/Raman_spectroscopy (accessed August 28, 2017).

(47) Bumbrah, G. S.; Sharma, R. M. Raman Spectroscopy - Basic Principle, Instrumentation and Selected Applications for the Characterization of Drugs of Abuse. Egypt. J. Forensic Sci. 2016, 6 (3), 209-215.

(48) Braz, A.; López-López, M.; García-Ruiz, C. Raman Spectroscopy for 
Forensic Analysis of Inks in Questioned Documents. Forensic Sci. Int. 2013, 232 (1-3), 206-212.

(49) Moura, C. C.; Tare, R. S.; Oreffo, R. O. C.; Mahajan, S. Raman Spectroscopy and Coherent Anti-Stokes Raman Scattering Imaging:

Prospective Tools for Monitoring Skeletal Cells and Skeletal Regeneration. J. R. Soc. Interface 2016, 13, 9-11.

(50) Dresselhaus, M. S.; Jorio, A.; Hofmann, M.; Dresselhaus, G.; Saito, R. Perspectives on Carbon Nanotubes and Graphene Raman Spectroscopy. Nano Lett. 2010, 10 (3), 751-758.

(51) Kim, U. J.; Furtado, C. A.; Liu, X.; Chen, G.; Eklund, P. C. Raman and IR Spectroscopy of Chemically Processed Single-Walled Carbon Nanotubes. J. Am. Chem. Soc. 2005, 127 (44), 15437-15445.

(52) Schmitt, J.; Flemming, H. C. FTIR-Spectroscopy in Microbial and Material Analysis. Int. Biodeterior. Biodegradation 1998, 41 (1), 1-11.

(53) Attenuated Total Reflectance. https://en.wikipedia.org/wiki/Attenuated_total_reflectance (accessed August 27, 2017).

(54) Hussain, S. Spectroscopic Investigation of Modified Single Wall Carbon Nanotube (SWCNT). J. Mod. Phys. 2011, 2 (6), 538-543.

(55) Michaelis, L.; Hill, E.S. The Viologen Indicators. J. Gen. Physiol. 1933, 16, 859-873.

(56) Tokue, H.; Oyaizu, K.; Sukegawa, T.; Nishide, H. TEMPO/Viologen Electrochemical Heterojunction for Diffusion-Controlled Redox Mediation: A Highly Rectifying Bilayer-Sandwiched Device Based on Cross-Reaction at the Interface between Dissimilar Redox Polymers. ACS Appl. Mater. Interfaces 2014, 6 (6), 4043-4049.

(57) Dam, H. T. V.; Ponjeé, J. J. Electrochemically Generated Colored Films of Insoluble Viologen Radical Compounds. J. Electrochem. Soc. 1974, 121 (12), 1555.

(58) Bhowmik. P. K.; Akhter, S.; Han, H. Thermotropic Liquid Crystalline MainChain Viologen Polymers. Polym. Chem. 1995, 33, 1927-1933.

(59) Bhowmik, P. K.; Han, H.; Cebe, J. J.; Burchett, R. A.; Sarker, A. M. MainChain Viologen Polymers with Organic Counterions Exhibiting 
Thermotropic Liquid-Crystalline and Fluorescent Properties. J. Polym. Sci. Part A Polym. Chem. 2002, 40 (5), 659-674.

(60) Awada, H.; Daneault, C. Chemical Modification of Poly(Vinyl Alcohol) in Water. Appl. Sci. 2015, 5 (4), 840-850.

(61) Hatazaw, T.; Terrill, R. H.; Murray, R. W. Microelectrode Voltammetry and Electron Transport in an Undiluted Room Temperature Melt of an

Oligo(ethyleneglycol )-Tailed Viologen. Ana. Chem. 1996, 68 (4), 597-603.

(62) Endo, T.; Kameyama, A.; Mambu, Y.; Kashi, Y.; Okawara, M. Synthesis of Polyethers Containing Viologen Moiety and Their Application to ElectronTransfer Catalyst. J. Polym. Sci. Part A Polym. Chem. 1990, 28 (9), 25092516.

(63) Nuclear Magnetic Resonance Spectroscopy. https://www2.chemistry.msu.edu/faculty/reusch/virttxtjml/spectrpy/nmr/nmr 1.htm (accessed Sep 5, 2017).

(64) University of California Chemistry Gopher Site. http://www.chem.ucla.edu (Accessed September 5, 2017).

(65) Macomber, R. S. A Complete Introduction to Modern NMR Spectroscopy; John Wiley \& Sons: New York, 1997; pp 68-88.

(66) Mabbott, G. A. An Introduction to Cyclic Voltammetry. J. Chem. Educ. 1983, 60 (9), 697.

(67) Van Benschoten, J. J.; Lewis, J. Y.; Heineman, W. R.; Roston, D. A.; Kissinger, P. T. Cyclic Voltammetry Experiment. J. Chem. Educ. 1983, 60 (9), 772.

(68) Kissinger, P. T.; Heineman, W. R. Cyclic Voltammetry. J. Chem. Educ. 1983, 60 (9), 702.

(69) Ching, S.; Dudek, R.; Tabet, E. Cyclic Voltammetry with Ultramicroelectrodes. J. Chem. Educ. 1994, 71, 602-605.

(70) Mahou, R.; Wandrey, C. Versatile Route to Synthesize Heterobifunctional Poly(ethylene Glycol) of Variable Functionality for Subsequent Pegylation. Polymers. 2012, 4 (1), 561-589.

(71) Tahara, H.; Baba, R.; Iwanaga, K.; Sagara, T.; Murakami, H. Active 
Ferrocene - Viologen Linked Ionic Liquid. Chem. Commun. 2017, 1-4.

(72) Jung, D. H.; Ko, Y. K.; Jung, H. T. Aggregation Behavior of Chemically Attached Poly(Ethylene Glycol) to Single-Walled Carbon Nanotubes (SWNTs) Ropes. Mater. Sci. Eng. C 2004, 24 (1-2), 117-121.

(73) Bilalis, P.; Katsigiannopoulos, D.; Avgeropoulos, A.; Sakellariou, G. NonCovalent Functionalization of Carbon Nanotubes with Polymers. RSC Adv. 2014, 4 (6), 2911-2934.

(74) Ma, P. C.; Siddiqui, N. A.; Marom, G.; Kim, J. K. Dispersion and Functionalization of Carbon Nanotubes for Polymer-Based Nanocomposites: A Review. Compos. Part A Appl. Sci. Manuf. 2010, 41 (10), 1345-1367.

(75) Ni, Y.; Hu, H.; Malarkey, E. B.; Zhao, B.; Montana, V.; Haddon, R. C.; Parpura, V. Chemically Functionalized Water Soluble Single-Walled Carbon Nanotubes Modulate Neurite Outgrowth. J. Nanosci. Nanotechnol. 2005, 5 (10), 1707-1712.

(76) Zhao, B.; Hu, H.; Haddon, R. C. Synthesis and Properties of a WaterSoluble Single-Walled Carbon Nanotube-Poly(m-Aminobenzene Sulfonic Acid) Graft Copolymer. Adv. Funct. Mater. 2004, 14 (1), 71-76.

(77) Acyl Chlorides. https://en.wikipedia.org/wiki/Acyl_chloride (accessed Jan 1, 2017).

(78) Laborda, E.; González, J.; Molina, Á. Recent Advances on the Theory of Pulse Techniques: A Mini Review. Electrochem. commun. 2014, 43, 2530.

(79) Hyk, W.; Stojek, Z. Direct Determination of Diffusion Coefficients of Substrate and Product by Chronoamperometric Techniques at Microelectrodes for Any Level of lonic Support. Anal. Chem. 2002, 74, 149-157.

(80) Denuault, G.; Mirkin, M. V.; Bard, A. J. Direct Determination of Diffusion Coefficients by Chronoamperometry at Microdisk Electrodes. J. Electroanal. Chem. Interfacial Electrochem. 1991, 308, 27-38 